\title{
Precharacterization Report for Instrumented Fuel Assembly (IFA)-527
}

Prepared by M. E. Cunningham, E. R. Bradley, J. L. Daniel,

N. C. Davis, D. D. Lanning, R. E. Willifọrd

Pacific Northwest Laboratory

Operated by

Battelle Memorial Institute

Prepared for

U.S. Nuclear Regulatory

Commission 


\section{NOTICE}

This report was prepared as an account of work sponsored by an agency of the United States Government. Neither the United States Government nor any agency thereof, or any of their employees, makes any warranty, expressed or implied, or assumes any legal liability or responsibility for any third party's use, or the results of such use, of any information, apparatus product or process disclosed in this report, or represents that its use by such third party would not infringe privately owned rights.

Available from

GPO Sales Program

Division of Technical Information and Document Control

U. S. Nuclear Regulatory Commission

Washington, D. C. 20555

Printed copy price:

$\$ 4.75$

and

Nâtional Technical Information Service

Springfield, Virginia 22161 
NUREG/CR-2168

PNL-3824

R3

\title{
Precharacterization Report for Instrumented Fuel Assembly (IFA)-527
}

Manuscript Completed: June 1981

Date Published: July 1981

Prepared by

M. E. Cunningham, E. R. Bradley, J. L. Daniel,

N. C. Davis, D. D. Lanning, R. E. Williford

Pacific Northwest Laboratory

Richland, WA 99352

\author{
Prepared for \\ Division of Accident Evaluation \\ Office of Nuclear Regulatory Research \\ U.S. Nuclear Regulatory Commission \\ Washington, D.C. 20555 \\ NRC FIN B2043
}




\section{ACKNOWLEDGMENTS}

The authors wish to acknowledge the Haiden Project staff for their time and effort in the design and fabrication of instrumented fuel assembly (IFA)-527. The efforts of R. W. Miller and A. Appelhans, past and present U.S. Nuclear Regulatory Commission (NRC) representatives at Halden, are appreciated for overseeing installation and operation of this assembly and providing information for this report.

We also acknowledge the sponsorship of the Fuel Behavior Research Branch of the NRC.

We would like to thank the following Pacific Northwest Laboratory (PNL) personnel: C. L. Mohr for his ongoing review and advice and S. K. Edler for her editing assistance. 


\section{ABSTRACT}

This report is a resource document covering the rationale, design, fabrication, and preirradiation characterization of instrumented fuel assembly (IFA)-527. This assembly is being irradiated in the Halden Boiling Water Reactor (HBWR) in Norway as part of the Experimental Support and Development of Single-Rod Fuel Codes Program conducted by Pacific Northwest Laboratory (PNL) and sponsored by the Fuel Behavior Research Branch of the U.S. Nuclear Regulatory Commission (NRC). Data from this assembly will be used to better understand light water reactor (LWR) fuel behavior under normal operating conditions. 


\section{SUMMARY}

The six-rod instrumented fuel assembly (IFA)-527 is being irradiated in the Halden Boiling Water Reactor (HBWR) in Halden, Norway. This is the fourth and last test assembly to be irradiated under the U.S. Nuclear Regulatory Commission (NRC) Experimental Support and Development of Single-Rod Fuel Codes Program. The principal goal of this assembly is to provide data to improve the understanding of fuel cracking and relocation.

This report is a resource document covering the rationale, design, fabrication, and preirradiation characterization of IFA-527. This assembly is nighly similar to the three previous assembilies irradiated under this program: IFA-431, -432 , and -513 . IFA-527 contains six rods, each instrumented with two fuel centerline thermocouples, a bellows-type internal gas pressure transducer, and a cladding axial elongation monitor. All rods are backfilled with $100 \%$ xenon to amplify the thermal effects due to fuel cracking and relocation. In addition, rods 1 through 5 are nominally identical so that data of a statistical nature may be obtained. Rod 6 has a small fuel-cladding gap and will provide data for evaluating the lower bound of gap conductance under known fuel-cladding contact conditions.

The fuel for IFA-527 was fabricated to be similar to the fuel used in IFA-431, -432, and -513; based on microstructural analysis, it is believed that the fuel in all four assemblies should behave similarly. Fuel thermal conductivity and thermal resintering tests were conducted on both IFA-527 and IFA-513 fuel, and the results are in agreement with previous tests. 



\section{CONTENTS}

ACKNOWLEDGMENTS

$i j i$

ABSTRACT .

SUMMARY

INTRODUCTION

TEST OBJECTIVES

ANALYSIS OF FUEL CRACKING AND RELOCATION

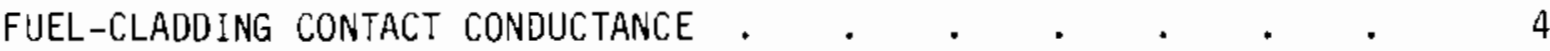

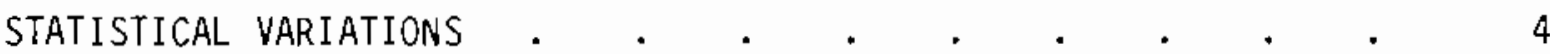

BURNUP-ENHANCED FISSION GAS RELEASE $\quad \cdot \quad \cdot \quad \cdot \quad \cdot \quad \cdot \quad \cdot \quad 5$

INSTRUMENTED FUEL ASSEMBLY (IFA)-527 DESIGN AND ASSEMBLY

FABRICATION

ROD DESIGN

ASSEMBLY DESIGN

FUEL ROD FABRICATION

FUEL FABRICATION AND CHARACTERIZATION

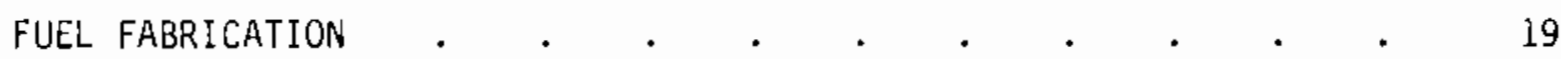

FUEL CHARACTERIZATION $\quad . \quad$. . . . . . . . . . . . . . . 25

Experimental Procedure . . . . . . . . . . 25

Porosity Evaluation . . . . . . . . . . . 26

Grain Size Evaluation . . . . . . . . 30

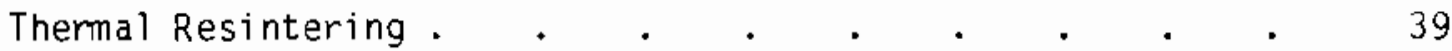

Thermal Conductivity . . . . . . . . . . 41

ASSEMBLY OPERATION

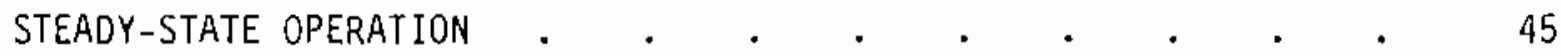

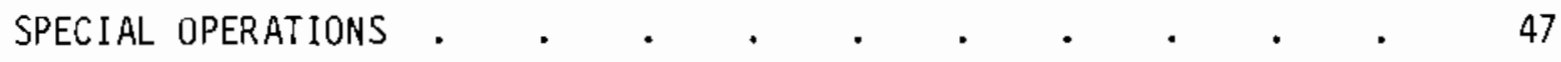




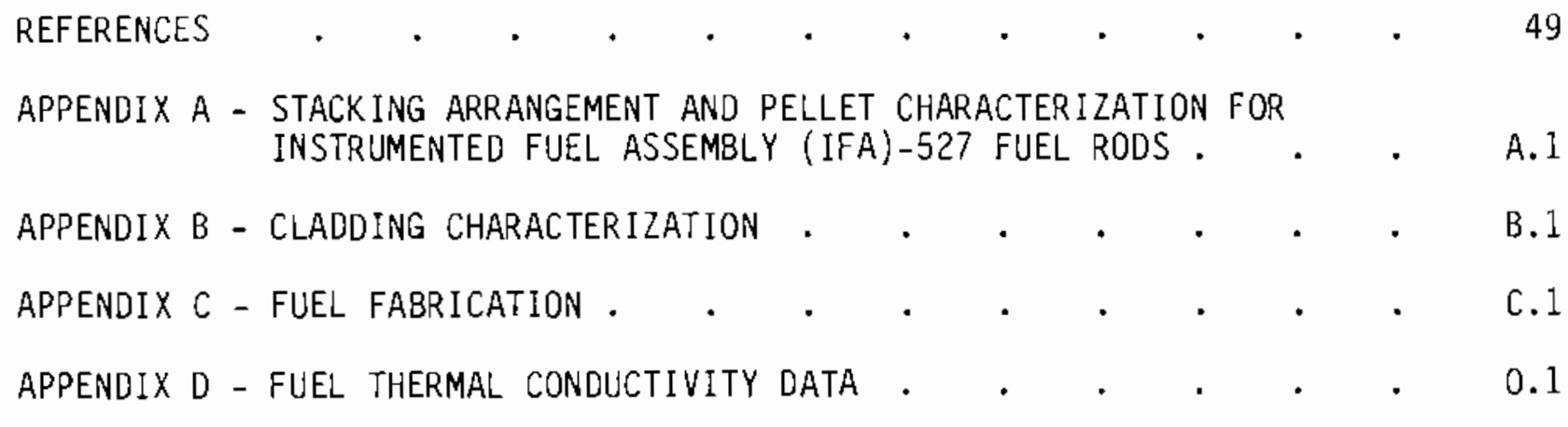




\section{FIGURES}

1 Schematic Arrangement of Fuel Rod for Instrumented Fuel Assembly (IFA)-527 . . . . . . . . . . . . . 9

2 Schematic Design of Instrumented Fuel Assembly (IFA)-527 . . 11

3 HBWR Core Loading No. 44, June 1980 . $\quad$. $\quad$. . . . 12

4 Orientation of Instrumented Fuel Assembly (IFA)-527

Relative to Core Centerline . . . . . . . . . 13

5 Arrangement of Fuel and Instruments Relative to

Reference Axial Thermal Flux Profile . . . . . . 14

6 Completed Instrumented Fuel Assembly (IFA)-527 . . . . . 14

7 Details of Plenum Spring $. \quad . \quad . \quad . \quad . \quad . \quad . \quad . \quad 18$

8 PNL Visual Standards for $\mathrm{UO}_{2}$ fuel Pellets . . . . . 23

9 Microstructure of $\mathrm{U}_{2}$ Fuel Pellets for Instrumented Fuel Assemblies (IFA)-527, $-513,-431$, and -432 . . . . . 27

10 Pore Size and Volume Distribution for $95 \%$ TD Stable $\mathrm{UO}_{2}$ Fuel Used in IFA-527, $-513,-431$, and -432 . . . . . . 28

11 Microstructure of $\mathrm{UO}_{2}$ Powder Used for Fabricating Instrumented Fuel Assembly (IFA)-513 and -527 Pellets . . . . . 30

12 General Porosity Characteristics of $95 \%$ TD Stable 102 Pellets Used in Instrumented Fuel Assembly (IFA)-527 . . . 31

13 Typical Porosity Characteristics of $\mathrm{UO}_{2}$ Pellets Used for Instrumented Fuel Assembiy (IFA) -527 . . . . . . 32

14 Summary of Radial Distribution of Pore Size and Volume . . 33

15 Radial Distribution of Pore Population as a Function of Pore Size . . . . . . . . . . . . . . . 35

16 Variation in Grain Size for 95\% TD Stable $\mathrm{U0}_{2}$ Pellets Used in Instrumented Fuel Assemblies (IFA) $-527,-513,-431$, and -432 . 37

17 Summary of Radial Variation in Grain Size for IFA-527 and -513 and IFA-431 and -432 . . . . . . .

18 Comparison of IFA-513 and -527 Fuel Thermal Conductivity with IFA-431 and -432 Thermal Conductivity and Selected Expressions . 
19 Special Operational Procedures for Instrumented Fue? Assembly

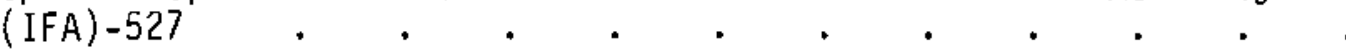

A.1 Stacking Arrangement for Instrumented Fuel Assembly (IFA)-527, Design Dimensions... . . . . . . A.2

B.1 Cladding Inside Diameter Profilometry Data for Rod 1 of Instrumented Fuel Assembly (IFA)-527. . . . . . . B.2

B.2 Cladding Inside Diameter Profilometry Data for Rod 2 of Instrumented Fuel Assembly (IFA)-527 . . . . . . B.3

B.3 Cladding Inside Diameter Profilometry Data for Rod 3 of Instrumented Fuel Assembly (IFA)-527 . . . . . . B.4

B.4 Cladding Inside Diameter Profilometry Data for Rod 4 of Instrumented fuel Assembly (IFA)-527 . . . . . . . 8.5

B.5 Cladding Inside Diameter Profilometry Data for Rod 5 of Instrumented Fuel Assembiy (IFA)-527 . . . . . . . . B.6

B.6 Cladding Inside Diameter Profliometry Data for Rod 6 of Instrumented Fuel Assembly (IFA)-527 . . . . . . B.7 
$\underline{\text { TABLES }}$

1 Instrumented Fuel Assembly (IFA)-527 Rod Design Parameters . $\quad 8$

2 As-Fabricated Dimensions and Variances for Instrumented Fuel

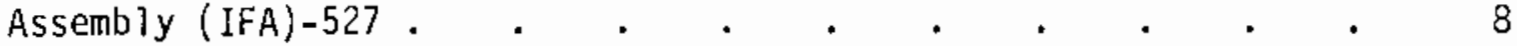

3 Pellet Specifications and Required Characterization

for Instrumented Fuel Assembly (IFA)-527 $\quad$. $\quad$. $\quad . \quad$. $\quad$. 21

4 Summary of Chemical Analysis for Instrumented Fuel Assembly

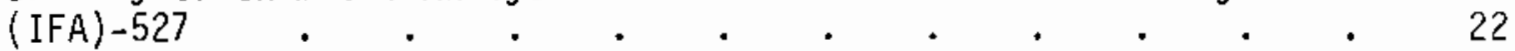

5 Summary of Fuel Pellet Specifications and Inspection Results for Instrumented Fuel Assembly (IFA)-527 . . . . . . . 24

6 Summary of Calcuiated Pore Distributions from All Data for Each

Halden Fuel Assembly . . . . . . . . . . . . 28

7 Pore Distributions for Instrumented Fuel for Assembly (IFA)-527 . 33

8 Grain Size of As-Sintered Pellets. . . . . . . . . 39

9 As-Sintered Characterization of Pellets to Be Resintered . . 40

10 Resintered Characterization of Pellets . . . . . . . 40

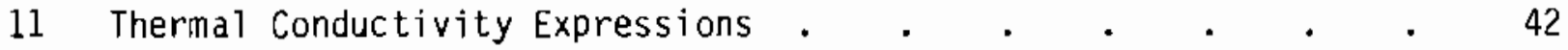

A.1 Pellet Data for Rod 1 of Instrumented Fuel Assembly (IFA)-527 - A.3

A.2 Pellet Data for Rod 2 of Instrumented Fuel Assembiy (IFA)-527 A A.4

A.3 Pellet Data for Rod 3 of Instrumented Fuel Assembly (IFA) -527 - A.5

A.4 Pellet Data for Rod 4 of Instrumented Fuel Assembly (IFA)-527 . A.6

A.5 Pellet Data for Rod 5 of Instrumented Fuel Assembly (IFA)-527 - A.7

A.6 Pellet Data for Rod 4 of Instrumented Fuel Assembly (IFA) -527 - A.8

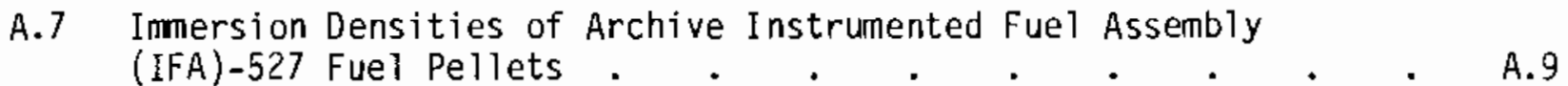

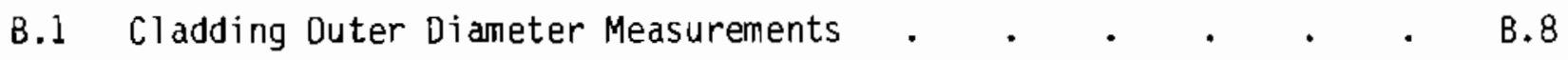

0.1 Instrumented Fuel Assembly (IFA) -527 (Pellet 822) Measured
Diffusivity and Calculated Themal Conductivity . . . . . D.1

0.2 Instrumented Fue 1 Assembly (IFA) -513 (Pellet 324) Measured
Diffusivity and Caiculated Themal Conductivity . • . . D.2 



\section{INTRODUCTION}

If a loss-of-coolant accident (LOCA) should occur in a light water reactor (LWR), the short-term thermal stored energy and iong-term decay heat of the fuel rods become the driving forces for fuel damage. To assess the anount of energy that would be present in the core of a commercial LWR should a LOCA occur, the U.S. Nuclear Regulatory Commission (NRC) must rely on computer codes, which are designed to account for fuel type, fuel and cladding dimensions, coolant conditions, power level, operating history, and a host of other considerations. However, these codes are only as reliable as the data bases that are used to build them and to verify their results.

The Experimenta] Support and Deveiopment of Single-Rod Fuel Codes Program was primarily established to develop a well-characterized data base to assure such reliability. The program was begun at Pacific Northwest Laboratory (PNL) $^{(a)}$ in 1974 by the Fuel Behavior Research Branch of the NRC. The data generated from this program is now being used in the development and verifica$t i o n$ of the NRC audit codes GAPCON-THERMAL ${ }^{(1)}$ and FRAPCON. (2)

To date, four instrumented fuel assemblies (IFAs) have been built and irradiated in the Halden Boiling Water Reactor (HBWR), Halden, Norway. The first of these assemblies, IFA-431, was irradiated from June 1975 to February 1976 and obtained an assembly average burnup of $389 \mathrm{GJ} / \mathrm{kgU}(4.5 \mathrm{GWd} / \mathrm{MTM})$. The second assembly, IFA-432, is identical in design to IFA-431 and began irradiation in December 1975; it is still in the reactor and is providing data at high fuel burnup. (b) The design of the third assembly, IFA-513, is similar to the two previous assemblies with some differences--principally fuel length and initial fill gas composition and pressure. IFA-513 segan irradiation in November 1978 and is still in-reactor. (c) The data obtained from all three of these assemblies has been consistent and useful for verifying existing models, developing new models, and developing new techniques for analysis of fuel rod data.

(a) Operated for the U.S. Department of Energy (DOE) by Battelle Memorial Institute.

(b) As of October 4,1980 , the assembly average burnup for IFA-432 was approximately $2335 \mathrm{GJ} / \mathrm{kgU}$ (27 GWd/MTM).

(c) As of 0ctober 4, 1980, the assembly average burnup for IFA-513 was $775 \mathrm{GJ} / \mathrm{kgU}$ (9 GWd/MTM). 
To continue the work begun with IFA-431, -432 , and -513 , the fourth (and final) assembly was charged into the H8WR in June 1980. This assembly, designated IFA-527, is principally designed to provide additional data on the phenomena of fuel cracking and relocation. To emphasize the thermal effects of cracking and relocation, all six rods in IFA-527 have an initial fill gas of pure xenon at 1 -atm pressure. In addition, because cracking and relocation are of a statistical nature, five of the six rods are nominally identical; the sixth rod has a smaller initial fuel-cladding gap.

This report is a repository of information on the objective, design, and fabrication of IFA-527. Since this assembly shares some design features and materials with the previous assemblies, their precharacterization reports $(a)$ are referenced when appropriate. The information included in this report is organized as follows:

- Test 0bjectives

- IFA-527 Design and Assembly Fabrication

- Fuel Fabrication and Characterization

- Assembiy 0peration

- Appendices.

(a) Precharacterjzation report for IFA-431 and -432 hereafter referred to as 8NWL-1988; (3) precharacterization report for IFA-513 hereafter referred to as PNL $-3156 .(4)$ 


\section{TEST OBJECTIVES}

A principal objective of the NRC/PNL Experimental Support and Development of Single-Rod Fuel Codes Program has continually been to obtain wellcharacterized thermal-mechanical fuel rod data over the spectrum of normal LWR operation. By varying the density, stability, and dimensions of the fuel and the composition and initial pressure of the fill gas, thermal and mechanical data has been obtained under a variety of known conditions. By using replicate rods filled with xenon gas, data from IFA-527 will be used for:

- analysis of fuel cracking and relocation

- definition of the lower boundary for fuel-cladding contact conductance

- insight into the possibie statistical variation in behavior that can occur between nominally identical rods

- further insight into the question of enhanced fission gas release with increasing burnup.

ANALYSIS OF FUEL CRACKING AND RELOCATION

Thermal stresses in $\mathrm{UO}_{2}$ fuel pellets that arise from radial temperature gradients are sufficient to cause cracking of the pellets. Subsequently, the resulting pellet fragments may undergo some limited movement relative to their original positions (relocation). Fuel cracking and relocation can have several effects in a fuel rod:

- increased gap conductance due to decreased fuel-cladding gap width

- decreased effective fuel thermal conductivity due to the presence of cracks

- decreased elastic modulus of $\mathrm{UO}_{2}$ due to the presence of cracks.

The action of fuel cracking and relocation is reflected through temperatures and cladding deformation (radial and axial). A model has been developed that uses measured fuel centerline temperature and total cladding elastic elongation data to deduce gap conductance, effective fuel thermal conductivity, and elastic moduli (radial and axial). (5) 
Because the analysis of relocation is dependent upon measured temperatures, slight shifts in temperature can indicate changes in fuel condition. By using xenon as a fill gas (it has the lowest thermal conductivity of the noble gases), the temperature effect of fuel changes is magnified as compared to helium fill gas. Thus, it may be possible to observe fuel changes that are not as easily observed with helium fill gas.

\section{FUEL-CLADDING CONTACT CONDUCTANCE}

The conductance of heat fron the fuel to the cladding is principally dependent upon the thermal conductivity of the gas occupying the volume between the fuel and cladding, the distance between the fuel and cladding, and any contact that occurs between the fuel and cladding. Previous assemblies provided data on helium-filled rods with large gaps and closed gaps; the rods in this assembly will provide data on xenon-filled rods with initial gaps of both normal $(230 \mu \mathrm{m})$ and small size $(50 \mu \mathrm{m})$. In particuiar, rod 6 , which has a small gap, will have fuel-cladding contact when brought to power; thus, a lower bound on gap conductance under known contact conditions will be established. The uncertainty in fill gas thermal conductivity as a function of burnup is also minimized by using xenon fill gas. Thus, solid conductance may be estimated at higher burnups where fuel swelling and relocation may cause gap closure of the normal gap size rods.

\section{STATISTICAL VARIATIONS}

Although fuel rods may be built to the same design specifications and may meet specified tolerances, there will be local variations in dimensions and material properties. The combination of these variations and differences in operating conditions (neutron flux, coolant conditions) may result in different behavior from nominally identical rods. The question may then arise as to whether the observed variation is significant; and in particular, how much difference is there between the observed variation and the anticipated uncertainty in fuel rod performance or predictions of fuel rod performance. 
Rods 1 through 5 of IFA-527 are nominally identical; there will be a variation in operating conditions because of an expected radial neutron flux tilt across the assembly (IFA-527 is located at the edge of the core in a lowpower region to avoid extreme fuel temperatures caused by the xenon fiil gas reducing gap conductance). A comparison of behavior between these rods will provide an estimate of the variation that can be expected between nominally identical rods. Comparison to uncertainties associated with fuel performance code predictions may also prove useful in evaluating uncertainty assessment techniques. ${ }^{(6)}$

BURNUP-ENHANCED FISSION GAS RELEASE

The increased rate of fission gas release from the fuel matrix as a function of increasing burnup is a concern in fuel rod design. Fission gas release is highly temperature dependent and involves a thermal feedback loop for heliumfilled rods: fission gas release degrades fill gas thermal conductivity, which decreases gap conductance, which leads to higher fuel temperatures and thus to more fission gas release. This process can obscure an increasing rate of fission gas release due to burnup effects.

Because IFA-527 fuel rods were initially filled with xenon, temperatures cannot increase due to the above described thermal feedback effect because the release of additional xenon (fission gas) has little effect on heat transfer. Thus, if a near constant power/temperature history is maintained while the rate of fission gas release increases (as indicated by gas pressure measurements), the increase can be attributed to burnup-related effects (i.e., burnup-induced microstructrual changes). 


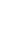




\section{INSTRUMENTED FUEL ASSEMBLY (IFA)-527 DESIGN AND ASSEMBLY FABRICATION}

The design of IFA-527 is very similar to that of IFA-431, -432 , and -513 and is discussed in this section in three parts: individual rod design, overall assembiy design, $(a)$ and fuel rod fabrication. Associated instrumentation will be discussed where appropriate throughout the report.

\section{ROD DESIGN}

Five of the six rods in IFA-527 are nominally identical, and rod 6 is similar but with a smaller fuel-cladding gap size. The cladding is annealed seamless Zircaloy-2, and the fuel is compacted and sintered $\mathrm{UO}_{2}$ of $295 \%$ theoretical density (TD) enriched to 9.90 weight percent (wt\%) uranium-235. To reduce flux peaking at the ends of the fuel columns, a poison peliet consisting of $95 \%$ natural $\mathrm{NO}_{2}$ and $5 \% \mathrm{Dy}_{2} \mathrm{O}_{3}$ is located at each end. Table 1 lists rod design parameters, and Table 2 summarizes the as-built dimensions and variations. A general rod design schematic is shown in Figure 1 . The pellet stacking order for each rod is presented in Appendix A.

The instrumentation for each rod consists of two fuel centerline therinocouples and a bellows-type pressure transducer. Because the themocouples ( $W-3 \%$ Re/W-25\% Re with Be0 insulators) are located in both the lower (near the neutron flux peak) and upper ends of the fuel rods (see Figure 1), they provide temperature measurements at two power levels. The power level at the upper thermocouple is approximately 75\% of the power at the lower thermocouple. The pressure transducer is connected to the plenum and automatically provides continuous pressure measurements.

Assumed measurement uncertainty for the fuel thermocouples is $+3 \%$ for temperatures less than 2473K. (7) This includes calibration, instrumentation, and some irradiation effects at low burnup. The uncertainty will increase with burnup due to decalibration caused by neutron irradiation. The pressure transducers are quoted by Haiden to have an uncertainty of $\pm 1.5 \%$ at $0.2 \mathrm{MPa}$.

(a) Halden has supplied PNL with copies of the design drawings for the fuel rods, instrumentation, and supporting hardware. 
TABLE 1. Instrumented Fuel Assembly (IFA)-527 Rod Design Parameters

$\begin{array}{lll}\text { Cladding: (a) } & \text { Material } & \text { Zircaloy-2 } \\ & \text { Outer Diameter } & 12.789 \mathrm{~mm} \\ & \text { Inner Diameter } & 10.909 \mathrm{~mm} \\ \text { Fuel: } & & \\ & \text { Material } & \mathrm{UO}_{2} \\ & \text { Enrichment } & 9.90 \mathrm{wt} \% 235 \mathrm{U} \\ & \text { Density } & 95 \% \text { theoretical } \\ & \text { Diameter } & 10.681 \mathrm{~mm} \text { (rods } 1 \text { through 5) } \\ & \text { Peliet Length } & 10.833 \mathrm{~mm} \text { (rod 6) } \\ & 12.7 \mathrm{~mm} \\ \text { Poison Pellets: } & \text { Material } & 95 \% \text { natural } \mathrm{UO}_{2}, 5 \% \mathrm{Dy}_{2} \mathrm{O}_{3} \\ & \text { Diameter } & 10.2 \mathrm{~mm} \\ & \text { Length } & 7.0 \mathrm{~mm}\end{array}$

Fill Gas: $\quad 100 \%$ Xe at $0.1 \mathrm{MPa}$

(a) See Appendix A of BNWL-1988 for cladding certification.

TABLE 2. As-Fabricated Dimensions and Variances for Instrumented Fuel Assembly (IFA) -527

\begin{tabular}{|c|c|c|c|}
\hline $\begin{array}{l}\text { Rod } \\
\text { No. }\end{array}$ & $\begin{array}{c}\text { Pellet Length, } \\
\pm 1 \sigma\end{array}$ & $\begin{array}{c}\text { Pellet Diameter, } \\
\text { Im }+1 \sigma\end{array}$ & $\begin{array}{c}\text { Theoretical } \\
\text { Density, (a) } \\
\% \pm 10\end{array}$ \\
\hline 1 & $12.609+0.088$ & $10.681+0.004$ & $95.04+0.154$ \\
\hline 2 & $12.616 \mp 0.083$ & $10.683 \mp 0.004$ & $95.04 \mp 0.209$ \\
\hline 3 & $12.680 \mp 0.068$ & $10.681 \mp 0.003$ & $94.93 \mp 0.199$ \\
\hline . & $12.718 \mp 0.083$ & $10.683 \mp 0.004$ & $94.82 \mp 0.121$ \\
\hline 5 & $12.662 \mp 0.136$ & $10.683 \mp 0.003$ & $94.89 \mp 0.147$ \\
\hline 6 & $12.852 \mp 0.112$ & $10.864 \mp 0.002$ & $95.35 \overline{+0.095}$ \\
\hline
\end{tabular}

\begin{tabular}{|c|c|c|c|c|}
\hline $\begin{array}{l}\text { Rod } \\
\text { No. }\end{array}$ & 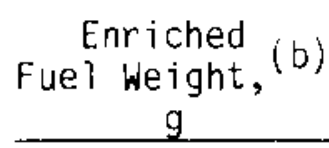 & $\begin{array}{l}\text { Enriched } \\
\text { Fuel Length, } \\
\text { mm }\end{array}$ & Fuel Length, ${ }_{\mathrm{m}}^{\text {Total }}$ & $\begin{array}{c}\text { Plenum }_{(d)} \\
\text { Length, } \\
\mathrm{mm}\end{array}$ \\
\hline 1 & 717.5 & 776.2 & 792.9 & 32.3 \\
\hline 2 & 715.5 & 773.7 & 792.2 & 32.4 \\
\hline 3 & 716.5 & 775.5 & 793.0 & 32.2 \\
\hline 4 & 717.5 & 777.4 & 792.5 & 33.1 \\
\hline ? & 719.0 & 777.6 & 793.0 & 31.8 \\
\hline 6 & 739.5 & 770.3 & 790.0 & 33.3 \\
\hline
\end{tabular}
(a) Geometric density.
(b) Reported by Halden, excludes poison pellets.
(c) Reported by Halden, includes poison pellets.
(d) Top of fuel stack to end of cladding (accuracy is 0.1 to $0.2 \mathrm{~mm}$ ). 


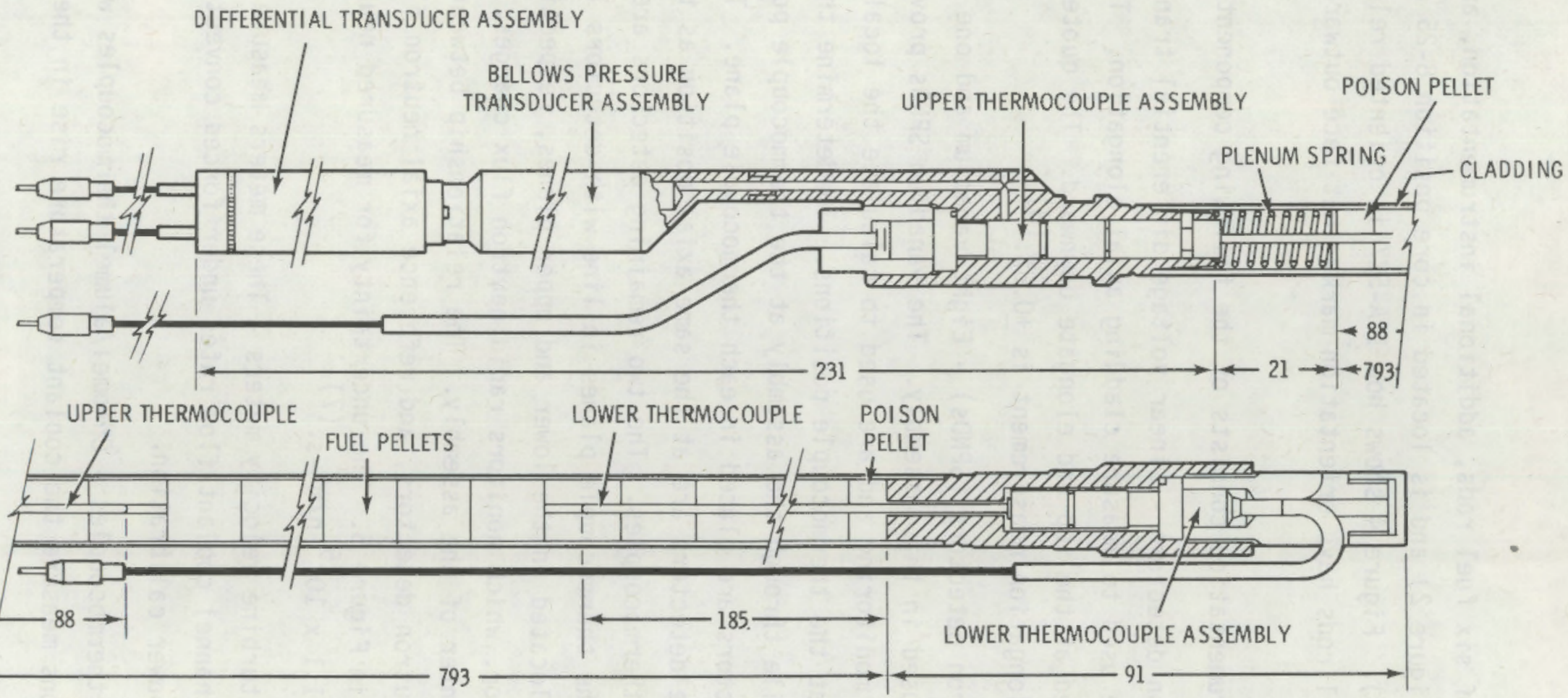

FIGURE 1. Schematic Arrangement of Fuel Rod for Instrumented Fuel Assembly (IFA)-527 (fabricated dimensions are in $\mathrm{mm}$ ) 


\section{ASSEMBLY DESIGN}

IFA-527 consists of six fuel rods, additional instrumentation, and supporting hardware (see Figure 2) and is located in core position 8-25 of the HBWR core (see Figure 3 ). Figure 4 shows how IFA-527 is oriented relative to the core centerline; all rods have orientation marks that face outward from the assembly center.

The assembly instrumentation consists of the following components:

- cladding elongation detectors - Linear voltage differential transducers (LVDTS) are used to measure cladding axial elongation. The fuel rods are fixed at the top and elongate downward. The quoted uncertainty for elongation measurement is $\pm 0.6 \%$.

- self-powered neutron detectors (SPNDs) - Eight vanadium and one cobalt SPNDs are used in this assembly. The vanadium SPNDs provide steady-state flux monitoring and are used to calculate the local linear heat rate at the thermocouple positions. To determine the neutron flux profile through the assembly at the thermocouple positions, three detectors are placed in each thermocouple plane. The centerlines of the detectors are at the same axial position as the junctions of the thermocouples. The two remaining detectors are located between the thermocouple planes in line with detectors 1 and 6 , which are located in the lower and upper planes, respectively. The cobalt detector, which monitors rapid neutron flux changes, is located in the center of the assembly. The relationship between the thermocouples, neutron detectors, and reference axial neutron flux profile is shown in Figure 5 . The uncertainty for measured neutron flux is $\pm 3.0 \%$ at $1.1 \times 10^{15} \mathrm{n} / \mathrm{m}^{2}$-s. (7)

- inlet and outlet turbine velocity meters - These meters measure inlet and outlet fuel channel coolant flow rates under forced convection during assembly power calibration.

- inlet and outlet thermocouples - Chromel/alumel thermocouples with insulated junctions measure the coolant temperature rise in the fuel channe?. 


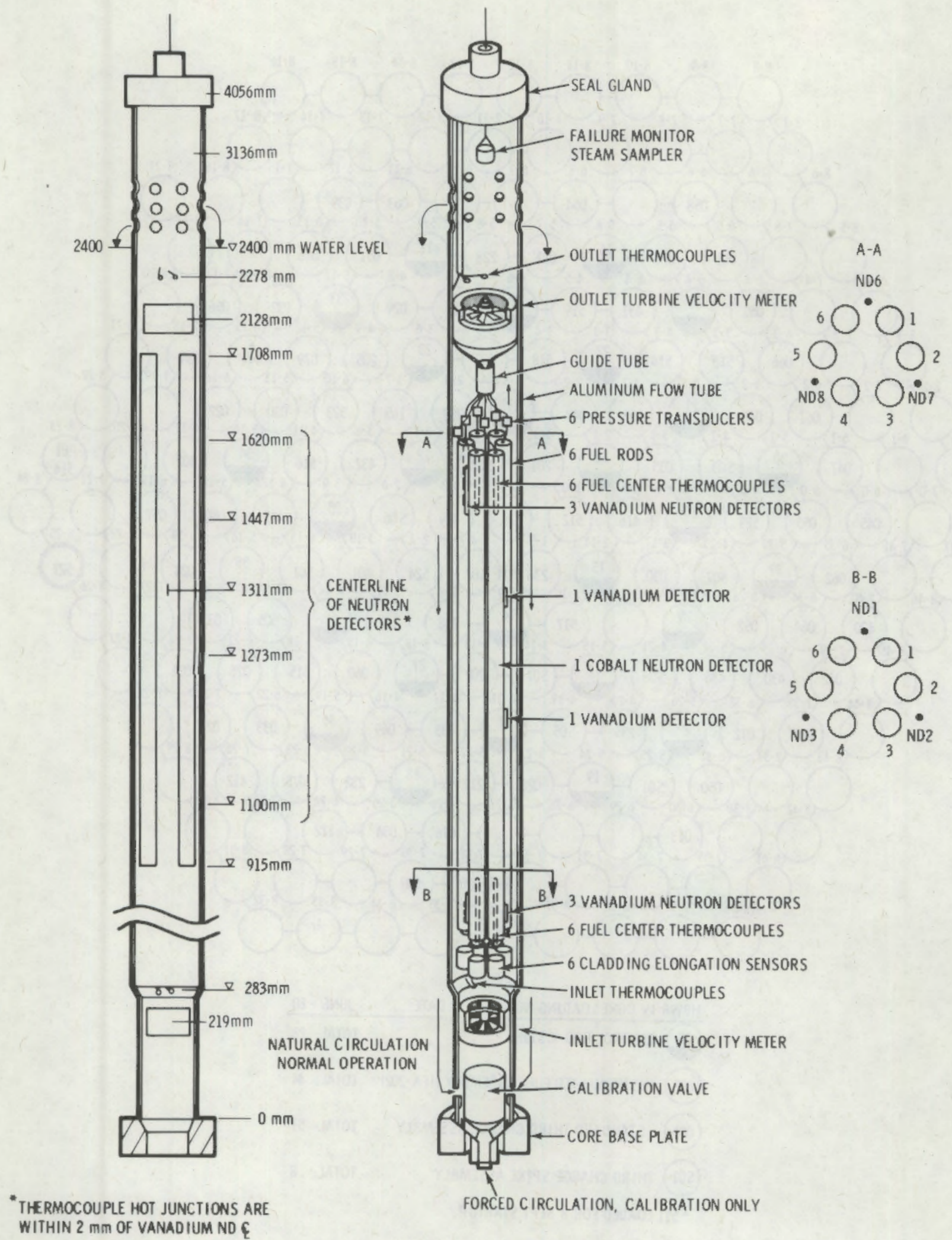

FIGURE 2. Schematic of Instrumented fuel Assembly (IFA)-527 (neutron detectors 4 and 5 are in line with detectors 1 and 6 ; not drawn to scale) 


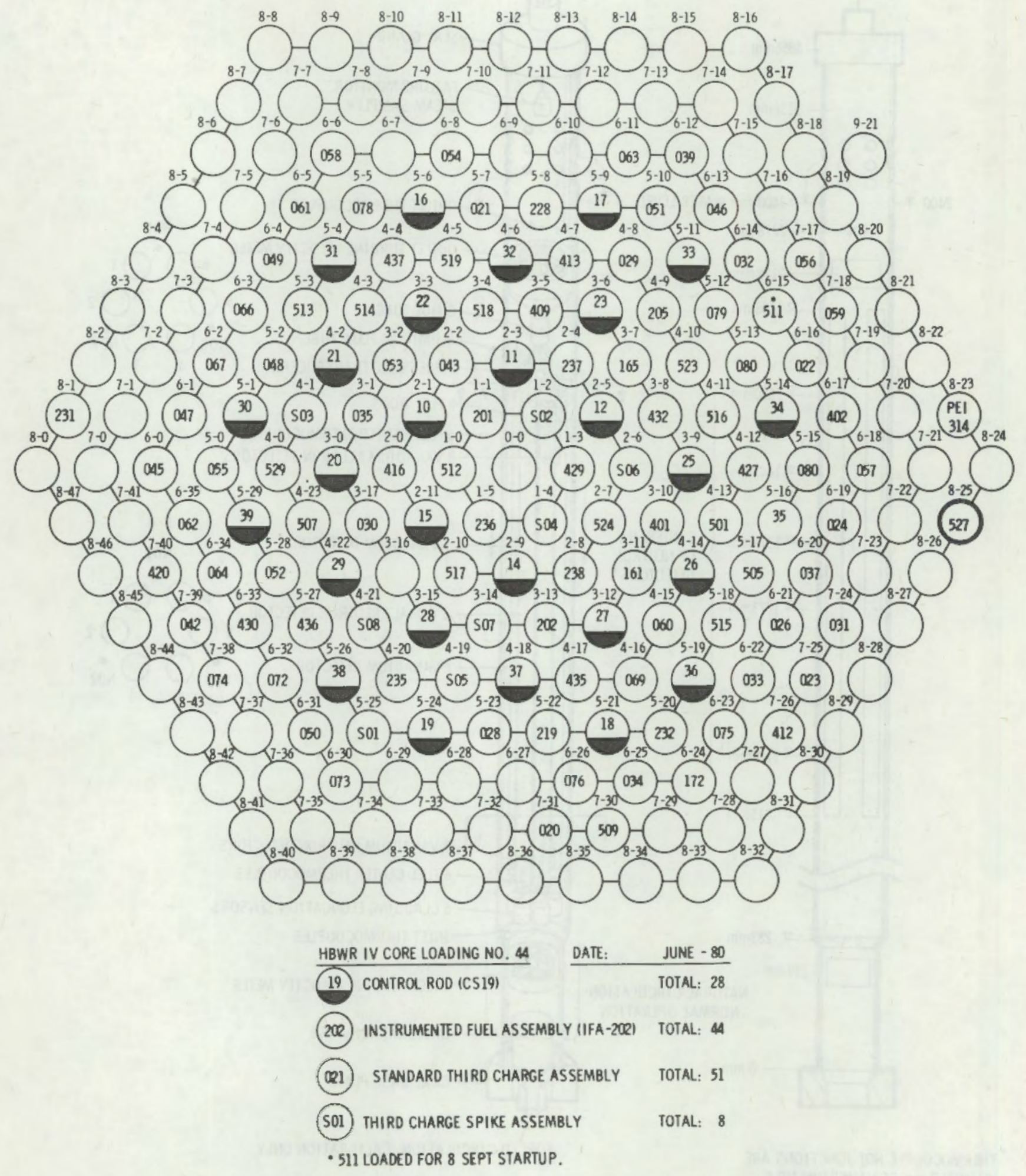

FIGURE 3. HBWR Core Loading No. 44, June 1980 


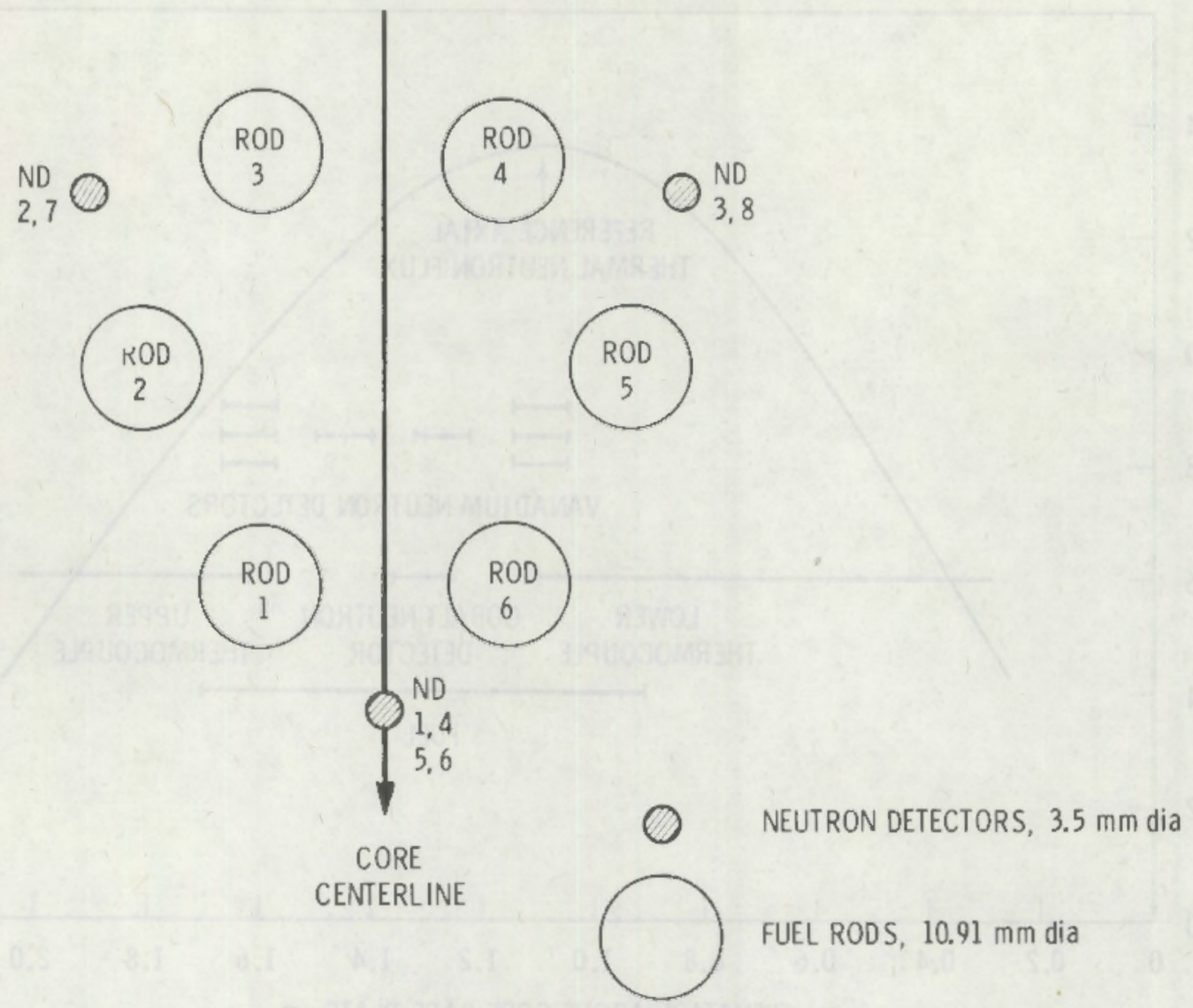

FIGURE 4. Orientation of Instrumented Fuel Assembly (IFA) -527 Relative to Core Centerline

The four photographs in Figure 6 were taken after IFA-527 was fabricated. The designations on the photographs are defined below:

- $527-X-X$ designates which fuel rod is pictured

- PF-X and TRAFO - fuel rod internal gas pressure bellows and rod pressure LVDTs, respectively (operate as one unit)

- Tf-X - fuel thermocouple assembly

- ND-7 - vanadium neutron detector 7, located at top of assembly

- EC-X - LVDT for measuring cladding axial elongation. 


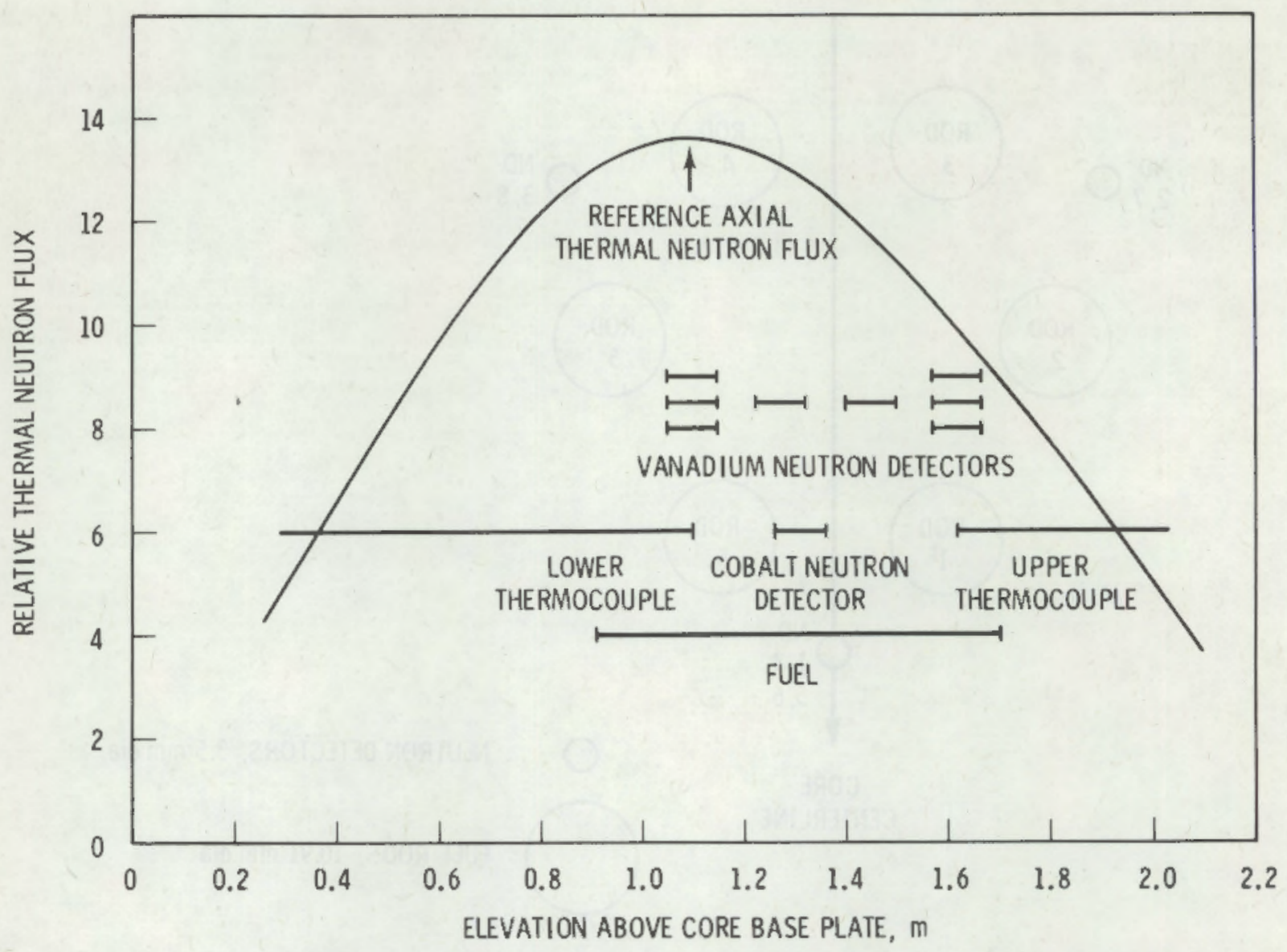

FIGURE 5. Arrangement of Fuel and Instruments Relative to Reference Axial Thermal Flux Profile

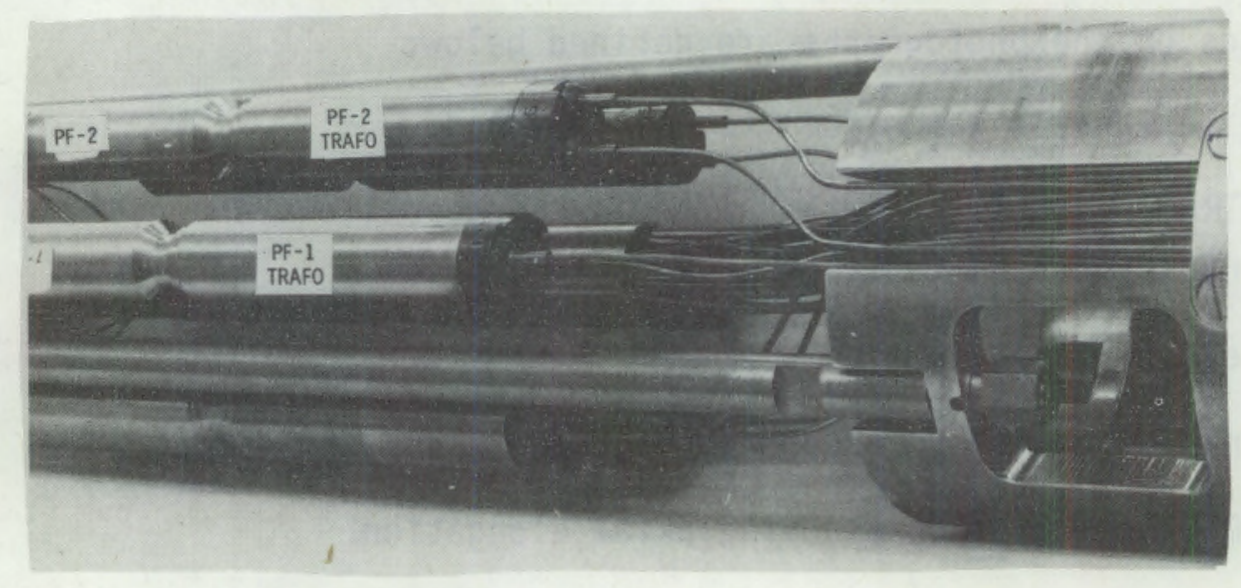

(a) Upper end of assembly showing gas pressure bellows and differential transducer assemblies

FIGURE 6. Completed Instrumented Fuel Assembly (IFA)-527 


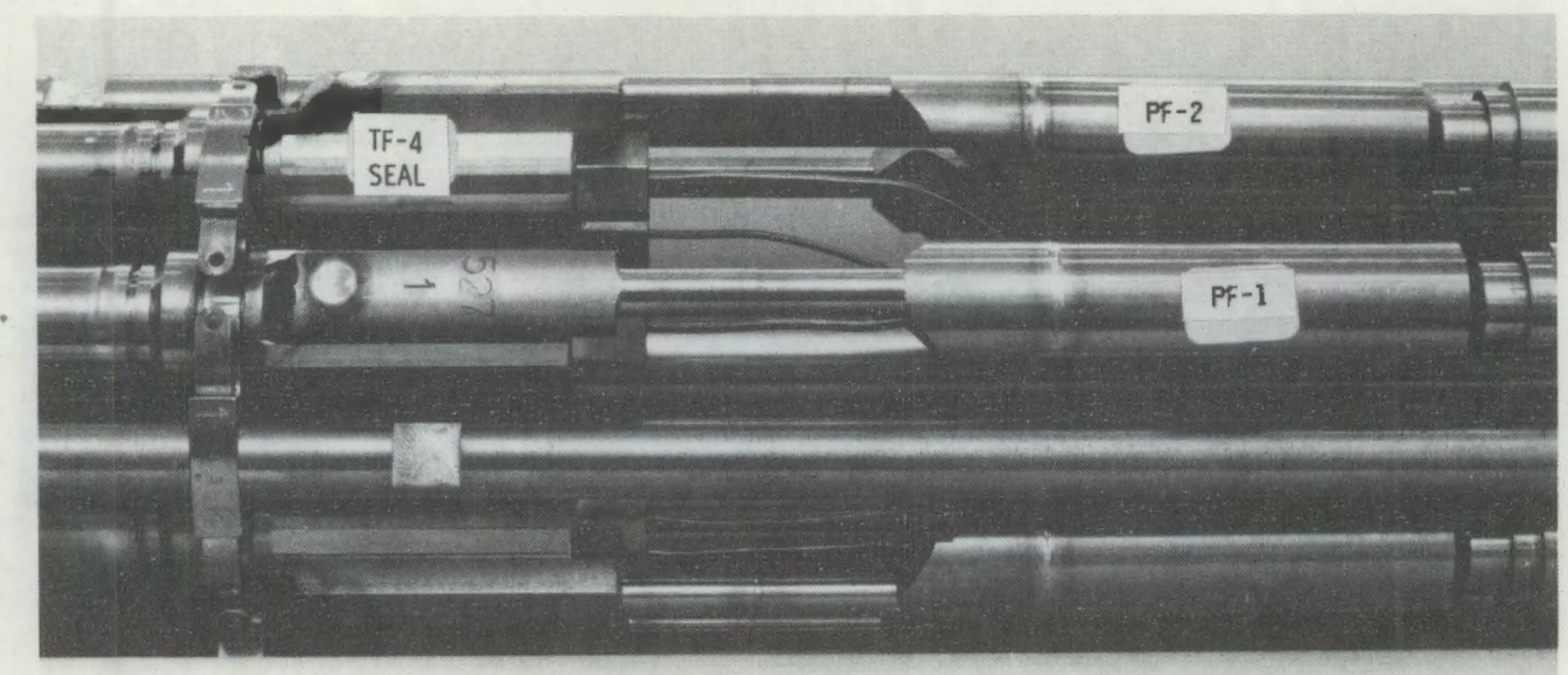

(b) Upper end of assembiy showing upper ends of rods

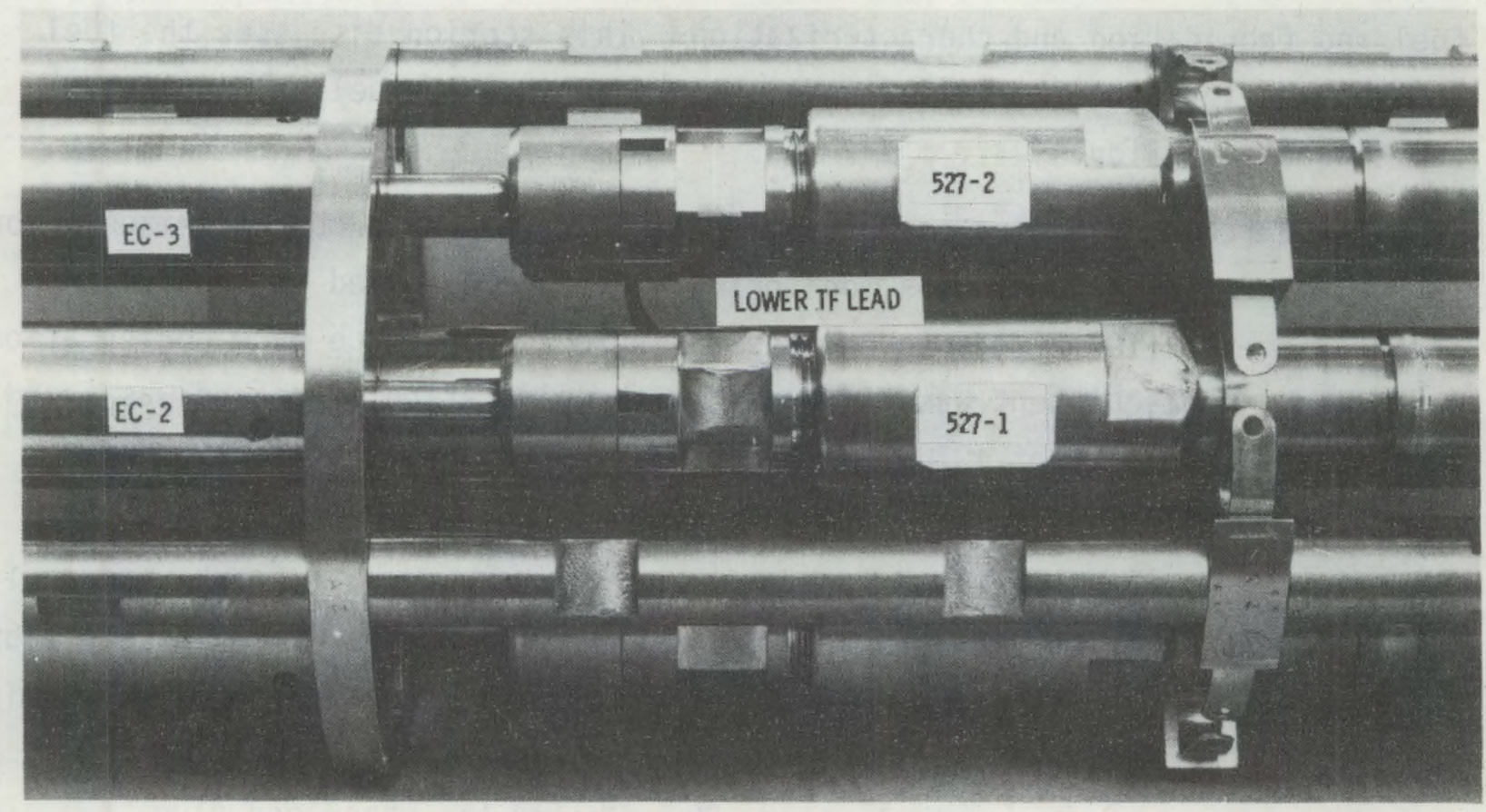

(c) Lower end of assembly showing lower ends of rods and elongation sensors FIGURE 6. (Contd) 


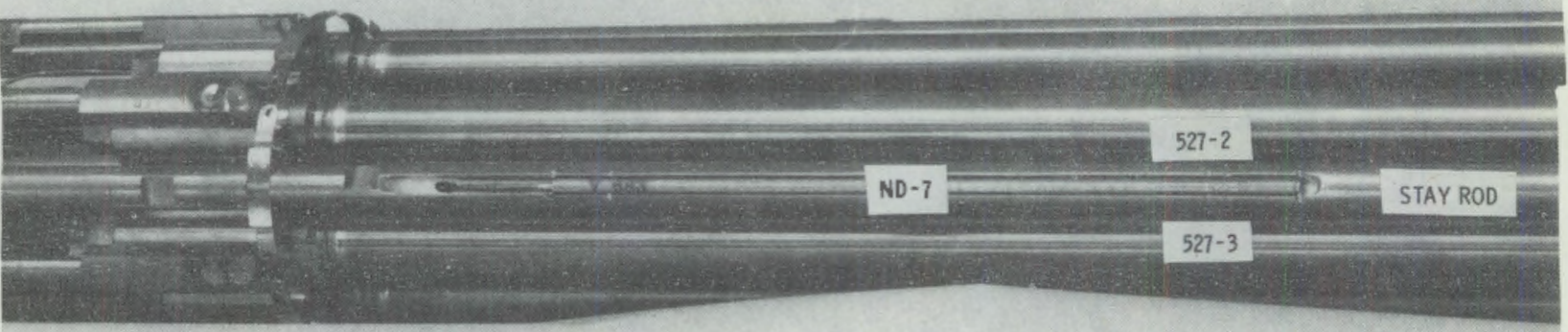

(d) Vanadium neutron detector and fuel rods

FIGURE 6. (contd)

\section{FUEL ROD FABRICATION}

The fuel pellets were fabricated and characterized at PNL and were then shipped to the Institutt for Atomenergi's laboratory in Kjeller, Norway, for fuel rod fabrication and characterization. This section discusses the fuel rod fabrication, and the following section describes the pellet fabrication and characterization.

The Zircaloy-2 tubing to be used as cladding was also characterized prior to fuel loading. A continuous monitoring air gauge was used to measure the inside diameter (ID) of the tubes, and a single linear trace at $0^{\circ}$ orientation was taken. The equipment was calibrated with calibration rings and was found to have a sensitivity of $\pm 0.002 \mathrm{~mm}$. Appendix $B$ contains the profilometry traces of the cladding.

The first step in the fuel rod fabrication process was to clean the fuel pellets with alcohol and then dry them in vacuum at $623 \mathrm{~K}$ for $1 \mathrm{~h}$. Assembly of the fuel rods began with the loading of the fuel and the thermocouples. During loading, the lower thermocouple tips were positioned $185 \mathrm{~mm}$ above the lower end plug; the upper thermocouple tips, $88 \mathrm{~mm}$ below the upper end plug. 
After welding the lower end plug to the cladding, the plenum length was measured (see Table 2); and the plenum spring (Figure 7) and bearing disk were inserted. Next, the upper end plug and bellows pressure transducer assembly were welded to the fuel rod. The free volume within the fuel rod was then measured by a method using a silicon oil manometer with the following results:

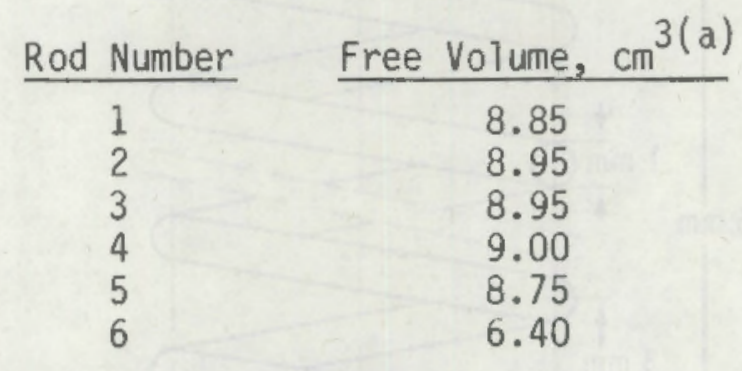

(a) Measured free volume consists of the fuel rod and pressure transducer internal volurines; its accuracy is $\pm 0.05 \mathrm{~cm}^{3}$.

After the fuel rod assembly was completed, the end plugs, seal welds, and the active fuel length were $x$-ray inspected; no faults were found. As a final check for fuel rod integrity, a helium mass spectrometer with a sensitivity of $2 \times 10^{-10} \mathrm{~cm}^{3} / \mathrm{s}$ at standard temperature and pressure (STP) was used to measure helium leakage; no leakage was found.

To complete the assembly of the fuel rods, the rods were evacuated and refilled with xenon and the vent holes in the end plugs were welded shut. The nominal gas composition in volume percent (vol\%) for xenon fill gas was:

\begin{tabular}{lc} 
Fil1 Gas Components & Volume Percent \\
\cline { 2 - 3 } Xenon & 99.99 \\
Krypton & 0.01 \\
Nitrogen & 0.002 \\
Oxygen and Argon & 0.0003 \\
Hydrogen & 0.0001 \\
Hydrocarbons & 0.0002 \\
$\mathrm{H}_{2} \mathrm{O}$ & 0.0002
\end{tabular}




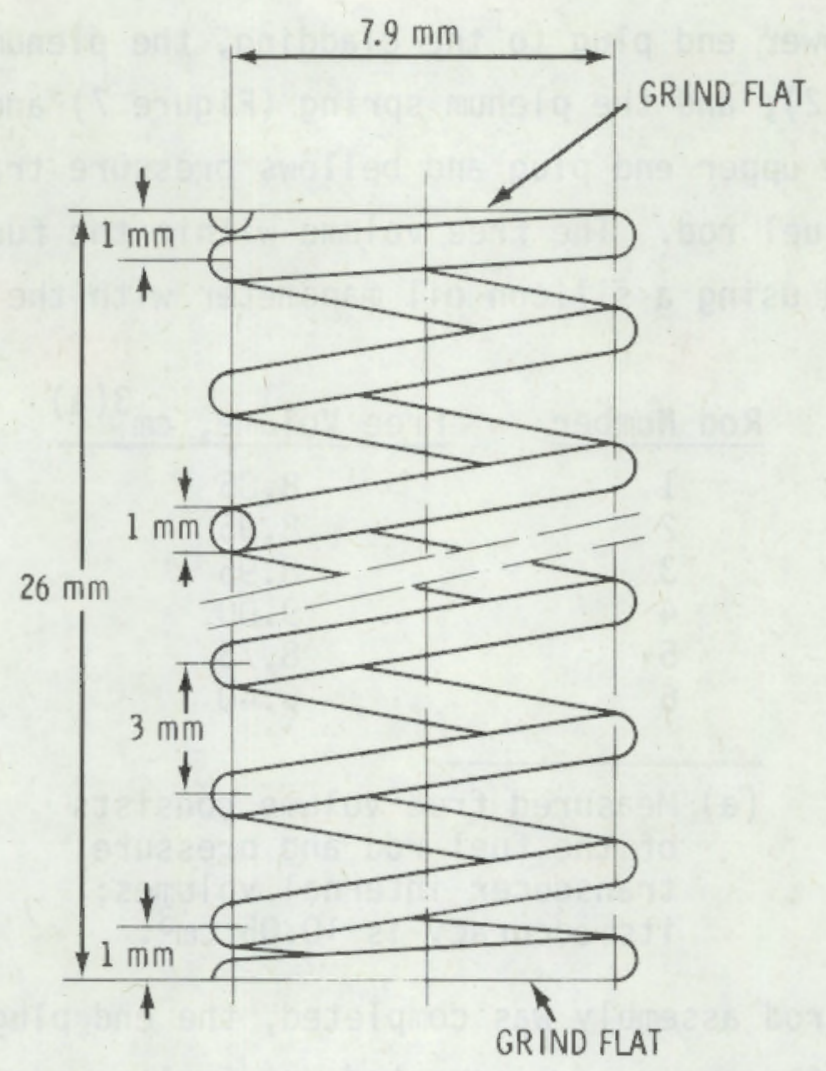

TO BE HARDENED:

$650^{\circ} \mathrm{C}$ FOR 4 HOURS

THEN COOLING IN AIR

VOLUME $=0.156 \mathrm{~cm}^{3}$

MATERIAL $=$ INCONEL $\times 750$, COLD DRAWN

NUMBER OF TURNS $=8$

\section{FIGURE 7. Details of Plenum Spring}

Electron beam welding in a vacuum $\left(1.3 \times 10^{-2} \mathrm{~Pa}\right)$ was used for all welds except for those at the vent holes in the end plugs, which were closed by tungsten inert gas (TIG) welding. Prior to welding, all surfaces were cleaned with $x y 1_{0}^{(a)}$ and alcohol.

(a) $x y l 0 l$ is the Norwegian equivalent of $x y$ lene $\left(\mathrm{C}_{8} \mathrm{H}_{10}\right)$. 


\section{FUEL FABRICATION AND CHARACTERIZATION}

The pellet fabrication process for IFA-527 included acquisition of the $\mathrm{UO}_{2}$ powder, sinterability tests, pellet fabrication, pellet certification, and pellet physical measurements. Microstructural characterization of porosity and grain size and out-of-reactor thermal conductivity measurements were also conducted.

\section{FUEL FABRICATION}

The fuel pellets for IFA-527 and -513 were fabricated from enriched $\mathrm{UO}_{2}$ ceramic-grade powder obtained from 0ak Ridge National Laboratory (ORNL). This powder was obtained under PNL Purchase Order 10990-AY and originated from ORNL Mfg. Batch No. 30-2785. When the powder was received, the containers were inspected and net weights were confirmed. It was then sampled and analyzed, and the data provided by ORNL was confirmed. After the analytical data was reviewed, a $\mathrm{UO}_{2}$ Powder Certification of Compliance Quality Control Release was approved and the powder was released for pellet production. Appendix $C$ of PNL-3156 contains details of the $\mathrm{UO}_{2}$ powder acquisition.

One preproduction sinterability test was performed prior to pellet production runs to evaluate the ability of the furnace to successfully sinter a $4-\mathrm{kg}$ batch of pellets made with depleted $\mathrm{UO}_{2}$ powder. Pellets of the $10 \%$ enriched powder used for Halden test pellets were also included in the test; these 24 pellets determined IFA-527 production parameters. This test was successful and cleared the way for the production of pellets for IFA-527. The test plan, data, and conclusions may be found in Appendix $C$ along with the pellet production process parameters, sintering data, and chemical analysis of the completed fuel pellets.

Specifications for IFA-527 pellets and their required characterization are presented in Table 3, and the following list outlines the procedure used to manufacture the fuel pellets:

- powder reduced to -100 mesh

- powder slugged to $4.3 \pm 0.1 \mathrm{~g} / \mathrm{cm}^{3}$ density

- powder granulated to -20 mesh 
- powder blended with $0.3 \pm 0.1$ wt\% sterotex

- powder pressed to pellets of $5.15+0.05 \mathrm{~g} / \mathrm{cm}^{3}$ density $\left(5.45 \mathrm{~g} / \mathrm{cm}^{3}\right.$ for larger pellets)

- pellets identified by numbering while in green condition

- pellets sintered in a hydrogen atmosphere from room temperature (RT) to $1173 \mathrm{~K}$ and in half hydrogen and half argon for remainder of sintering (1173-1973K, 1973K for $8 \mathrm{~h}$ )

- pellets preinspected

- pellets centerless ground to specified diameter of 0.4205 or 0.4275 \pm 0.0005 in. $(a)$

- final chemical analysis of the pellets was made (Table 4).

Before the pellets were given final cleaning and shipped to Halden, they were inspected and dimensional measurements were taken. All pellets were checked in the following manner, and the data was recorded.

- visual defects - The PNL visual standard for $\mathrm{UO}_{2}$ fuel pellets (shown in Figure 8 ) was used to inspect for chips and cracks.

- diameter - Measurements to the nearest 0.0001 in. were made at three positions: near each end and at the center. All pellets used in IFA-527 met the specified tolerance of \pm 0.0005 in.

- length - Each pellet was measured to the nearest 0.0001 in. at two locations.

- weight - Each pellet was weighed to the nearest $0.001 \mathrm{~g}$.

- density - The geometric density for all pellets was determined from the measured weight and average length and diameter for each pellet. The density of the archive pellets was also determined by a liquid immersion technique: water was used as the suspension medium. ${ }^{(b)}$ Geometric densities are lower than immersion densities because the measured volume is not reduced to account for surface roughness and chips and is therefore greater than the true volume.

(a) Dimensions are as specified in inches.

(b) The immersion density technique is described on pages 7-2 and 7-4 of BNWL-1988 
TABLE 3. Pellet Specifications and Required Characterization for Instrumented Fuel Assembly (IFA) -527

\section{SPECIFICATIONS}

\author{
Pellet Diameter \\ Pellet Length \\ Pellet Density \\ ID of Thermocouple Hole \\ Pellet Geometry \\ Enrichment \\ Powder
}

Pellet Defects and Cleanliness
$0.4275+0.0005$ or $($ a)
$0.4205+0.0005$ in.
$0.500+0.015 \mathrm{in}$.
$95+0.5 \%$ TD (stable structure)
0.067 to $0.071 \mathrm{in}$.
Flat ended
Nominal $10 \%{ }^{235} \mathrm{U}$
ASTM standard specification for nuclear-grade, sinterable uranium dioxide powder (C753-73)
PNL visual standard, ultrasonic plus forced air dry

\section{PELLET CHARACTERIZATION}

\begin{tabular}{l} 
Dimension \\
\hline Outer Diameter \\
Inner Diameter \\
Length
\end{tabular}

$\frac{\text { Technique Used }}{\text { Cross ends and center }}$
Go/no-go
Two locations $180^{\circ}$
apart

\begin{tabular}{|c|c|}
\hline Precision & Frequency, \% \\
\hline $0.0001 \mathrm{in.}$ & 100 \\
\hline $0.0001^{--}$in. & $\begin{array}{l}100 \\
100\end{array}$ \\
\hline
\end{tabular}

Density - Geometric

Weight

Density

Analytical balance Calculated

Density - Immersion

$\begin{array}{ll}0.001 \mathrm{~g}^{3}(\mathrm{~b}) & 100 \\ +0.01 \mathrm{~g} / \mathrm{cm}^{3(\mathrm{~b})} & 100 \\ +0.01 \mathrm{~g} / \mathrm{cm}^{3(\mathrm{~b})} & 100^{(\mathrm{c})}\end{array}$
(a) Units are reported as measured.
(b) Reported to three significant figures.
(c) Archive pellets. 
TABLE 4. Summary of Chemical Analysis for Instrumented Fuel Assembly (IFA)-527

\begin{tabular}{|c|c|c|}
\hline Fuel Makeup & Requirement ${ }^{(a)}$ & $\begin{array}{c}\text { Results for Sample } \\
\text { DB-122 }\end{array}$ \\
\hline Uranium-235, $\%$ & $10.0 \pm 0.2$ & $9.84 \pm 0.05$ \\
\hline Uranium, \% & $\begin{array}{l}87.7 \text { wt\% } \\
\text { minimum }\end{array}$ & 88.08 \\
\hline $\begin{array}{l}\text { Oxygen/Uranium } \\
\text { Ratio }\end{array}$ & $1.99 / 2.02$ & 2.004 \\
\hline$E B C(b)$ & 4 & 3.8 \\
\hline Gas Content & $\begin{array}{l}0.05 \mathrm{~cm}^{3} / \mathrm{gu} \\
\text { maximum }\end{array}$ & 0.007 \\
\hline $\begin{array}{l}\text { Aluminum } \\
\text { Carbon } \\
\text { Calcium + Magnesium } \\
\text { Chlorine } \\
\text { Chromium } \\
\text { Cobalt } \\
\text { Fluorine } \\
\text { Hydrogen (c) } \\
\text { Iron } \\
\text { Nickel } \\
\text { Nitrogen } \\
\text { Silicon } \\
\text { Thorium }\end{array}$ & $\begin{array}{r}250 \\
100 \\
200 \\
25 \\
250 \\
100 \\
15 \\
2 \\
500 \\
250 \\
75 \\
250 \\
10\end{array}$ & $\begin{array}{l}<50 \\
33 \\
100+<10 \\
<10 \\
30 \\
0.2 \\
<5 \\
<5 \\
100 \\
50 \\
<10 \\
<60 \\
40\end{array}$ \\
\hline
\end{tabular}
(a) Except for $\% 235 \mathrm{U}$ requirements are based on ASTM specification C753-73. Units are maximum allowable $\mu \mathrm{g} / \mathrm{gU}$, except where noted.
(b) Equivalent boron content.
(c) Including $\mathrm{H}_{2} \mathrm{O}$.

Table 5 summarizes inspection results; Appendix A contains the measured data for all pellets and the immersion density results for the archive pellets. 


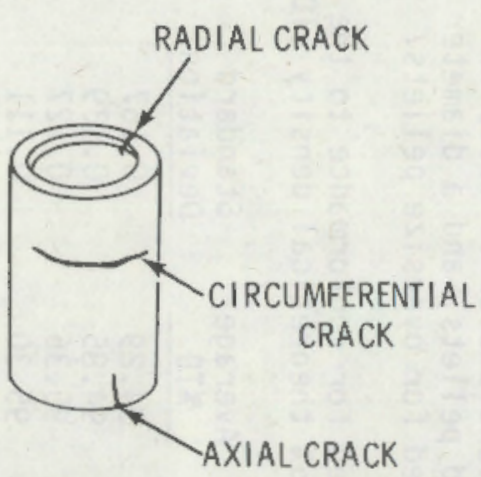

SURFACE CRACKS SHALL NOT EXCEED THE FOLLOWING LIMITS

1. END RADIAL CRACKS $\geq 25 \%$ OF DIAMETER

2. CIRCUMFERENTIAL CRACKS $180^{\circ}$

3. AXIAL CRACKS SHALL NOT EXCEED $25 \%$ OF PELLET LENGTH

4. MICRO CRACKING IS ACCEPTABLE

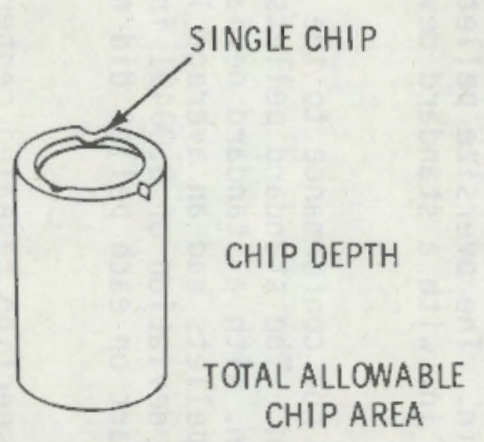

END CHIPS SHALL NOT EXCEED THE FOLLOWING LIMITS

(SAME LIMITS ON NON-DISHED PELLETS)

1. SINGIE CHIP $\leq 10 \%$ OF LAND AREA

2. TOTAL CHIPPING $<25 \%$ OF LAND AREA

3. CHIP DEPTH SHALL NOT EXCEED 0.020 in.

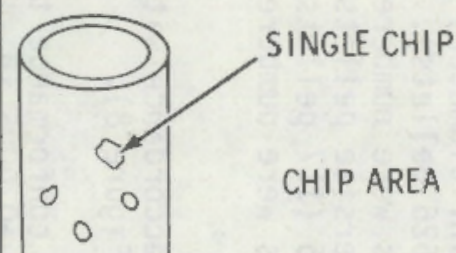

CIRCUMFERENTIAL CHIPS SHALL NOT EXCEED THE FOLLOWING LIMITS

1. SINGLE CHIPS SHALL NOT EXCEED $3 \%$ OF SURFACE AREA

2. TOTAL SURFACE OF CHIPS SHALL NOT EXCEED $10 \%$ OF SURFACE AREA

3. DEPTH 0.020 in.

INSPECTION SHALL REJECT ANY "BORDER-LINE" QUESTI ONABLE PELLET

FIGURE 8. PNL Visual Standards for $\mathrm{UO}_{2}$ Fuel Pellets 
TABLE 5. Summary of Fuel Pellet Specifications and Inspection Results for Instrumented Fuel Assembly (IFA)-527

Pellet Characteristic or Attribute

Summary

Visual Inspection of Chips and Cracks

Pellet Diameter

Quality Control Specification (a) and Inspection Results

Sufficient pellets were produced for two six-rod assemblies. Standard-size pellets $(0.4205-i n$. diameter) were numbered $81-319,400-640$, and 690-835 (626 pellets). Standard-size pellets with thermocouple holes were numbered 1-80, 320-399, and 641-689 (209 pellets). Oversize pellets (0.4275-in. diameter) were numbered 870-986 (117 pellets). Oversize pellets with thermocouple holes were numbered 837-869 (33 pellets).

All pellets were inspected in accordance with the applicable PNL visual standard (see Figure 8 ).

All pellets were inspected for conformance to the specifications of 0.4205 and $0.4275+0.0005$ in. The standard pellets had an average diameter of 0.4205 in. with a standard deviation of $0.00015 \mathrm{in}$. The oversize pellets had an average diameter of 0.4277 in. with a standard deviation of 0.00012 .

Pellet Length

All pellets were inspected for conformance to the specification of $0.500+0.015 \mathrm{in}$. The standard pellets had an average length of $\overline{0} .4985$ in. with a standard deviation of $0.00384 \mathrm{in}$. The oversize pellets had an average length of $0.5008 \mathrm{in}$. with a standard deviation of $0.00491 \mathrm{in}$. Two measurements taken $180^{\circ}$ apart on each pellet did not vary more than 0.001 in.

Pellet Centerline Hole

$100 \%$ attribute go/no-go inspection revealed centerline holes to be within the specified range of 0.067 to $0.071 \mathrm{in}$. An average hole diameter of $0.069 \mathrm{in}$. has been assumed for standard pellets, and a diameter of $0.070 \mathrm{in}$. has been assumed for oversize pellets.

Pellet Geometric Calculated Density

All pellets were inspected for conformance to the specification of $95 \%+0.5 \%$ theoretical density (TD).

\begin{tabular}{|c|c|c|}
\hline $\begin{array}{l}\text { Pellet } \\
\text { Type }\end{array}$ & $\begin{array}{c}\text { Average } \\
\text { \%TD }\end{array}$ & $\begin{array}{l}\text { Standard } \\
\text { Deviation }\end{array}$ \\
\hline $\begin{array}{l}\text { Standard without hole } \\
\text { Standard with hole } \\
\text { Oversize without hole } \\
\text { Oversize with hole }\end{array}$ & $\begin{array}{l}94.29 \\
94.85 \\
95.36 \\
95.30\end{array}$ & $\begin{array}{l}0.167 \\
0.139 \\
0.127 \\
0.111\end{array}$ \\
\hline
\end{tabular}

Pellet Water Immersion Density
All archive pellets were immersion density checked. The average density for the standard pellets was $95.59 \%$ TD, and the average density for the oversize pellets was $96.25 \%$ TD.

(a) Dimensions are repeated here as specified and measured. 


\section{FUEL CHARACTERIZATION}

Since the experimental data to be obtained from IFA-527 will be correlated with data from IFA-431, -432 , and 513 , it is important to understand the microstructural characteristics of the fuel. The fuel for IFA-527 was specified to be similar to the $95 \%$ TD stable $\mathrm{UO}_{2}$ fuel of IFA-432 and was made from the same powder as IFA-513. The characterization plan was therefore mainly aimed at comparing the key microstructural characteristics (pore volume, pore size distribution, and grain size) of the $95 \%$ TO stable $\mathrm{UO}_{2}$ used in IFA-527 to that used in IFA-431, -432 , and -513 . Checks on thermal resintering and thermal conductivity were also conducted to confirm the assumption of similarity to IFA-431 and -432 .

Experimental Procedure

The methods and procedures used to characterize the IFA-527 fuel pellets followed the same philosophy used for IFA-431 and -432 and reported in BNWL-1988. Measurements were taken to determine pore size and volume distribution as well as average grain size as a function of radial location.

Based on experience with the fuel used in IFA-431 and -432 , minor changes were made in testing and measurement procedures. Rather than providing a complete data reference base, these data are intended primarily as verification that the fuel pellets met their design criteria. Three pellets whose bulk density measurements were approximately the average value for the pellets loaded in the assembly were selected from the assembly fuel lot. Each pellet was sectioned transversely at its midpoint, encapsulated in epoxy resin, and polished by the procedure described in BNWL-1988. Special care was taken to minimize physical pullout of grains or $\mathrm{UO}_{2}$ particles. Light microscopy was used to examine the as-polished surfaces for pores larger than $2 \mathrm{um}$. Carefully controlled vacuum cathodic etching removed surface debris from submicron porosity; smaller pores were examined by scanning electron microscopy at the same sites on the polished surfaces. Grain sizes were recorded on the same surfaces after etching more vigorously (using $\mathrm{H}_{2} \mathrm{O}_{2}-\mathrm{H}_{2} \mathrm{SO}_{4}$ ) to reveal grain boundaries clearly. 
The microscopy, porosity measurements, computation of porosity characteristics, and determination of grain size were all conducted as reported in BNWL-1988. The following sites were specified for porosity study on each of the pellet sections: two peripheral, two midradius, and one center radial location. Data from all three pellets (15 sites) was combined to obtain "average" properties. Grain size data was obtained from measurements made with photomicrographs taken at a peripheral, midradius, and central area on each pellet.

\section{Porosity Evaluation}

The general pore size and volume distributions for IFA-527 (as sintered) are similar to those of IFA-431, -432 , and -513 . The general nature of the porosity may be seen in the typical microstructures shown in Figure 9.

Table 6 and Figure 10 provide an overall sumary of the microstructures; the porosity normally varied randomly throughout the pellets within the ranges shown.

Although the fuel for IFA-527 is generally similar to that for IFA-431 and -432, there is a significant difference (see Figure 10). A well-defined small volume component of porosity occurs centered at about 1-um diameter, while the large-diameter porosity peak $(>10 \mu \mathrm{m})$ tends to broaden toward larger pore sizes. The overall effect on pore volume is small, however, as shown by the data in Table 6. The increase in the submicron porosity component is small and would not be expected to have a significant effect on fuel behavior. The influence of porosity on the behavior of all four IFAs is expected to be similar.

The pellets for IFA-527 and -513 were fabricated from the powder shown in Figure 11. Pretreatment of the as-received powder resulted in rounded agglomerated particles averaging approximately 25 to $50 \mu \mathrm{m}$ in diameter (upper photos in Figure 11). Close examination of the large particle structure reveals that they are composed of close-packed, randomly shaped particles approximately 0.1-0.2 $\mu \mathrm{m}$ in diameter (lower photos in Figure 11). This combination of agglomerated particles permitted sintering to high density with some control over retained porosity. No IFA-431 or -432 powder samples were available for comparison. 

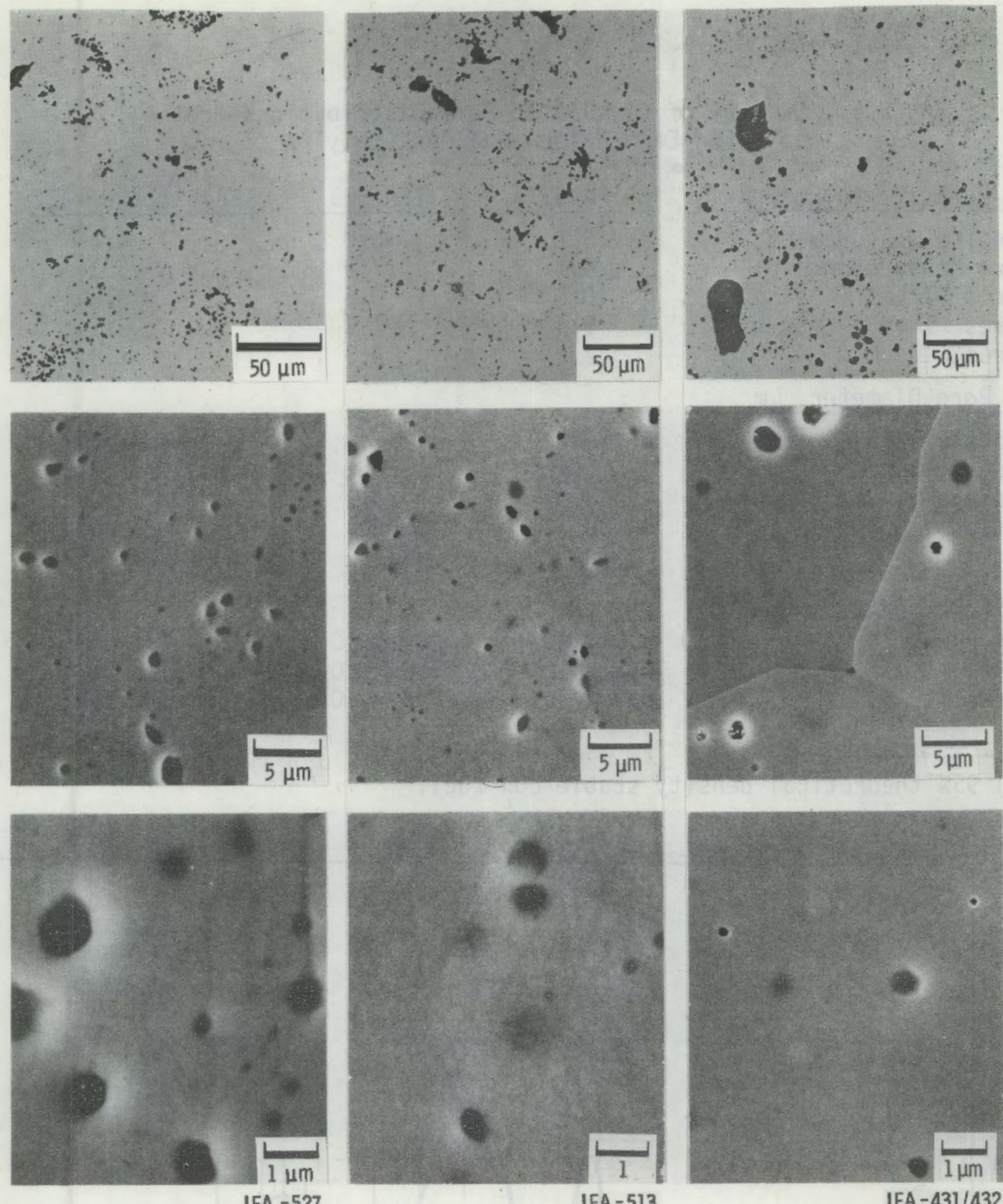

IFA - 527

IFA-513

IFA-431/432

FIGURE 9. Microstructure of $\mathrm{UO}_{2}$ Fuel Pellets for Instrumented Fuel Assemblies (IFAs) $-527,-513,-431$, and -432 
TABLE 6. Summary of Calculated Pore Distributjons from All Data for Each Halden Fuel Assembly(a)

\begin{tabular}{|c|c|c|c|}
\hline Porosity Volume, $\%$ & IFA- 527 & IFA-513 & IFA-431 and -43 \\
\hline $\begin{array}{l}\text { Density Measurement } \\
\text { Pore Measurement } \\
\text { Pores }<1 \mathrm{\mu m} \\
\text { Pores }>1 \mu \mathrm{m} \\
\text { Pores }>10 \mu \mathrm{m} \\
\text { Pore Diameter, } \mathrm{mm}\end{array}$ & $\begin{array}{l}5.1 \\
6.1 \\
0.7 \\
5.4 \\
2.2\end{array}$ & $\begin{array}{l}5.0 \\
7.9 \\
0.6 \\
7.3 \\
3.3\end{array}$ & $\begin{array}{l}4.4 \\
6.7 \\
0.6 \\
6.1 \\
1.8\end{array}$ \\
\hline 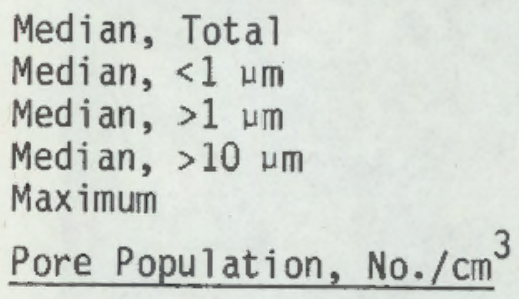 & $\begin{array}{r}5.6 \\
0.7 \\
5.6 \\
36 \\
114\end{array}$ & $\begin{array}{c}7.3 \\
0.7 \\
17.3 \\
28 \\
119\end{array}$ & $\begin{array}{r}5.1 \\
0.6 \\
5.1 \\
32 \\
101\end{array}$ \\
\hline $\begin{array}{l}\text { A11 Pores } \\
\text { Pores }>1 \mu \mathrm{m} \\
\text { Pores }>10 \mathrm{~mm}\end{array}$ & $\begin{array}{l}3.3 \times 10^{11} \\
7.8 \times 109 \\
5.0 \times 10^{6}\end{array}$ & $\begin{array}{l}2.4 \times 10^{11} \\
7.6 \times 10^{9} \\
8.3 \times 10^{6}\end{array}$ & $\begin{array}{l}2.4 \times 10^{11} \\
6.3 \times 109 \\
4.5 \times 10^{6}\end{array}$ \\
\hline
\end{tabular}

(a) $95 \%$ theoretical density stable $\mathrm{UO}_{2}$ fuel.

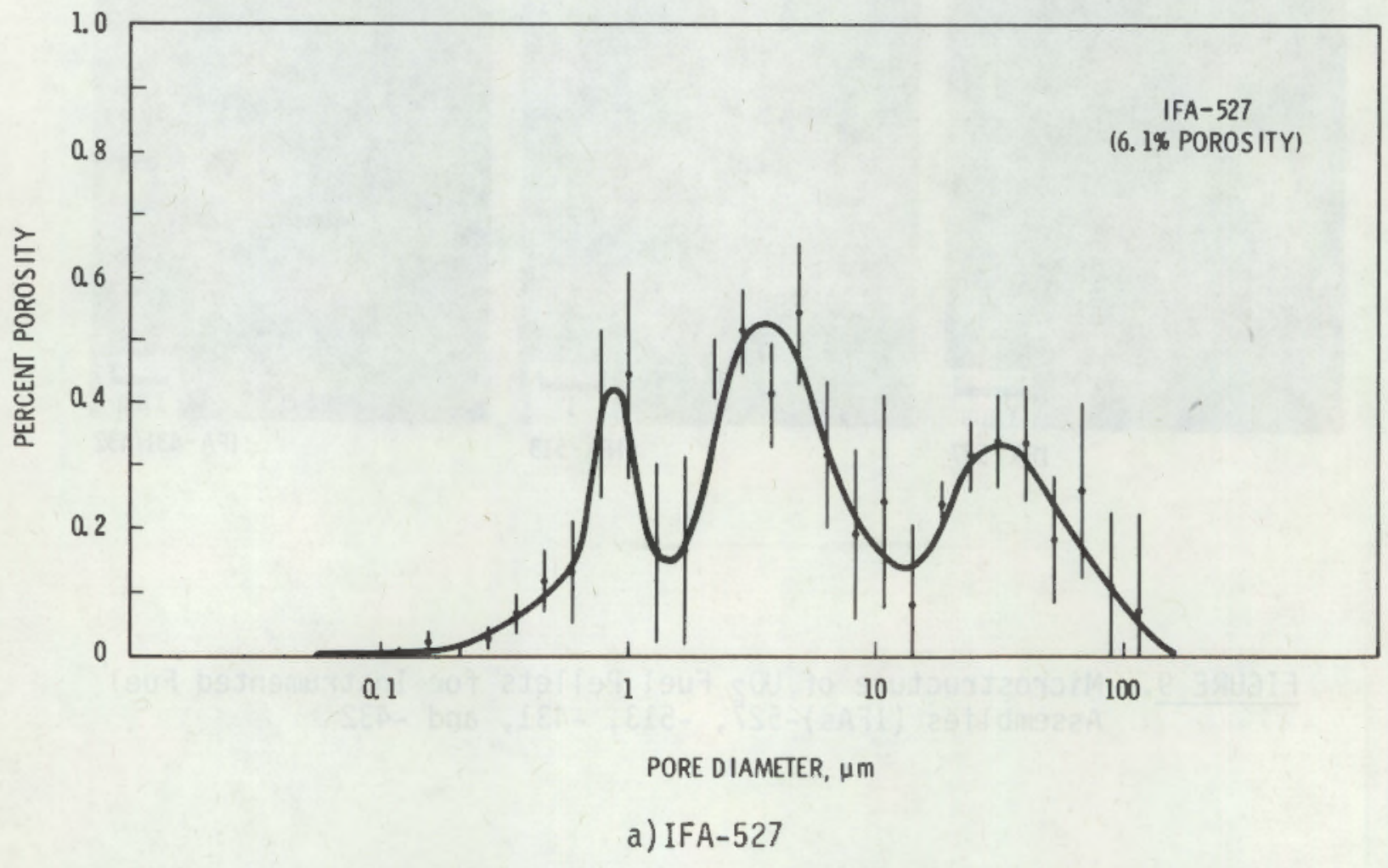

FIGURE 10. Pore Size and Volume Distribution for 95\% TO Stable $\mathrm{UO}_{2}$ Fuel Used in IFA-527, $-513,-431$, and -432 (vertical lines indicate $2 \sigma$ confidence limits at midpoint of each size range) 


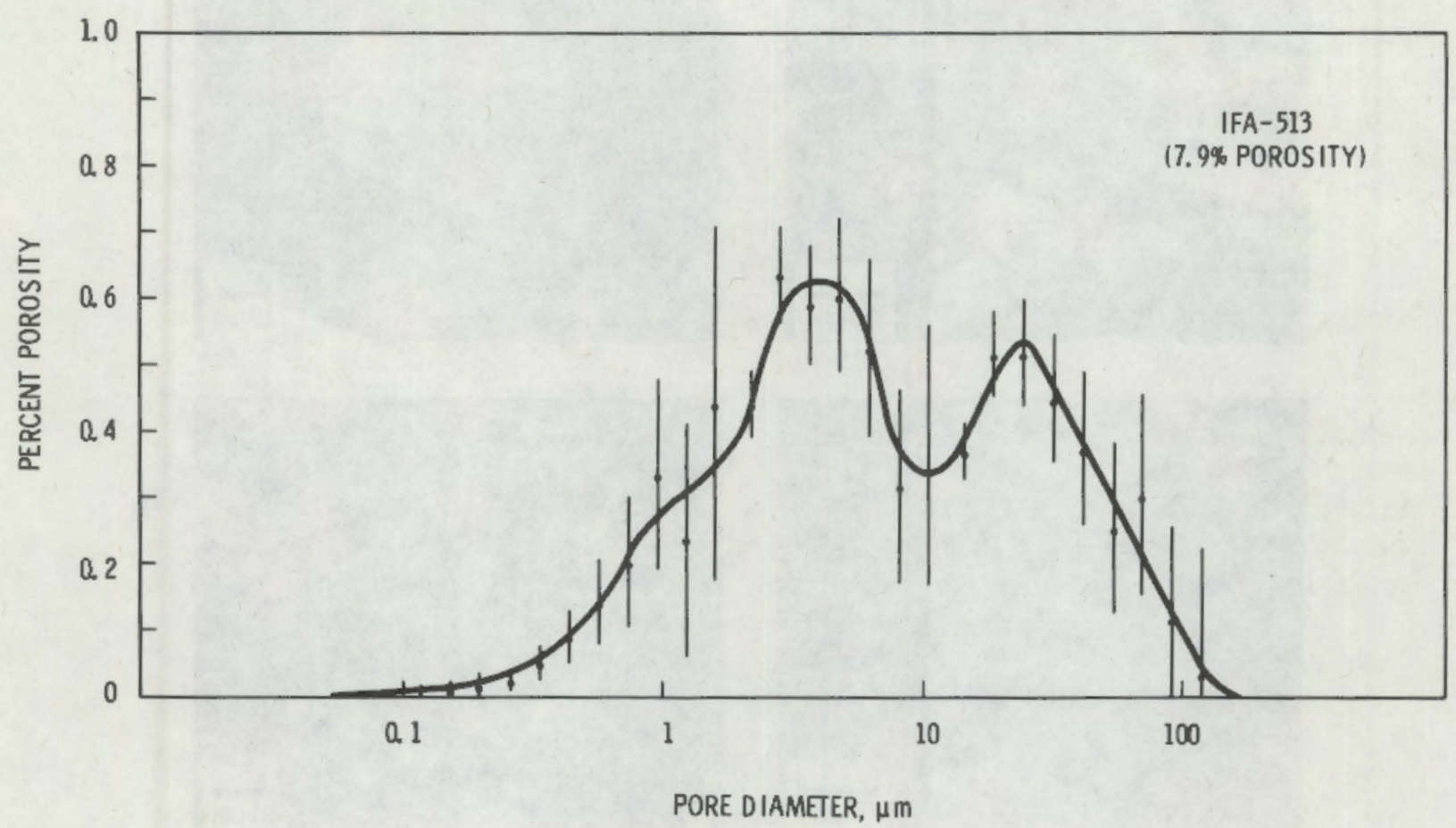

b) IF A-513

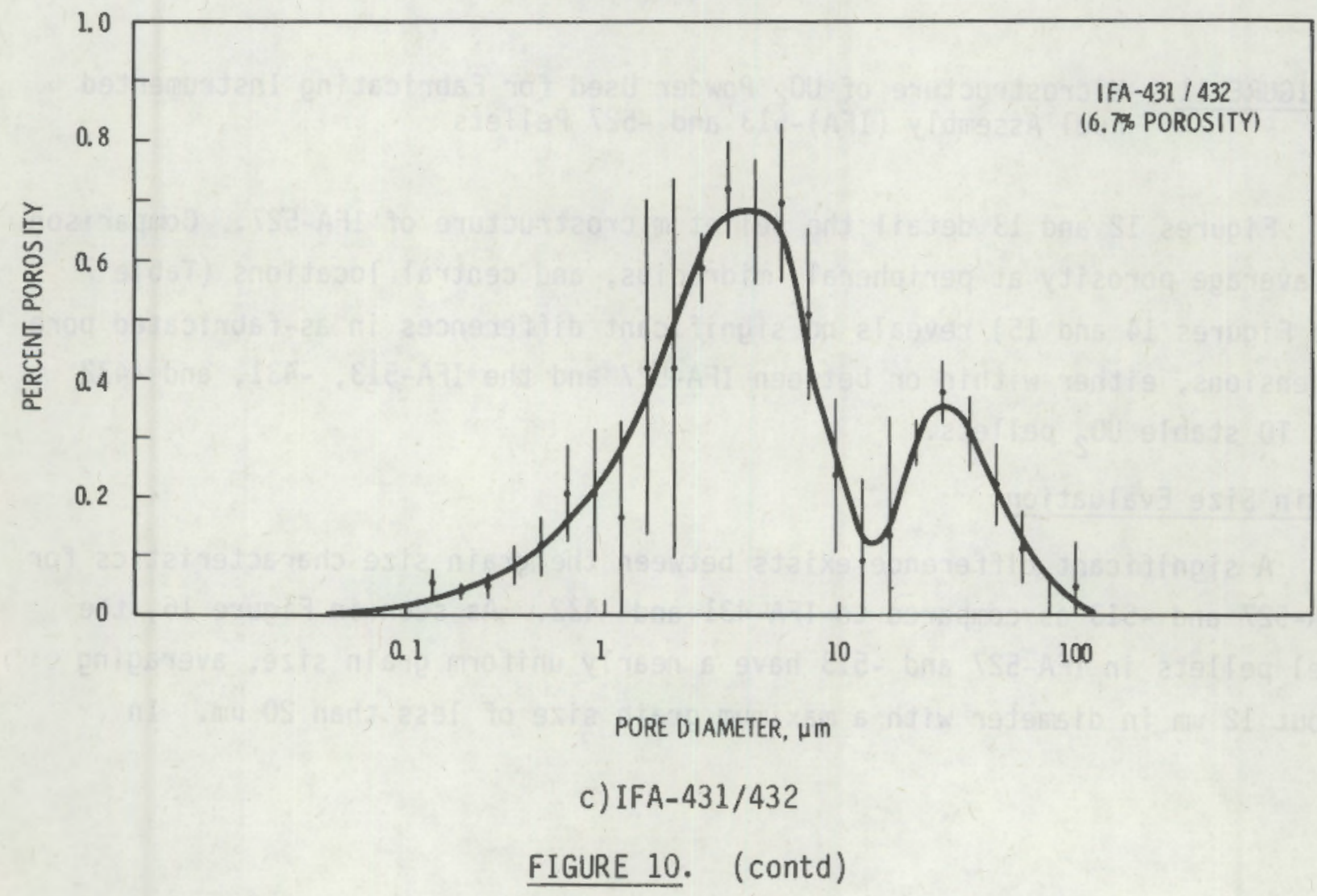



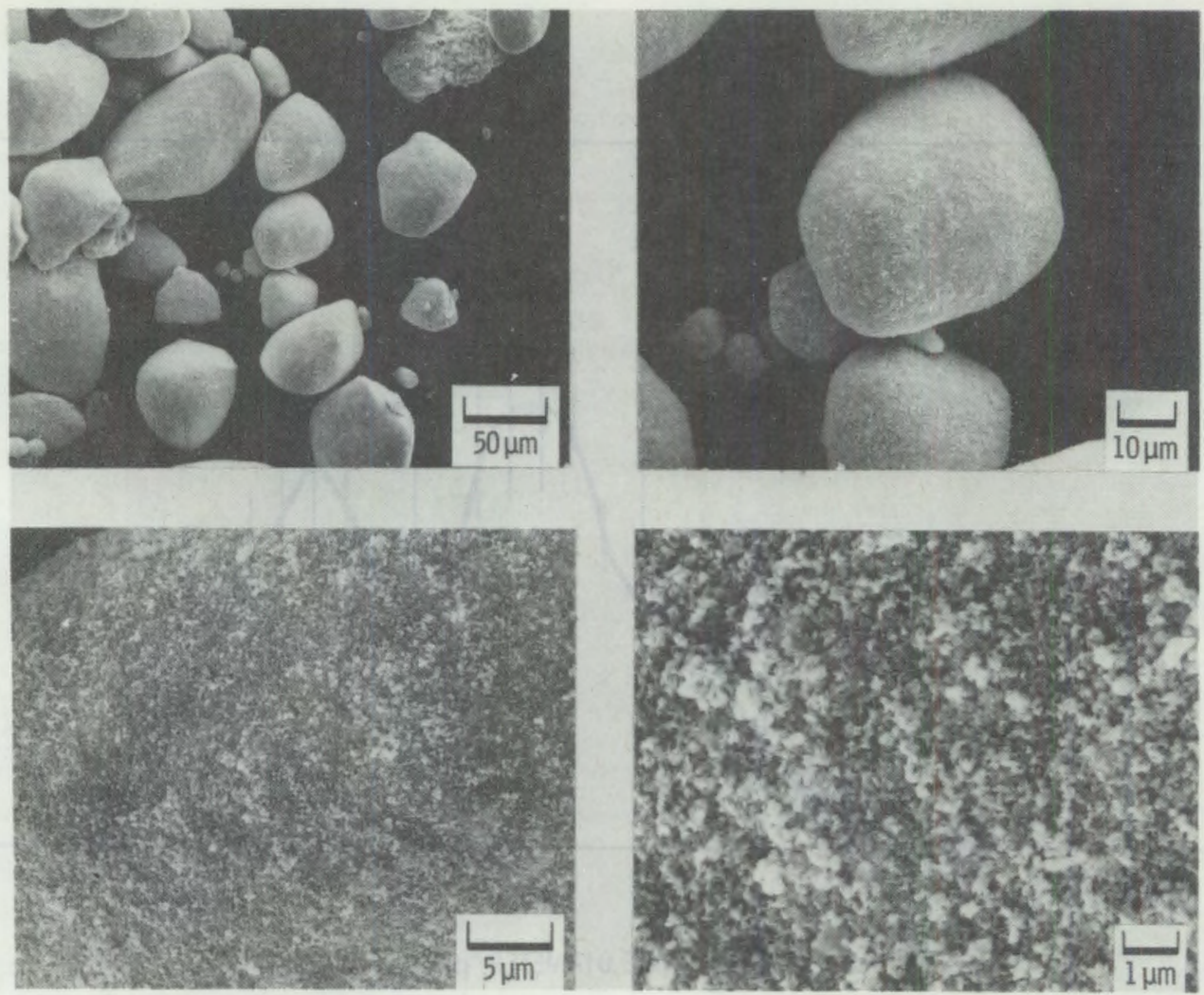

FIGURE 11. Microstructure of $\mathrm{UO}_{2}$ Powder Used for Fabricating Instrumented Fuel Assembly (IFA) -513 and -527 Pellets

Figures 12 and 13 detail the pellet microstructure of IFA-527. Comparison of average porosity at peripheral, midradius, and central locations (Table 7 and Figures 14 and 15 ) revea 15 no significant differences in as-fabricated pore dimensions, either within or between IFA-527 and the IFA-513, -431 , and -432 95\% TD stable $\mathrm{UO}_{2}$ pellets.

Grain Size Evaluation

A significant difference exists between the grain size characteristics for IFA-527 and -513 as compared to IFA-431 and -432 . As seen in Figure 16, the fuel pellets in IFA-527 and -513 have a nearly uniform grain size, averaging about $12 \mu \mathrm{m}$ in diameter with a maximum grain size of less than $20 \mu \mathrm{m}$. In 


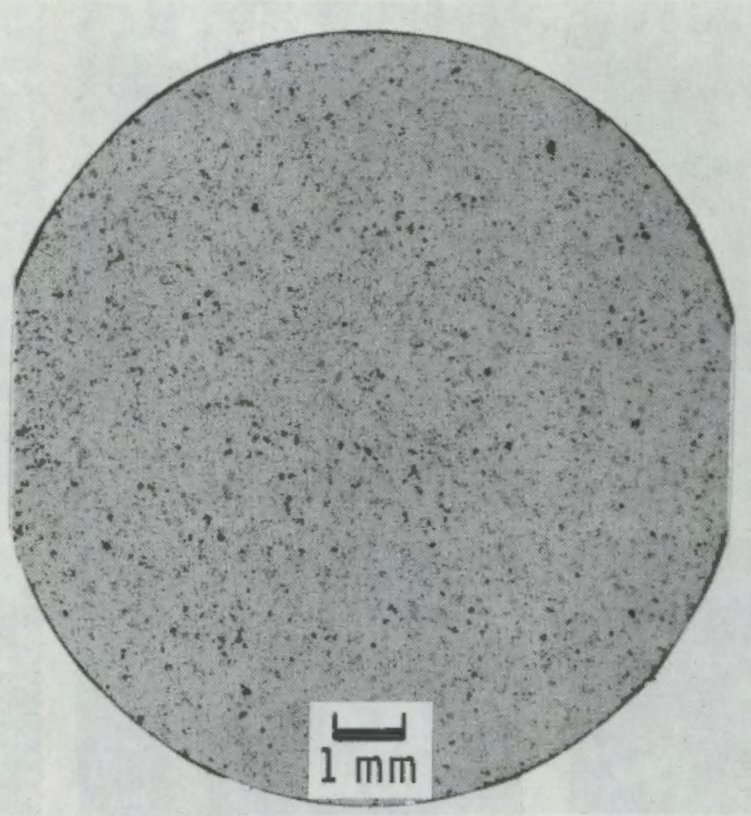

TRANSVERSE SECTION NEAR PELLET CENTER

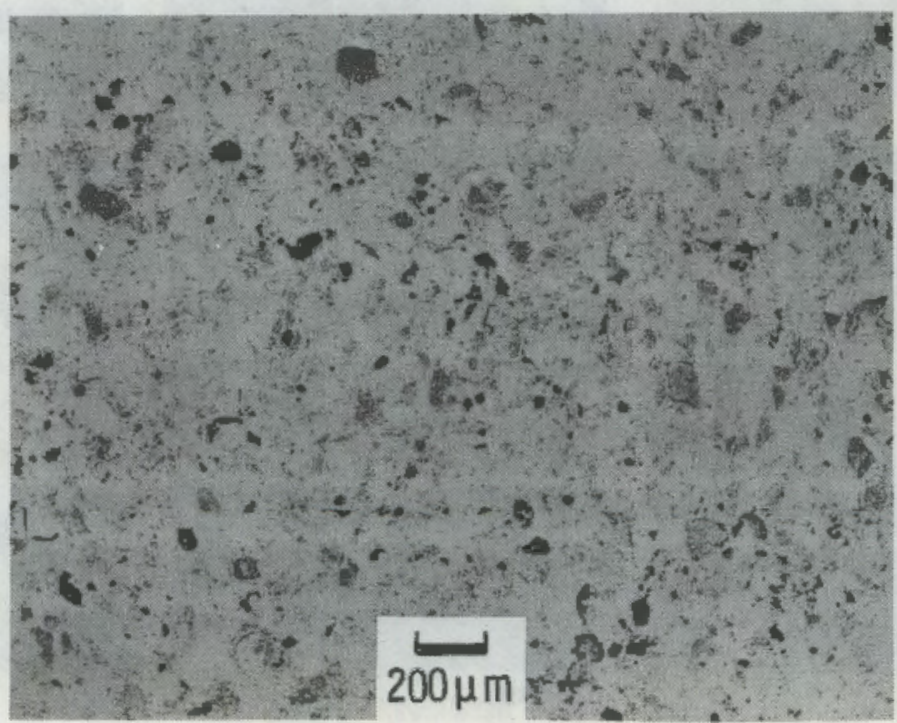

TYPICAL AREA OF TRANSVERSE SECTION

FIGURE 12. General Porosity Characteristics of 95\% TD Stable $\mathrm{UO}_{2}$ Pellets Used in Instrumented Fuel Assembly (IFA) -527 

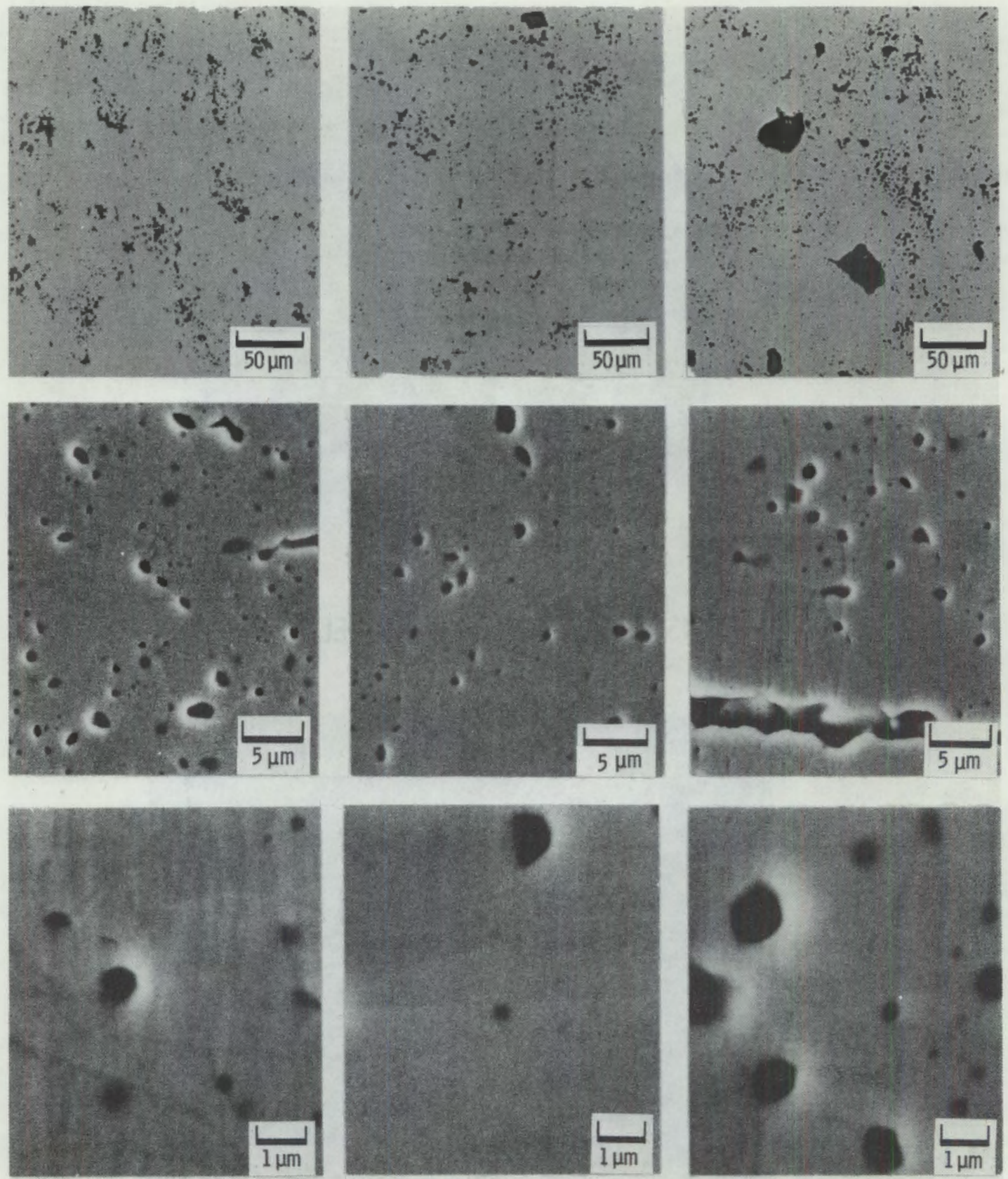

MIDRADIUS

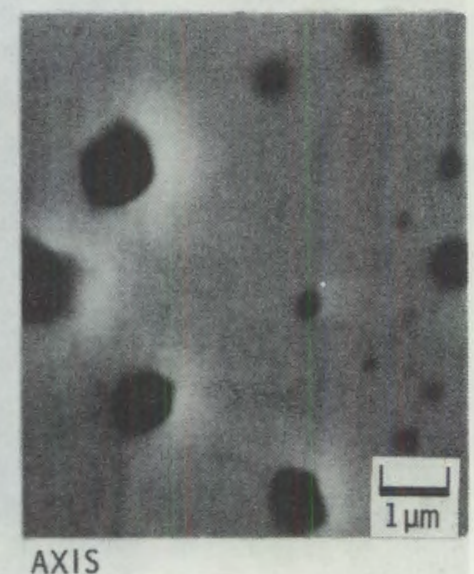

FIGURE 13. Typical Porosity Characteristics of $\mathrm{UO}_{2}$ Pellets Used for Instrumented Fuel Assembly (IFA)-527. No discernible difference exists as a function of radial position in the pellets. 

TABLE 7. Pore Distributions for Instrumented Fuel
Assembly (IFA)-527(a)

Porosity Volume, $\%$

By Pore Measurement

Pores $<1 \mu \mathrm{m}$

Pores $>1 \mu \mathrm{m}$

Pores $>10 \mu \mathrm{m}$

Pore Diameter, $\mu \mathrm{m}$

Median, Total

Median, <1 $\mu \mathrm{m}$

Median, >1 $\mu \mathrm{m}$

Median, $>10 \mu \mathrm{m}$

Maximum

Pore Population, No. $/ \mathrm{cm}^{3}$

Al1 Pores

Pores $>1 \mu \mathrm{m}$

Pores $>10 \mu \mathrm{m}$
Radial Location

\begin{tabular}{cccc}
\hline Periphery & Midradius & Axis \\
6.8 & 5.8 & & 5.6 \\
0.7 & 1.0 & & 0.4 \\
6.1 & 4.8 & & 5.2 \\
2.3 & 2.4 & & 2.5
\end{tabular}

$\begin{array}{rcc}5.2 & 4.5 & 8.4 \\ 0.6 & 0.8 & 0.6 \\ 6.2 & 7.1 & 9.7 \\ 43 & 30 & 33 \\ 114 & 88 & 88\end{array}$

$3.1 \times 10^{11}$

$11 \times 10^{9}$

$4.7 \times 10^{11}$

$5.5 \times 10^{9}$

$2.8 \times 10^{6}$

$5.5 \times 10^{6}$

$4.3 \times 10^{11}$

$5.3 \times 10^{9}$

$8.6 \times 10^{6}$

(a) $95 \%$ theoretical density stable $\mathrm{UO}_{2}$ fuel.

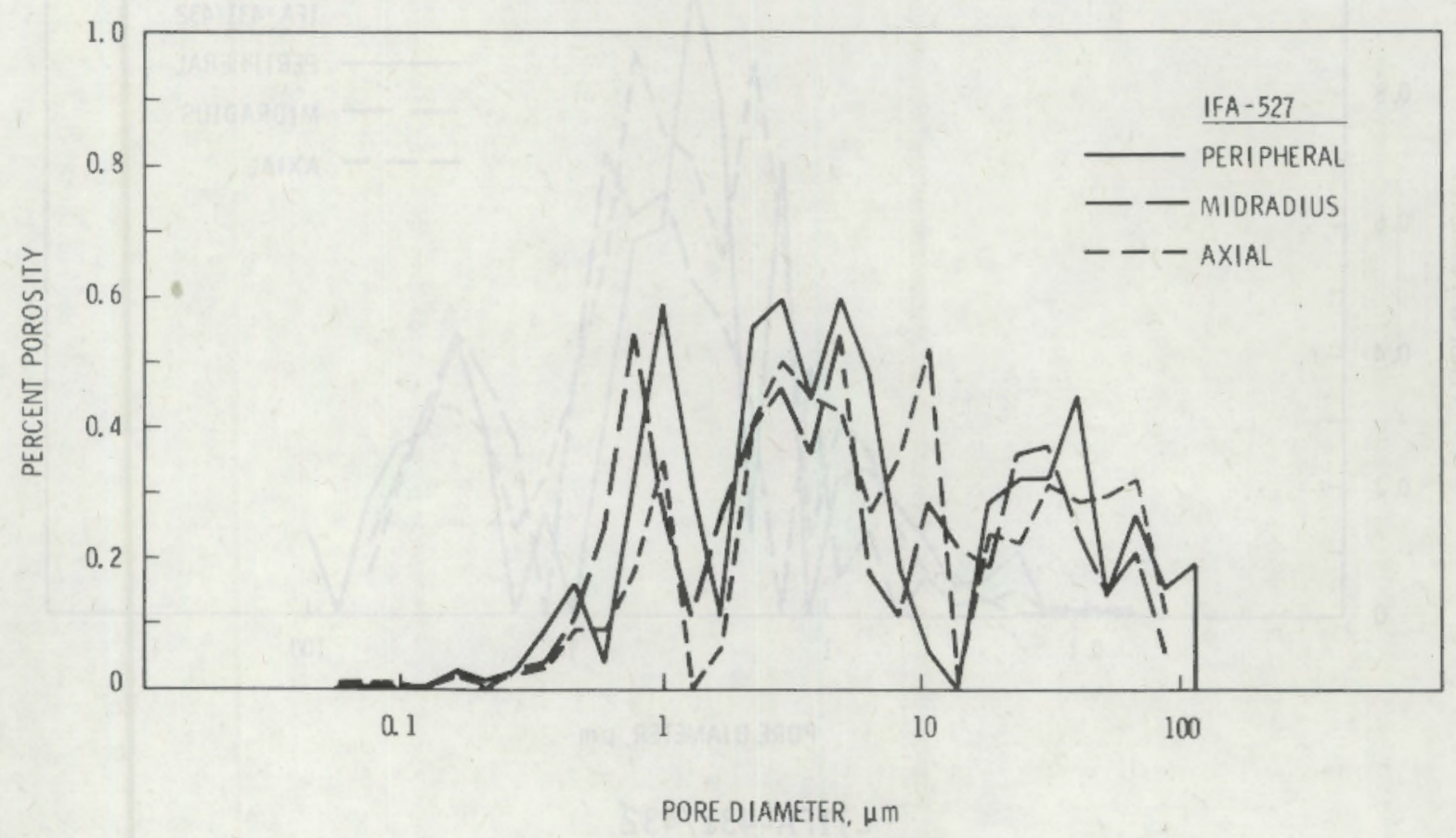

a) IFA-527

FIGURE 14. Summary of Radial Distribution of Pore Size and Volume (1ine segments join peak values of midpoint of successive size ranges) 

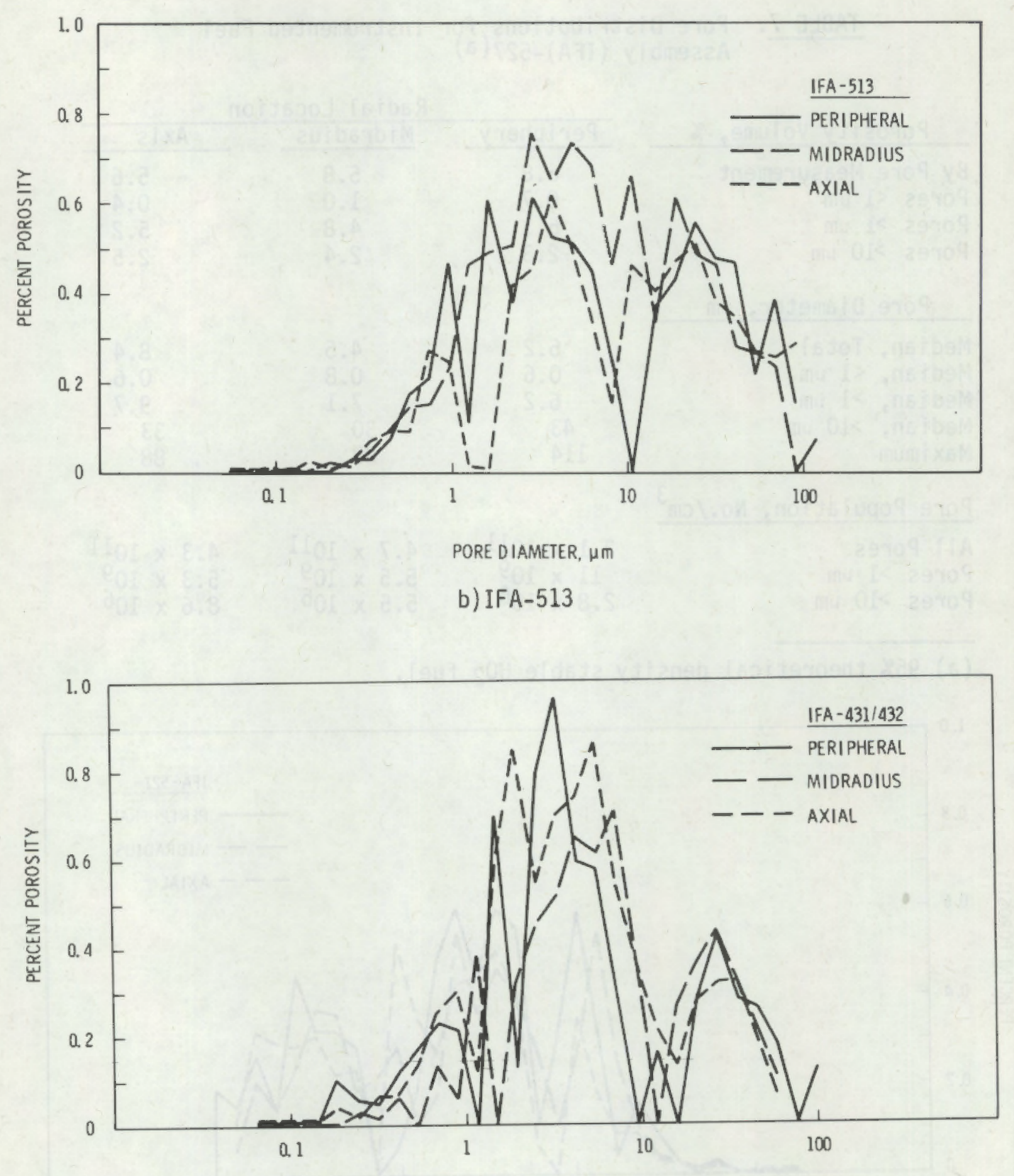

PORE DIAMETER, $\mu \mathrm{m}$

c) IFA- $431 / 432$

FIGURE 14. (contd) 


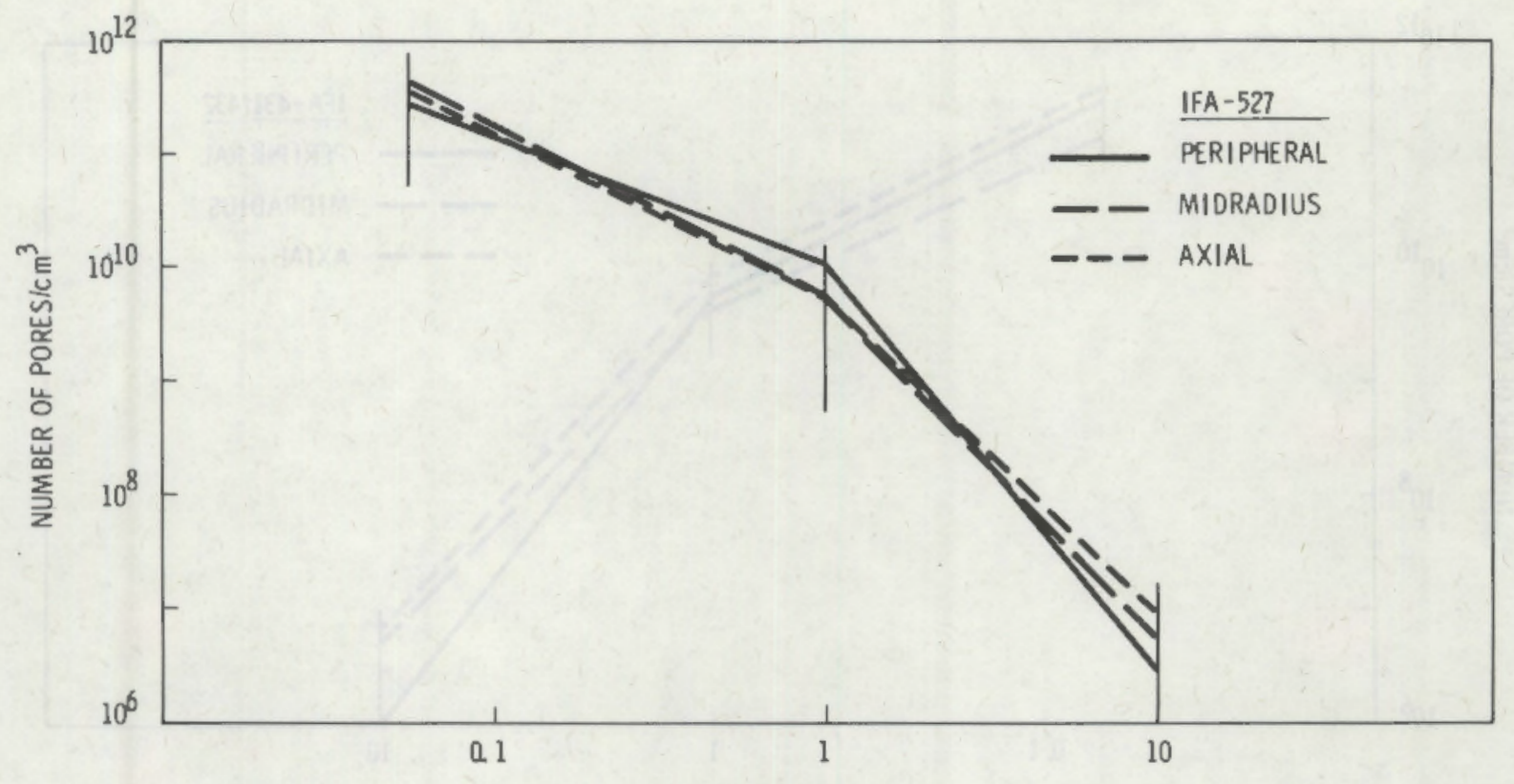

PORE DIAMETER, $\mu \mathrm{m}$

a) IFA-527

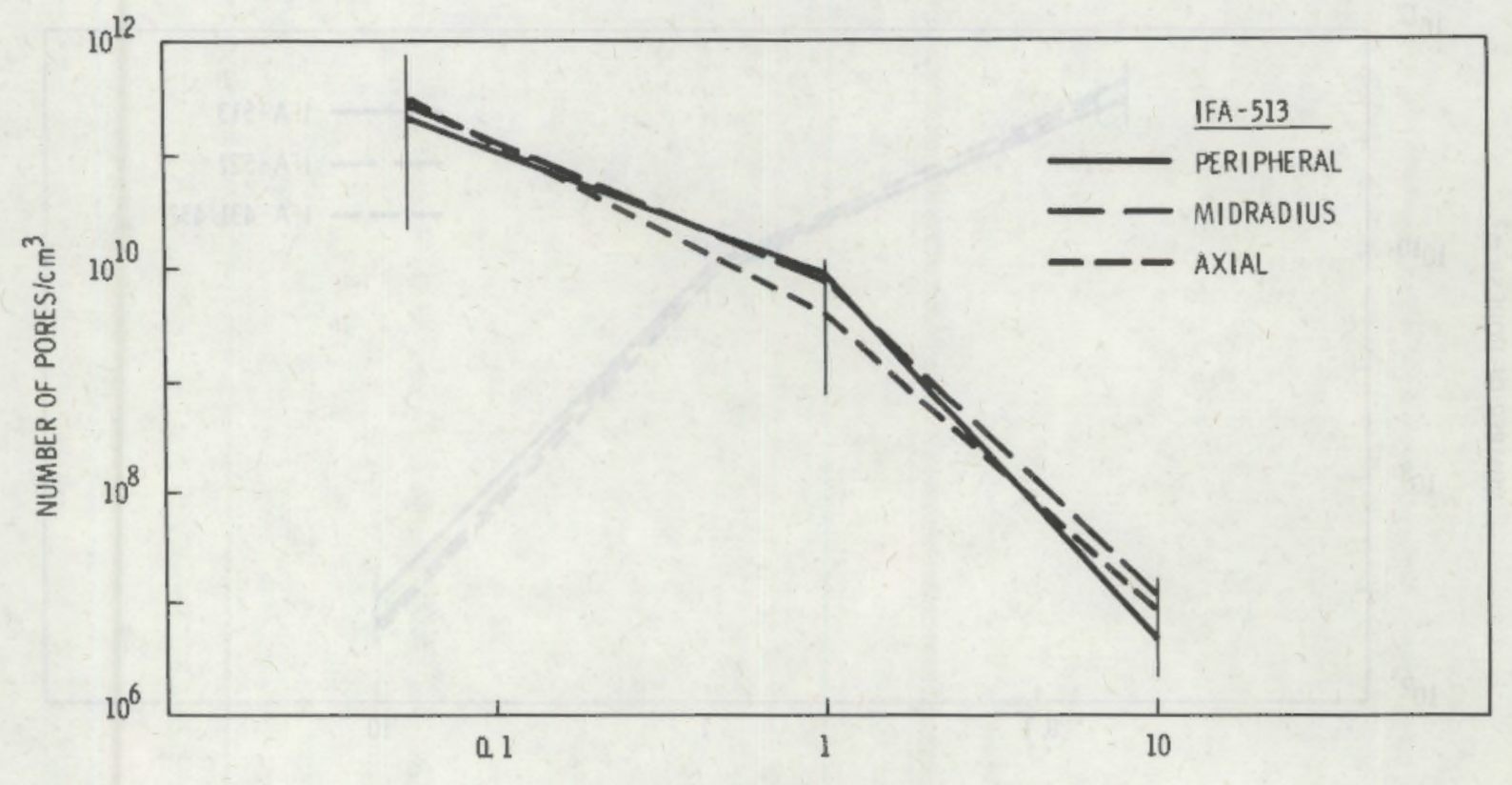

PORE DIAMETER, $\mu \mathrm{m}$

b) IFA- 513

FIGURE 15. Radial Distribution of Pore Population as a Function of Pore Size (cumulative total number of pores larger than the corresponding pore size) 


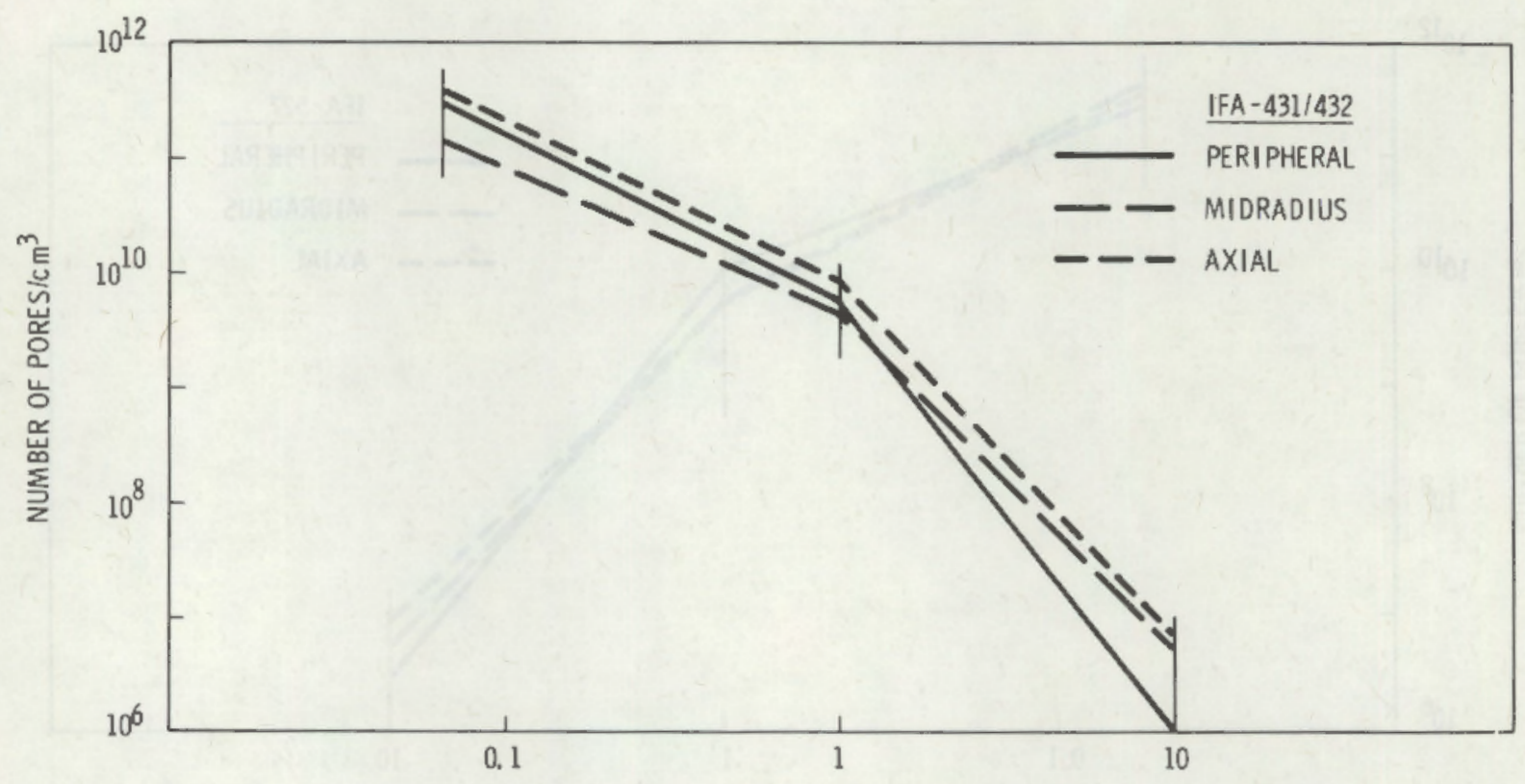

PORE DIAMETER, $\mu \mathrm{m}$

c) IFA-431/432

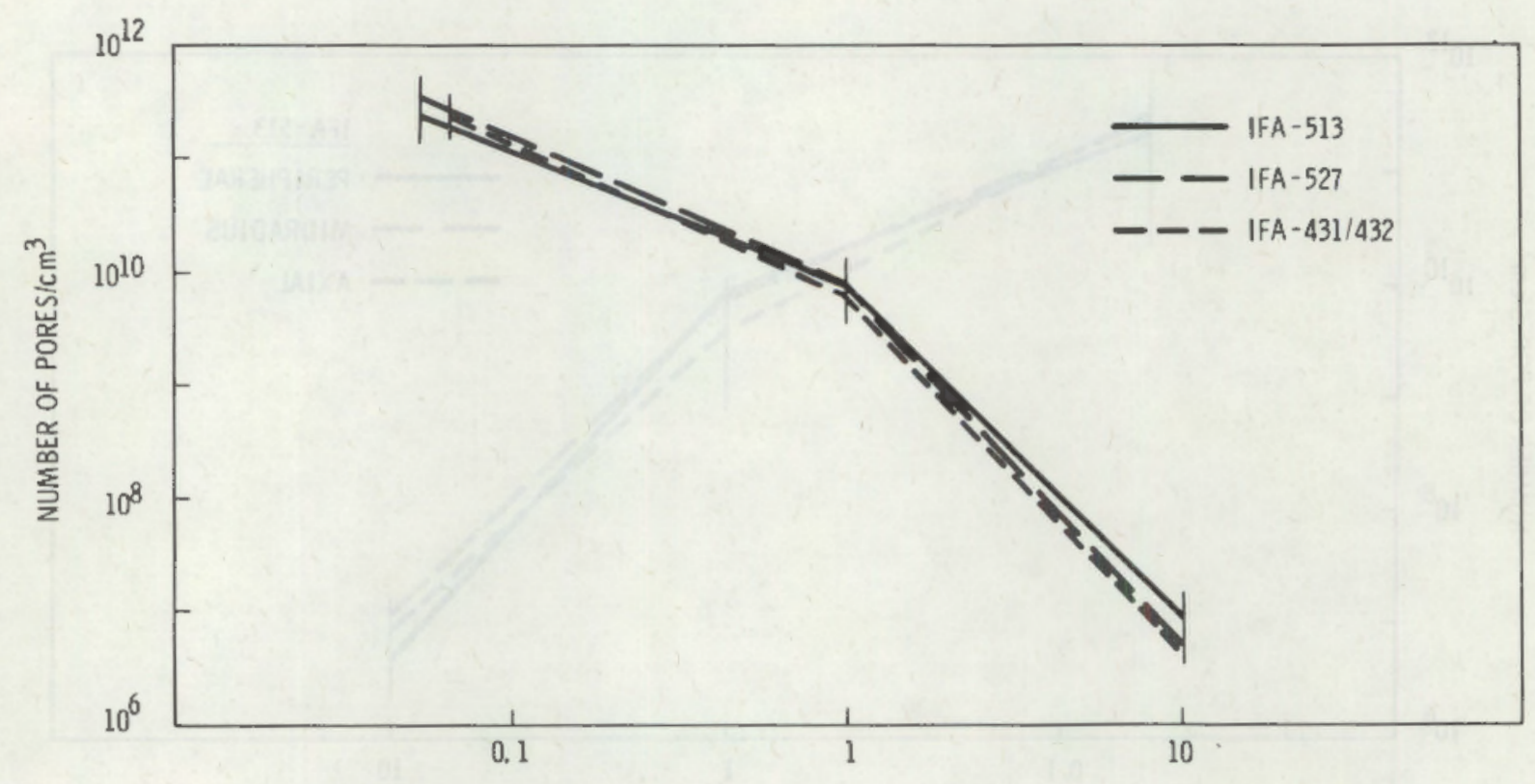

PORE DIAMETER, $\mu \mathrm{m}$

d) Comparison of IFA-527, -513 , and $-431 / 432$

FIGURE 15. (contd) 

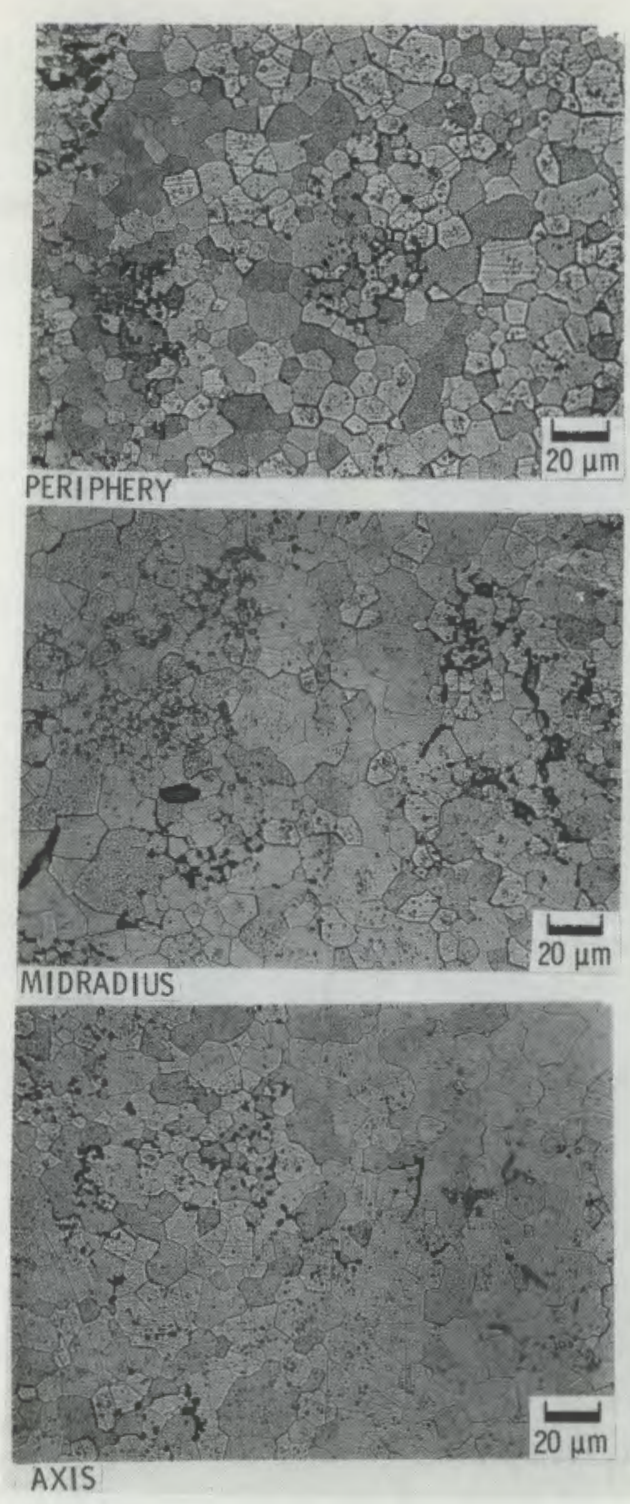

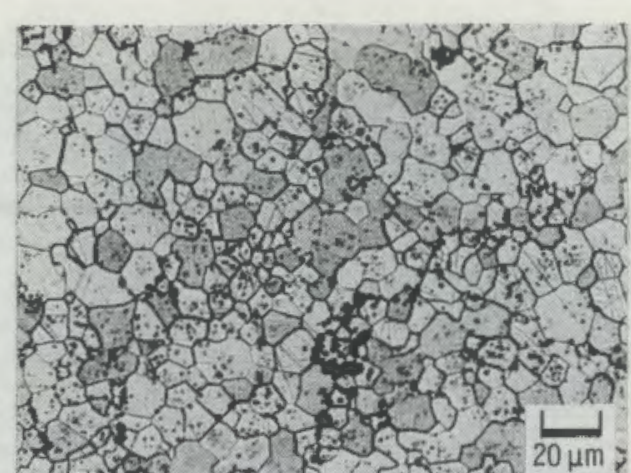

PERIPBERY

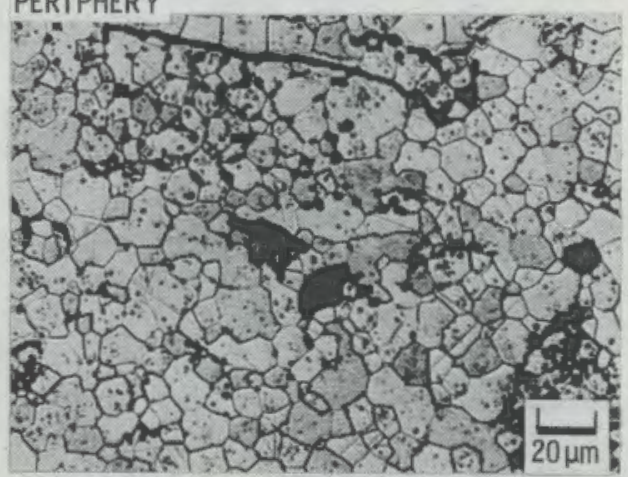
MIDRADIUS

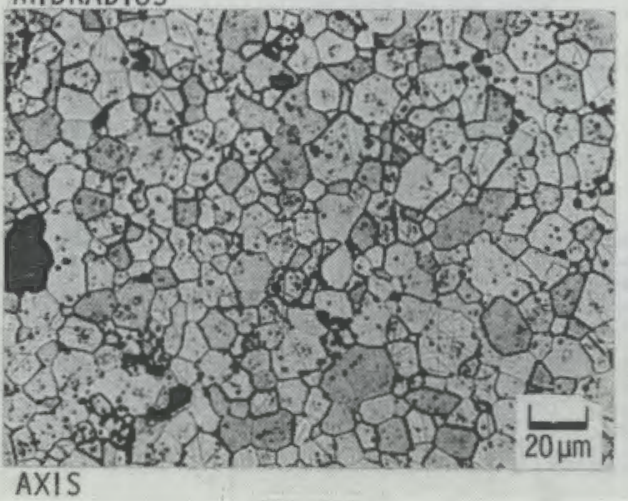

IFA-513

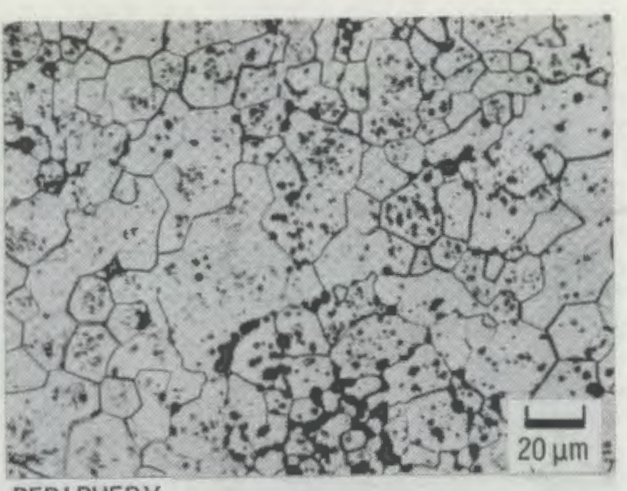

PERIPHERY

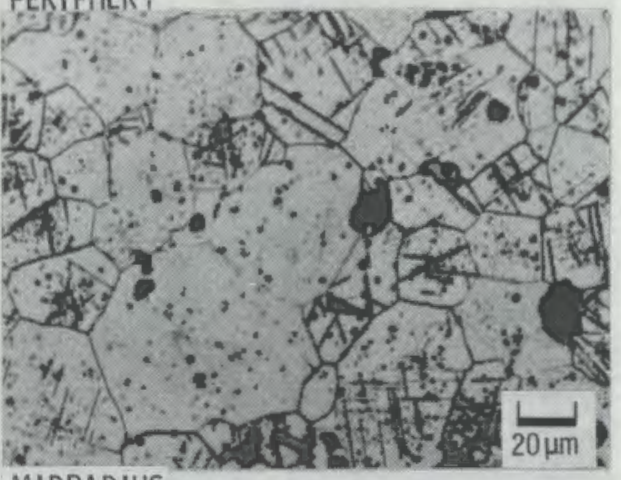
MIDRADIUS

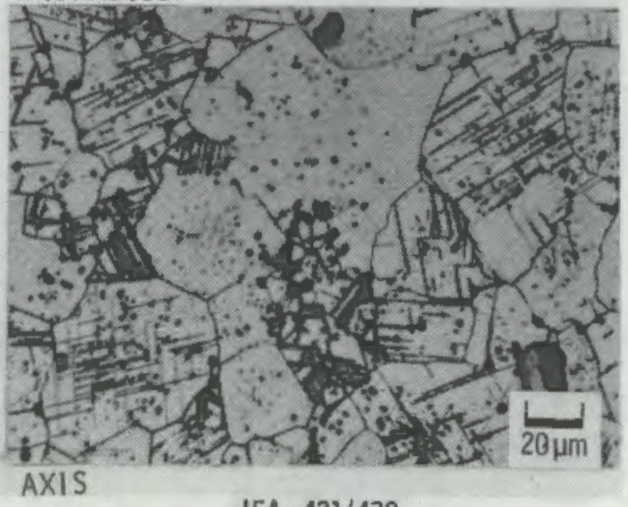

IFA-431/432

FIGURE 16. Variation in Grain Size for 95\% TD Stable $\mathrm{UO}_{2}$ Pellets Used in Instrumented Fuel Assemblies (IFA) $-527,-513,-431$, and -432 
contrast, IFA-431 and -432 have a marked radial gradient in grain size, from an average diameter of $22 \mathrm{um}$ at the pellet periphery to over $70 \mu \mathrm{m}$ at the midradius and axial positions. The maximum grain diameter observed for IFA-431 and -432 fuel was over $80 \mathrm{~mm}$. The differences between the assemblies are further illustrated in Figure 17 and Table 8. The observed grain size differences can probably be explained by the various combinations of starting powder, furnace, and sintering conditions used for fabricating the pellets. The clusters of small grain-boundary porosity observed in IFA-527 are scattered randomiy throughout the pellet and are probably responsible for the 1-um peak in the pore distribution curve (see Figure 10). The grain size for IFA-527, while much smaller than those for IFA-431 and -432 , is not likely to cause any densification instability. ${ }^{(9)}$

In conclusion, the fuel pellets used in all four fuel assemblies are similar in microstructure. The greatest similarity is in porosity characteristics

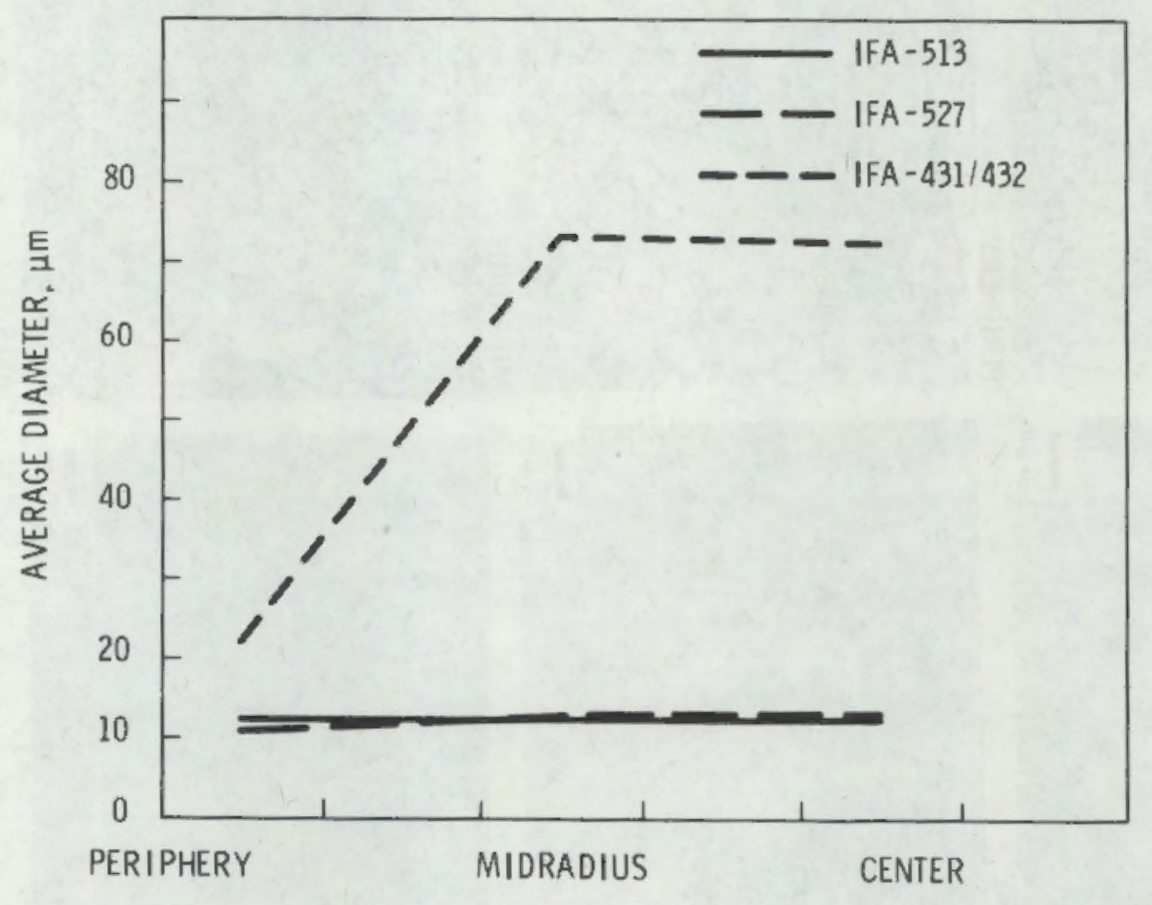

LOCATION OF GRAINS WITHIN PELLET

FIGURE 17. Summary of Radial Variation in Grain Size for IFA-527 and -513 and IFA-431 and -432 
TABLE 8. Grain Size of As-Sintered Pellets (a)

\begin{tabular}{|c|c|c|c|}
\hline \multirow[b]{2}{*}{ Position } & \multicolumn{3}{|c|}{ Average Diameter, $\mu \mathrm{m}$} \\
\hline & IFA-527 ${ }^{(\mathrm{b})}$ & IFA-513(b) & IFA-431 and $-432^{(c)}$ \\
\hline $\begin{array}{l}\text { Peripheral } \\
\text { Midradius } \\
\text { Axial }\end{array}$ & $\begin{array}{l}11 \pm 1 \\
13 \pm 1 \\
13 \pm 2\end{array}$ & $\begin{array}{l}12 \pm 2 \\
12 \pm 2 \\
12 \pm 1\end{array}$ & $\begin{array}{l}22 \\
73 \\
72\end{array}$ \\
\hline
\end{tabular}

(a) $95 \%$ theoretical density stable fuel.

(b) Averages from transverse sections of three pellets.

(c) Averages of transverse and longitudinal sections of two pellets.

although IFA-527 contains a small component of 1-um porosity not present in the others. The greatest difference is in grain size; the grain sizes of IFA-431 and -432 are two to five times larger than those in IFA-527 and -513 . Based on the densification studies by Freshley et al. ${ }^{(9)}$ the combination of characteristics in both fuel batches (few pores smaller than 1- $\mu \mathrm{m}$ diameter, total porosity of 5 to $7 \%$, and grain size greater than 10-um diameter) is expected to result in similar microstructural behavior (including densification stability).

Thermal Resintering

At the time the IFA-513 precharacterization report (PNL-3156) was published, no thermal resintering tests had been performed on the fuel. Because the microstructure of the IFA-513 fuel was similar to that of IFA-432, it was concluded that there would be little densification of the IFA-513 fuel. A thermal resintering test has now been performed on three IFA-513 pellets and one IFA-527 pellet.

The pellets were resintered in a refractory metal-cold wall furnace with a tungsten element. The atmosphere was $50 \% \mathrm{Ar} / 50 \%$ He flowing at $283 \mathrm{l} / \mathrm{h}$ $\left(10 \mathrm{ft}^{3} / \mathrm{h}\right)$. The furnace heating rate was $150 \mathrm{~K} / \mathrm{h}$ to $723 \mathrm{~K}$; then $300 \mathrm{~K} / \mathrm{h}$, to 1973K. The pellets were held at $1973 \mathrm{~K}$ for $24 \mathrm{~h}$ and then cooled at $400 \mathrm{~K} / \mathrm{h}$.

Table 9 presents the as-sintered characterization of the four pellets. Table 10 presents the same measurements after the resintering test. It can be seen that the average increase in immersion density was approximateiy $0.32 \%$ TD. The average density increase for the $95 \%$ TD stable fuel used in IFA-431 and 
TABLE 9. As-Sintered Characterization of Pellets to Be Resintered

\begin{tabular}{|c|c|c|c|c|}
\hline Parameter (a) & $\frac{\text { IFA-527 }}{\text { Pellet } 835}$ & Pellet 151 & IFA-513 & Perlet 368 \\
\hline Diameter, in. & 0.4209 & 0.4202 & 0.4207 & 0.4209 \\
\hline Length, in. & 0.4975 & 0.4965 & 0.5025 & 0.4985 \\
\hline Weight, $g$ & 11.801 & 11.720 & 11.867 & 11.783 \\
\hline $\begin{array}{l}\text { Geometrical Density, } \\
\text { g/cm }{ }^{3} \\
\text { \%TD }\end{array}$ & $\begin{array}{l}10.40 \\
94.9\end{array}$ & $\begin{array}{l}10.39 \\
94.8\end{array}$ & $\begin{array}{l}10.37 \\
94.6\end{array}$ & $\begin{array}{l}10.38 \\
94.7\end{array}$ \\
\hline $\begin{array}{l}\text { Immersion Density, } \\
\mathrm{g} / \mathrm{cm}^{3} \\
\% \mathrm{TD}\end{array}$ & $\begin{array}{l}10.48 \\
95.6\end{array}$ & $\begin{array}{l}10.48 \\
95.6\end{array}$ & $\begin{array}{l}10.44 \\
95.3\end{array}$ & $\begin{array}{l}10.47 \\
95.5\end{array}$ \\
\hline
\end{tabular}

(a) Presented in as-measured units.

TABLE 10. Resintered Characterization of Pellets

\begin{tabular}{|c|c|c|c|c|}
\hline Parameter(a) & $\frac{\text { IFA-527 }}{\text { Pellet } 835}$ & Pellet 151 & $\begin{array}{l}\text { IFA-513 } \\
\text { Pellet } 321\end{array}$ & Pellet 368 \\
\hline Diameter, in. & 0.4205 & 0.4199 & 0.4203 & 0.4203 \\
\hline Length, in. & 0.4970 & 0.4960 & 0.5020 & 0.4975 \\
\hline Weight, $g$ & 11.799 & 11.718 & 11.861 & 11.778 \\
\hline $\begin{array}{l}\text { Geometrical Density, } \\
\text { g/cm }{ }^{3} \\
\text { \%TD }\end{array}$ & $\begin{array}{l}10.43 \\
95.2\end{array}$ & $\begin{array}{l}10.41 \\
95.0\end{array}$ & $\begin{array}{l}10.39 \\
94.8\end{array}$ & $\begin{array}{l}10.41 \\
95.0\end{array}$ \\
\hline $\begin{array}{l}\text { Immersion Density, } \\
\text { g/ } \mathrm{cm}^{3} \\
\text { \%TD }\end{array}$ & $\begin{array}{l}10.51 \\
95.9\end{array}$ & $\begin{array}{l}10.51 \\
95.9\end{array}$ & $\begin{array}{l}10.48 \\
95.6\end{array}$ & $\begin{array}{l}10.51 \\
95.9\end{array}$ \\
\hline
\end{tabular}

(a) Presented in as-measured units. 
-432 was approximately $0.25 \%$ TD. Therefore, the thermal resintering behavior for the IFA-513 and -527 fuel is very similar to that of the previous fuel.

Thermal Conductivity

In addition to the thermal resintering tests, thermal conductivity measurements were also made on IFA-513 and -527 pellets using the same technique as for IFA-431/432. That is, a laser "flash" technique was used to measure the thermal diffusivity, from which the thermal conductivity was then calculated.

Thermal conductivity is calculated from

$$
\lambda=\alpha P C_{p}
$$

where $\lambda=$ thermal conductivity, $W / m-K$

$\alpha=$ measured thermal diffusivity, $\mathrm{m}^{2} / \mathrm{s}$

$\rho=$ density, $\mathrm{kg} / \mathrm{m}^{3}$

$C_{p}=$ heat capacity, $\mathrm{J} / \mathrm{kg}-\mathrm{K}$.

Density was assumed to be temperature dependent and determined by

$$
\rho=\frac{\rho_{0}}{\left(1+\frac{\Delta L}{L_{0}}\right)^{3}}
$$

Appendix $D$ tabulates $\alpha$ and $\lambda$ as a function of temperature. Table 11 lists the resulting polynomial fits for thermal conductivity and the equations for $\Delta L / L_{0}$ and $C_{p}$. Figure 18 compares the IFA-513 and -527 fuel thermal conductivities to those of IFA-431 and -432 (BNW-1988), Lyons, ${ }^{(10)}$ and MATPRO-10. (11) The measured thermal conductivities of IFA-527 and IFA-513 are sufficiently similar to appear as a single curve in the figure. In addition, the expressions by Lyons and MATPRO-10 are in good agreement with the IFA-527/513 measurements. The measured thermal conductivity for the 95\% TD fuel used in IFA-431/432 is higher than that measured for IFA-527/513, which has been partially attributed to an improved technique when the IFA-527/513 measurements were made. 
TABLE 11. Thermal Conductivity Expressions(a)

IFA-527:

$$
\begin{aligned}
\lambda(T)= & 8.657-1.990 \times 10^{-2} T+4.605 \times 10^{-5} T^{2} \\
& -7.474 \times 10^{-8} T^{3}+7.190 \times 10^{-11} T^{4}-3.664 \times 10^{-14} T^{5} \\
& +7.587 \times 10^{-18} T^{6}
\end{aligned}
$$

IFA-513:

$$
\begin{aligned}
\lambda(T)= & 7.495-9.153 \times 10^{-3} \mathrm{~T}+3.637 \times 10^{-6} \mathrm{~T}^{2}+ \\
& 8.075 \times 10^{-9} \mathrm{~T}^{3}-1.293 \times 10^{-11} \mathrm{~T}^{4}+ \\
& 7.214 \times 10^{-15} \mathrm{~T}^{5}-1.441 \times 10^{-18} \mathrm{~T}^{6}
\end{aligned}
$$

IFA-431/432:

$$
\lambda(T)=\frac{1}{\left(11.7+1.50 \times 10^{-2} T+4.50 \times 10^{-6} T^{2}\right)}
$$

Lyons: (10)

$$
\lambda(T)=\frac{38.24}{402.4+T}+6.1256 \times 10^{-13}(T+273)^{3}
$$

MATPRO-10: (11)

$$
\lambda(T)=\frac{40.4}{464+T}+1.216 \times 10^{-4} \exp \left(1.867 \times 10^{-3} T\right)
$$

Density: $(b)(12)$

$$
\begin{aligned}
\frac{\Delta L}{L}= & -2.0701 \times 10^{-4}+8.4051 \times 10^{-6} \mathrm{~T}+1.6502 \times 10^{-9} T^{2} \\
& +2.6128 \times 10^{-13} \mathrm{~T}^{3}
\end{aligned}
$$

Heat Capacity: ${ }^{(b)} \quad C_{p}=2.2882 \times 10^{2}+3.8723 \times 10^{-1} T-8.3260 \times 10^{-4} T^{2}+$

$$
\begin{aligned}
& 1.0706 \times 10^{-6} T^{3}-7.7784 \times 10^{-10} T^{4}+2.8913 \times \\
& 10^{-13} T^{5}-4.0804 \times 10^{-17} T^{6}
\end{aligned}
$$

(a) $\mathrm{T}$ in ${ }^{\circ} \mathrm{C}$ rather than $\mathrm{K} ; \lambda(\mathrm{T})$ in $\mathrm{W} / \mathrm{m}-{ }^{\circ} \mathrm{C} ; \mathrm{C}_{\mathrm{p}}$ in $\mathrm{J} / \mathrm{kg}-{ }^{\circ} \mathrm{C}$.

(b) For calculating thermal conductivity from thermal diffusivity. 


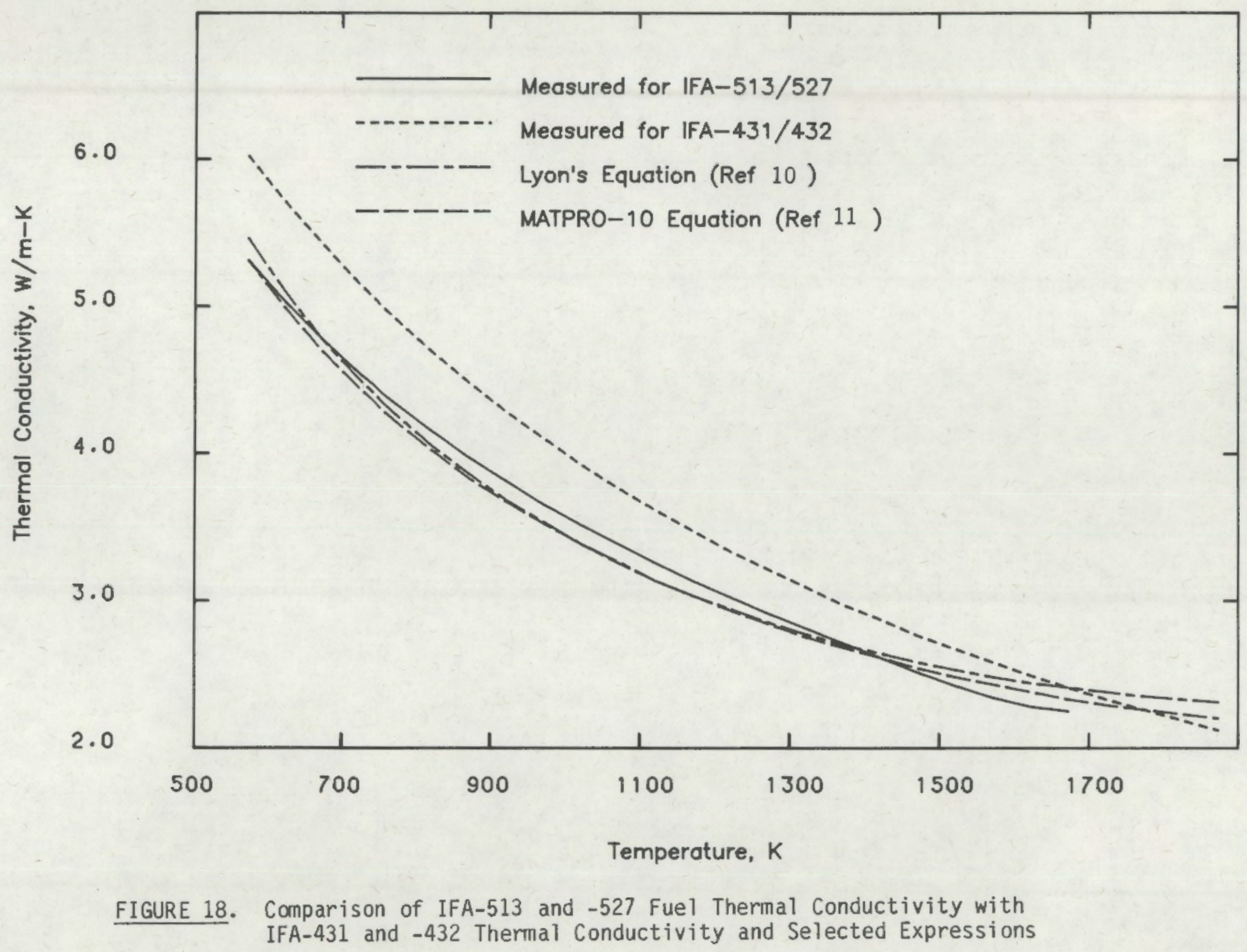





\section{ASSEMBLY OPERATION}

During its irradiation, IFA-527 will be subjected to two operating conditions: normal, steady-state HBWR operations and PNL-requested special operations. During the normal steady-state operation, the fuel rods will be exposed to operating conditions that provide a standard data set of steady-state fuel centerline temperatures, local linear heat rates, cladding axial elongation, and fuel rod internal gas pressure. The normal HBWR operating cycle consists of running at nearly full power for approximately 2 months followed by shutdown for fuel assembly changes, maintenance, and other necessary work. PNLrequested special procedures consist of transient operations that take place within normal power ranges. They are designed to provide additional data for the evaluation of fuel rod conditions.

\section{STEADY-STATE OPERATION}

To satisfactorily meet the goals of this fuel assembly, it will be necessary to obtain reliable thermocouple response throughout the irradiation. This will require reduced linear heat rates (relative to helium-filled rods) to prevent exposure of the thermocouples to possibly damaging temperatures. Experience at Halden has indicated a threshold temperature for thermocouple failure (for extended periods of operation) of 1900 to 1950K. The recommended peak temperature for IFA-527 of $1575 \mathrm{~K}$ prevents both thermocouple failure and fuel restructuring, which could begin at $1675 \mathrm{~K}$.

The appropriate linear heat rate necessary to prevent exceeding $1575 \mathrm{~K}$ may be determined from two sources: experimental data and computer code predictions. IFA-431 and -432 each contained a fuel rod that had an initial fill gas of xenon at 1-atm pressure. However, these rods had special designs (oversize pellets to restrain specific fuel regions) that are believed to have affected the thermal performance of the rods. (13) In turn, no code has yet been developed that adequately models all situations. 
Examination of the beginning-of-life (BOL) data for rod 4 of IFA-431 and IFA-432 has shown that a centerline temperature of $1575 \mathrm{~K}$ occurred at the following powers:

$$
\begin{array}{lll}
\text { IFA-431: } & \begin{array}{l}
\text { concentric region } \\
\text { eccentric region }
\end{array} & 16.0 \mathrm{~kW} / \mathrm{m} \\
\text { IFA-432: } & \begin{array}{l}
\text { concentric region } \\
\text { eccentric region }
\end{array} & 12.0 \mathrm{~kW} / \mathrm{m} \\
& 15.0 \mathrm{~kW} / \mathrm{m}
\end{array}
$$

GAPCON-THERMAL-3(1) predictions have been:

$$
\begin{array}{ll}
\text { no fuel relocation } & 11.0 \mathrm{~kW} / \mathrm{m} \\
\text { in-code relocation } & 12.0 \mathrm{~kW} / \mathrm{m} \\
30 \% \text { initial relocation, (a) no } & 15.5 \mathrm{~kW} / \mathrm{m} \\
\text { in-code relocation } &
\end{array}
$$

An initial relocation of approximately $30 \%$ has been consistently concluded for both IFA-431 and -432. Another factor to consider is that rod 4 of both IFA-431 and -432 experienced an increase in thermal resistance after the initial startup. That increase in resistance was equivalent to a $60 \mathrm{~K}$ increase in centerline temperature at the same linear heat rate.

The recormended maximum linear heat rate for IFA-527 is $14.0 \mathrm{~kW} / \mathrm{m}$ at $\mathrm{BOL}$, which will result in maximum centerline temperatures of less than $1575 \mathrm{~K}$, even after the expected thermal resistance increase. This maximum linear heat rate will occur at the lower thermocouples, which are positioned at the peak of the axial thermal neutron flux profile (see figure 5). The fuel in the region of the upper thermocouples will be at approximately $75 \%$ of full power or $10.5 \mathrm{~kW} / \mathrm{m}$.

Data from IFA-431 and -432 has also shown that after a burnup of $45 \mathrm{GJ} / \mathrm{kgU}$ the thermal resistance for xenon-filled rods will begin decreasing; which will allow the linear heat rate to be increased without exceeding the $1575 \mathrm{~K}$ temperature limit. After $85 \mathrm{GJ} / \mathrm{kgU}$ of burnup, it is expected that an increase of peak linear heat rate to 18.0 to $20.0 \mathrm{~kW} / \mathrm{m}$ will be possible. If the allowable maximum temperature is raised to $1675 \mathrm{~K}$ at this point, the corresponding maximum linear heat rate will be 23.0 to $24.0 \mathrm{~kW} / \mathrm{m}$.

(a) Reduction in the initial cold fuel-cladding gap of $30 \%$. 
Data is collected every 15 minutes during steady-state operation and is handled automatically by an IBM-1800 process computer. This data is stored on disk for $24 \mathrm{~h}$ and then transferred to magnetic tape for permanent storage.

\section{SPECIAL OPERATIONS}

Early analysis on IFA-431 and -432 indicated increasing needs for two types of data that had not been obtained during normal HBWR operation. First, more and higher quality low-power, steady-state data was needed. Normally, low-power data is obtained only during rises to full power; however, only a few rises occur during each operating cycle. In addition, because the vanadium neutron detectors are not completely stabilized under these conditions, (a) the resulting power estimates are biased in comparison to those that would be obtained under true steady-state conditions. The solution to this problem has been to use a "staircase" approach to power as illustrated in Figure 19a. By holding at intermediate power levels for 1 to $3 \mathrm{~h}$, both the amount and quality of low-power, steady-state data are improved.

Second, data was needed to better understand fuel rod behavior. Since theoretical considerations have shown that temperature data from power drops can be used to evaluate fuel rod thermal parameters, (14) a "step" power drop is performed after reaching full power. Ideally, this is an instantaneous $20 \%$ drop in power; realistically, however, this cannot be obtained. The requirements are for a 20\% drop in less than $15 \mathrm{~s}$ (see Figure 19b). The data obtained from this operation is used to analyze fuel rod thermal parameters, and the sequence is normally performed two or three times in succession.

By performing a staircase power rise just prior to the power drops, an improved correlation may be made between the steady-state data and the transient analysis. Preferably, the combined staircase and power-drop operations would be carried out once per month, depending on the reactor operations schedule. However, this sequence is particularly important during the initial startup of the assembly and during subsequent startups following extended shutdowns.

(a) The time constant for the vanadium neutron detectors is 5.4 minutes. 


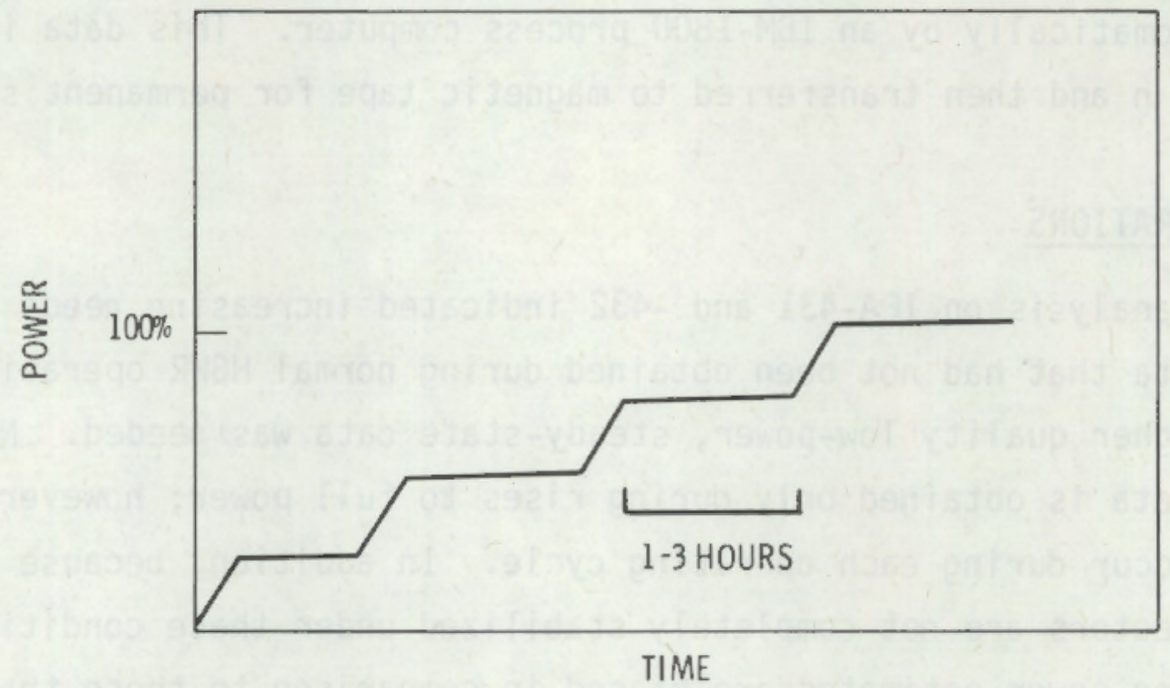

a) Staircase approach to power

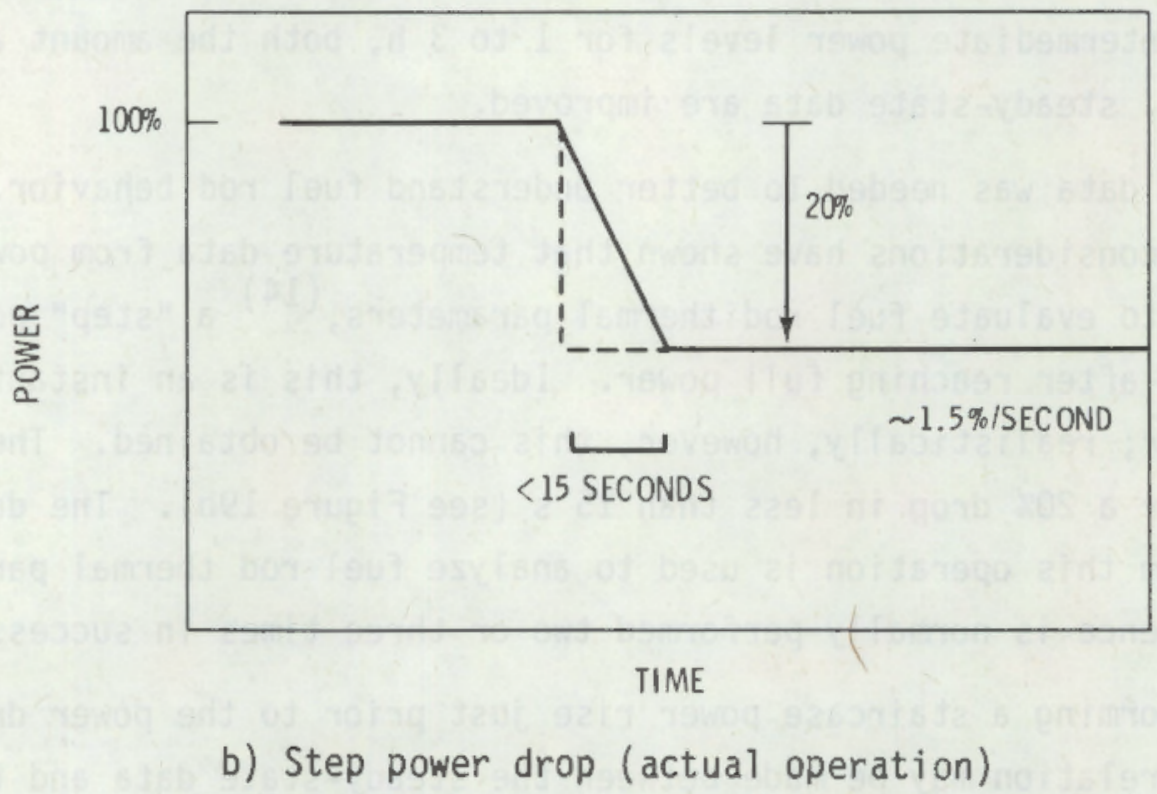

FIGURE 19. Special Operational Procedures for Instrumental Fuel Assembly (IFA) -527 


\section{REFERENCES}

1. Lanning, D. D., et al. January 1978. GAPCON-THERMAL-3 Code Description. PNL-2434, Pacific Northwest Laboratory, Richland, Washington.

2. Berna, G. A., et al. December 1980. FRAPCON-2: A Computer Code for the Calculation of Steady State Thermal-Mechanical Behavior of Oxide Fuel Rods. NUREG/CR-1845, U.S. Nuclear Regul atory Commission, Washington, D.C.*

3. Hann, C. R., et al. November 1977. Test Design, Precharacterization, and Fuel Assembly Fabrication for Instrumented Fuel Assemblies IFA-431 and IFA-432. NUREG/CR-0332, BNWL-1988, Pacific Northwest Laboratory, Richland, Washington. *

4. Bradley, E. R., et al. November 1979. Precharacterization Report for Instrumented Nuclear Fuel Assembly IFA-513. NUREG/CR-1077, PNL-3156, Pacific Northwest Laboratory, Richland, Washington. *

5. Williford, R. E., et al. April 1980. Interim Report: The Analysis of Fuel Relocation for the NRC/PNL Halden Assemblies IFA-431, IFA-432, and IFA-513. NUREG/CR-0588, PNL-2709, Pacific Northwest Laboratory, Richland, Washington. *

6. Cunningham, M. E., et al. October 1980. Application of Linear Propagation of Errors to Fuel Rod Temperature and Stored Energy Calculations. NUREG/CR-1753, PNL-3539, Pacific Northwest Laboratory, Richland, Washington. *

7. Hann, C. R., et al. February 1977. A Method for Determining the Uncertainty of Gap Conductance Deduced from Measured Fuel Centerline Temperatures. BNWL-2091, Pacific Northwest Laboratory, Richland, Washington.

8. Hann, C. R., et al. April 1978. Data Report for the NRC/PNL Halden Assembly IFA-431. NUREG/CR-0318, PNL-2494, Pacific Northwest Laboratory, Richland, Washington. *

9 Freshley, M. D., et al. 1976. "Irradiation-Induced Densification of $\mathrm{U0}_{2}$ Pellet Fuel." J. Nuc. Mat. 62:138-166.

10. Lyons, M. F., et al. 1964. U0? Pellet Thermal Conductivity from Irradiation with Central Melting. GEAP-4624, General Electric Co., San Jose, California. 
11. Reymann, G. A., and D. L. Hagrman. February 1978. MATPRO - Version 10: A Handbook of Materials Properties for Use in the Analysis of Light Water Reactor Fuel Rod Behavior. TREE-NUREG-1180, EG\&G Idaho, Inc., Idaho Falls, Idaho.

12. Bates, J. L. 1970. High-Temperature Thermal Conductivity of "RoundRobin" Uranium Dioxide. BNWL-1431, Pacific Northwest Laboratory, Richland, Washington.

13. Cunningham, M. E., R. E. Williford, and C. R. Hann. April 1979. Effects of Fill Gas Composition and Pellet Eccentricity: Comparison Between Instrumented Fuel Assemblies IFA-431 and IFA-432. NUREG/CR-0331, PNL-2729, Pacific Northwest Laboratory, Richland, Washington.*

14. Cunningham, M. E., D. D. Lanning, and S. D. Montgomery. October 1979. A Procedure for the Qualitative Interpretation of Fuel Centerline Thermocouple Response to Step Power Decreases. NUREG/CR-1012, PNL-3096, Pacific Northwest Laboratory, Richland, Washington. *

*Available for purchase from the NRC/GPO Sales Program, U.S. Nuclear Regulatory Commission, Washington, DC 20555, and/or the National Technical Information Service, Springfield, VA 22161. 
APPENDIX A

STACKING ARRANGEMENT AND PELLET CHARACTERIZATION FOR

INSTRUMENTED FUEL ASSEMBLY (IFA) -527 FUEL RODS 


\section{APPENDIX A}

\section{STACKING ARRANGEMENT AND PELLET CHARACTERIZATION FOR}

INSTRUMENTED FUEL ASSEMBLY (IFA)-527 FUEL RODS

Rods 1 through 5 of IFA-527 are identically designed rods while rod 6 has fuel of a larger diameter. Figure A.1 is a schematic of the stacking arrangement for the rods. Tables A.1 through A.6 identify the specific pellets loaded into each rod and their as-measured dimensions, weight, and geometrical density; and Table A.7 provides immersion density results for archive fuel pellets. 


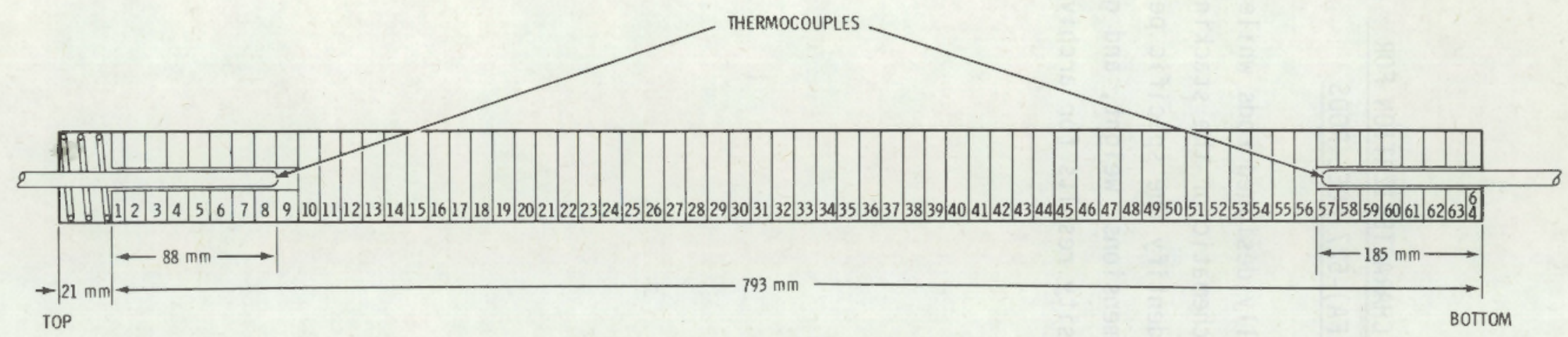

TOTAL NUMBER OF PELLETS IN EACH STACK - $\quad 64$ NUMBER OF SOLID FUEL PELLETS $=40$

NUMBER OF DRILLED FUEL PELLETS $=22$

NUMBER OF POISON PELLETS

FUEL. PELLET LENG TH $=12.700 \pm 0.381 \mathrm{~mm} 10.500 \pm 0.015 \mathrm{in.})$

FUEL PELLET DIAMETER $=10.681 \pm 0.013 \mathrm{~mm}(0.4205 \pm 0.005 \mathrm{in}$.$) , RODS 1$ THROUGH 5

$10.859 \pm 0.013 \mathrm{~mm}(0.4275 \pm 0.005 \mathrm{in}),. \mathrm{ROD} 6$

CENTRAL HOLE DIAMETER $=1.702-1.803 \mathrm{~mm}(0.067-0.071 \mathrm{in.})$

POISON PELLET LENGTH $=7.0 \mathrm{~mm}$ (SUPPLIED BY HALDEN)

FIGURE A.1. Stacking Arrangement for Instrumented Fuel Assembly (IFA)-527, Design Dimensions 
TABLE A.1. Pellet Data for Rod 1 of Instrumented Fuel Assembly (IFA) -527

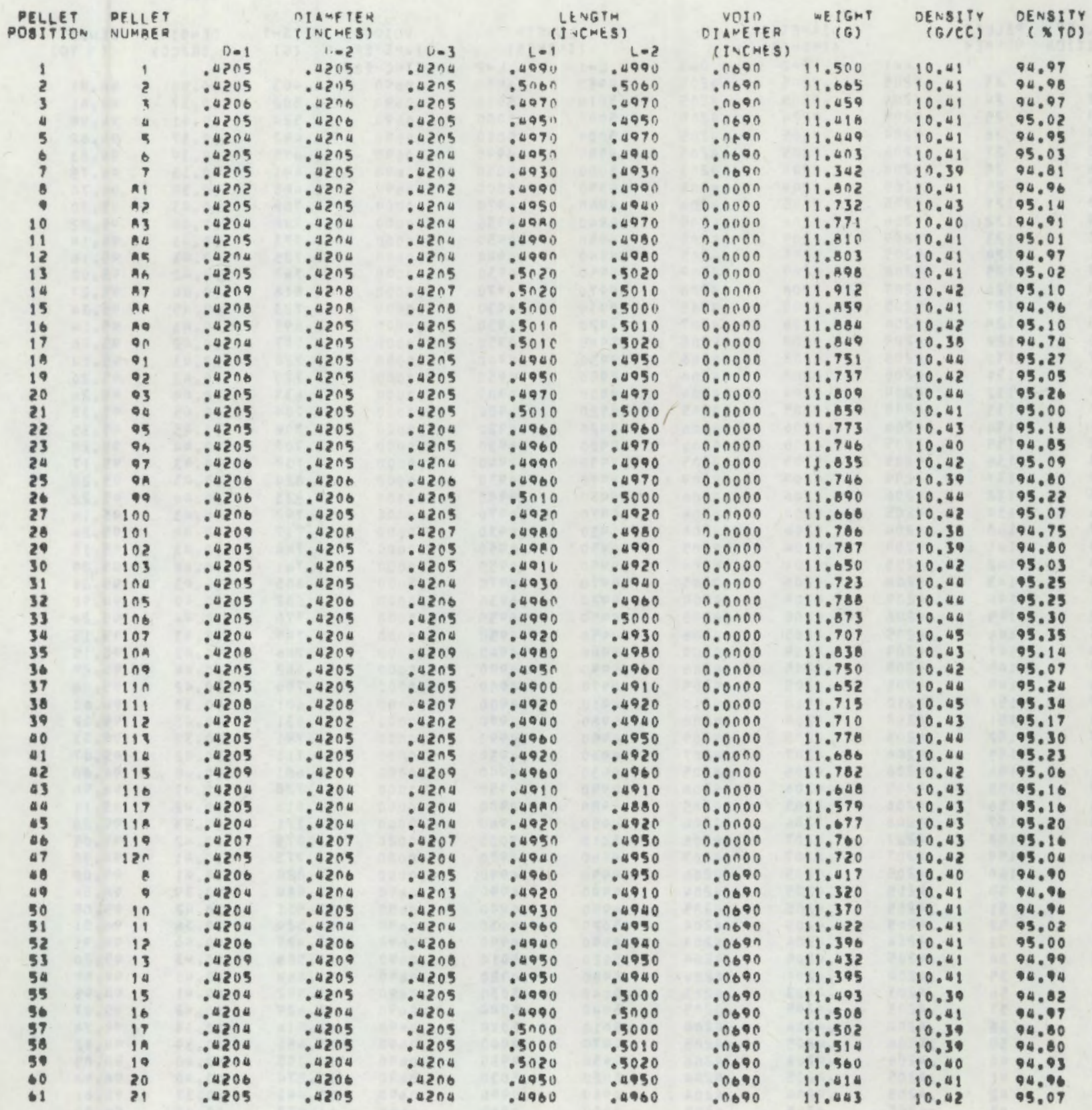

AVERAGE DIAMETER IS .4205 INCMES ITTH STO OEV OF .0001

AVERAGE LENGTM IS . 4064 INCHES WITM A STO DEV OF .00340

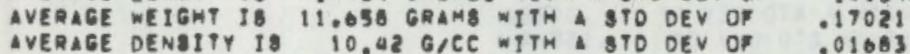

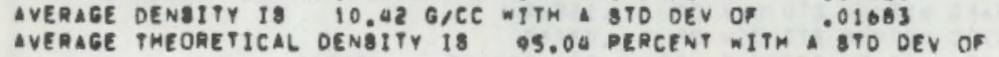

.15357

TOTAL FUEL LENGTM IS $30.27 B 5$ INCMEg

TOTAL UOR WEIGHT IS TI1.165 GAMME

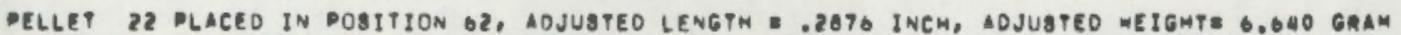


TABLE A.2. Pellet Data for Rod 2 of Instrumented Fuel Assembly (IFA) -527

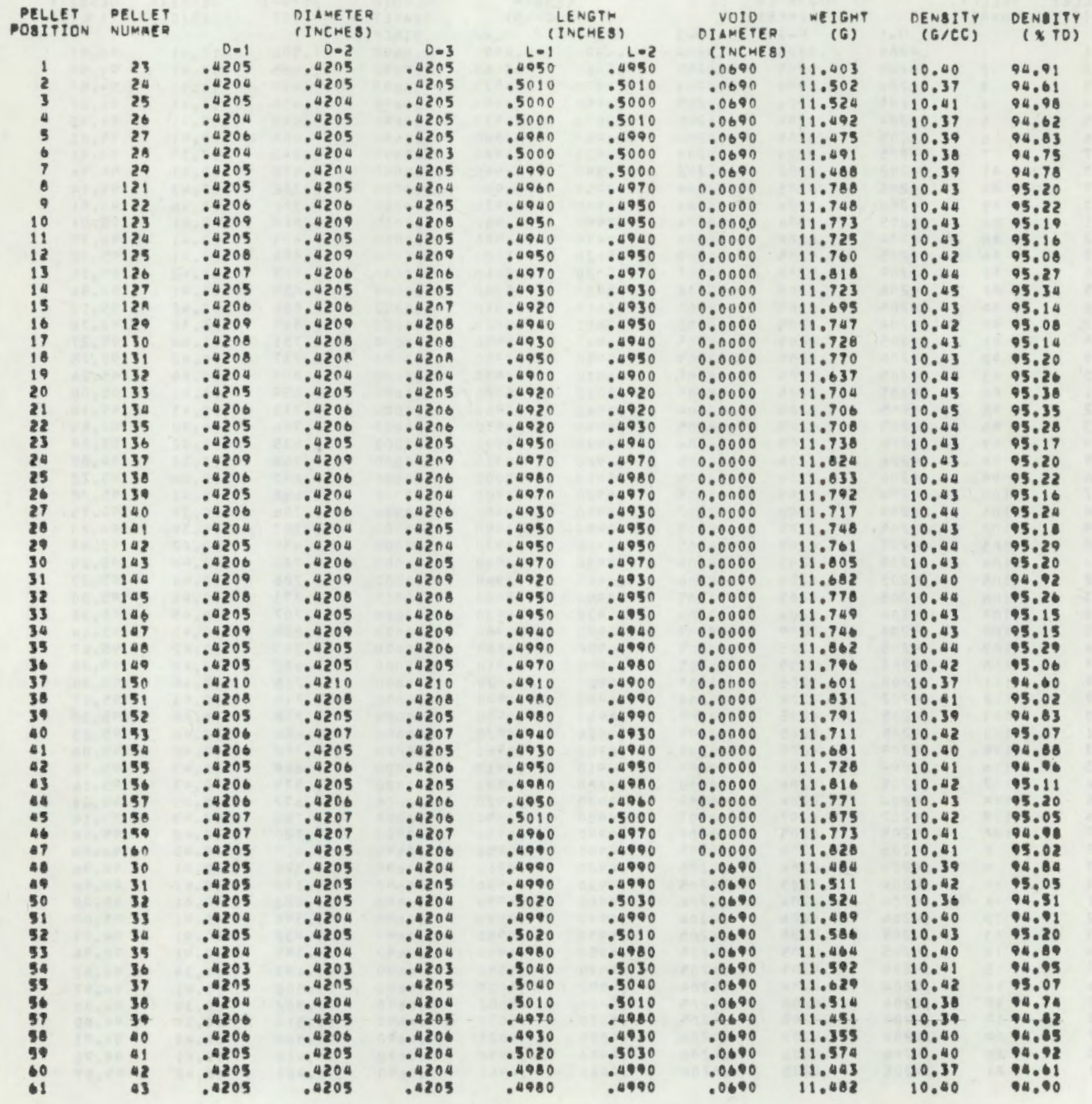

AVERAGE DIAMETER IS .4206 INCHES WITM ATO OEV OF .00016

AVERAGE LENGTH IS .4Q6T INCHES WITH A PTO DEV OF .00326

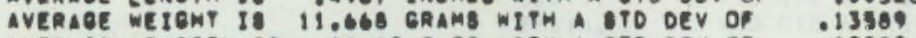

AVERAOE OENOITY IS 10.42 G/CC WITH BTD OEV OF :02202

AVERAEL THEONETICAL OENBITY IS OS.04 RERENT WITH B BTO DEY OF .20911

TOTAL FUEL LENOTM IO 30.2975 INENES

TOTAL UOS WEIOHT IS TII.TEO GNAMB

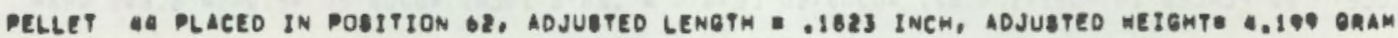


TABLE A.3. Pellet Data for Rod 3 of Instrumented Fuel Assembly (IFA) -527

\begin{tabular}{|c|c|c|c|c|c|c|c|c|c|c|}
\hline $\begin{array}{l}\text { PELLE } \\
\text { POSIPI }\end{array}$ & $\begin{array}{l}\text { PELLLET } \\
\text { NUMAER }\end{array}$ & & $\begin{array}{l}\text { DI IMETE } \\
\text { CINCHES }\end{array}$ & & & & $\begin{array}{l}\text { VOIO } \\
\text { OIAMETER }\end{array}$ & $\begin{array}{l}\text { WE IGHT } \\
\text { (G) }\end{array}$ & $\begin{array}{c}\text { OENBITY } \\
\text { (G/CC) }\end{array}$ & $\begin{array}{l}\text { DENEITY } \\
\text { ( } \$ \text { TOS }\end{array}$ \\
\hline & & $0=1$ & $0=2$ & 0.3 & $L=1$ & $L=2$ & (INCHES & & & \\
\hline 1 & as & .0205 & .4205 & .4204 & .5000 & .5000 & .0690 & 11.511 & 10.00 & 94.07 \\
\hline i & ab & .0204 & .4204 & .4204 & - WQAO & .4980 & .0000 & 11.044 & 10.38 & 94.73 \\
\hline 3 & 47 & .4204 & $.42 n a$ & .4204 & .4900 & .4980 & .0600 & 11.075 & 10.40 & 94.09 \\
\hline 4 & an & .4205 & .4205 & .4205 & .5010 & .5010 & .0600 & $i 1.543$ & 10.40 & 94.93 \\
\hline 5 & uQ & .0205 & .4205 & .0204 & .5010 & .5020 & .0690 & 11,500 & 10.36 & 04.56 \\
\hline 6 & 50 & .0204 & .4204 & .4204 & .4080 & .4900 & .0600 & 11.456 & 10.36 & 94.73 \\
\hline 7 & 51 & .4200 & .4205 & .4205 & $\triangle Q \Delta 0$ & .4980 & .0690 & 11.452 & 10.36 & 94.73 \\
\hline 6 & 161 & .4200 & .4207 & .0208 & .4970 & .4080 & 0.0000 & 11.820 & 10.43 & 95.17 \\
\hline ? & 163 & .4204 & .4204 & . 4204 & .0970 & .4970 & 0.0000 & 11.790 & 10.42 & 95.09 \\
\hline 10 & isu & .0205 & .4205 & .4206 & .4950 & .4950 & 0.0000 & 11.759 & 10.44 & 99.21 \\
\hline 11 & 165 & .4200 & .4206 & . & .5000 & .5000 & 0.0000 & 11.871 & 10.43 & 95.13 \\
\hline 12 & 166 & .4206 & .0206 & .4206 & .4000 & .4990 & 0.0000 & 11.046 & 10.43 & 95.13 \\
\hline 13 & 167 & .4205 & .0205 & .4205 & .5000 & .5000 & 0.0000 & 11.650 & 10.42 & 95.09 \\
\hline is & 160 & .4206 & .4206 & .4207 & .4990 & . ४९९० & 0.0000 & 11.062 & 10.40 & 95.25 \\
\hline is & ino & .0208 & .4208 & .4208 & .5000 & .5000 & 0.0000 & 11.096 & 10.44 & 05.25 \\
\hline is & 190 & .4206 & .4206 & .4205 & .4990 & $.40 B 0$ & 0.0000 & 11.008 & 10.41 & 94.94 \\
\hline 17 & 191 & .4209 & .4207 & .4207 & .4080 & .4990 & 0.0000 & 11.815 & 10.40 & 94.93 \\
\hline 16 & 172 & .0207 & .4207 & .4206 & .5000 & .5010 & 0.0000 & 11.000 & 10.42 & 95.09 \\
\hline 19 & 173 & .4200 & .4209 & .4208 & .4000 & .4900 & 0.0000 & 11.027 & 10.01 & 94,96 \\
\hline 20 & 194 & .4205 & .4205 & .4205 & .4070 & .4090 & 0.0000 & 11.782 & 10.42 & 05.04 \\
\hline 21 & 175 & .0207 & .4207 & .4206 & .4970 & .4960 & 0.0000 & 11.776 & 10.42 & 95.03 \\
\hline 22 & 196 & .4205 & .4205 & .4205 & .4090 & .4980 & 0.0000 & 11.821 & 10.42 & 95.07 \\
\hline 23 & 177 & .0207 & .4207 & .0206 & .4990 & .4090 & 0.0000 & 11.052 & 10.43 & 95,15 \\
\hline 20 & 170 & .4205 & .4205 & .0204 & .4960 & .4970 & 0.0000 & 11.700 & 10.43 & 95.20 \\
\hline 25 & 170 & .0205 & .4205 & .0204 & .4090 & .4980 & 0.0000 & 11.610 & 10.44 & 95.25 \\
\hline 26 & 100 & .4205 & .4205 & .0205 & .4970 & .4960 & 0.0000 & 11.700 & 10.43 & 95.12 \\
\hline 27 & 101 & .0205 & .4205 & .4205 & .4050 & .4960 & 0.0000 & 11.756 & 10.43 & 95.12 \\
\hline 20 & 102 & .4208 & .4200 & $.0200^{\circ}$ & .4050 & .4940 & 0.0000 & 11.761 & 10.03 & 95.19 \\
\hline 29 & 193 & .4208 & .4209 & .4200 & .5050 & .5050 & 0.0000 & 11.965 & 10,30 & 94,03 \\
\hline 30 & 104 & .4200 & .4206 & .4206 & .5010 & .5020 & 0.0000 & 11.005 & 10.41 & 94.99 \\
\hline 31 & 105 & .4205 & .0205 & .4205 & .5040 & .5050 & 0.0000 & 11.947 & $10.4 i$ & 94.90 \\
\hline 32 & 180 & .4208 & $.4200^{\circ}$ & .4200 & .5000 & .5010 & 0.0000 & 11.052 & 10.30 & 94.78 \\
\hline 33 & 187 & .4207 & .4206 & .0206 & .5020 & .5020 & 0.0000 & 11.077 & 10.39 & 94.80 \\
\hline 34 & 180 & .4205 & .4206 & .4206 & .5030 & .5000 & 0.0000 & 11.090 & 10.38 & 94.70 \\
\hline 35 & 180 & .4204 & .4205 & .4205 & .5010 & .5010 & 0.0000 & 11.045 & 10.39 & 94.81 \\
\hline 36 & 190 & .4204 & .4205 & .4206 & .5030 & .5020 & 0.0000 & 11.000 & 10.30 & 94.03 \\
\hline 37 & 191 & .4206 & .4207 & $.02 n$ & .5030 & .5030 & 0.0000 & 11.902 & 10,30 & 94.79 \\
\hline 30 & 103 & .0205 & .4205 & .4206 & .5010 & .5020 & 0.0000 & 11.059 & 10,30 & 9.78 \\
\hline 39 & 10 & .4206 & .4206 & .4206 & .5040 & .5000 & 0.0000 & 11.924 & 10.30 & 94.01 \\
\hline 10 & $i \oplus 5$ & .4205 & .4206 & .0206 & .5010 & .5020 & 0.0000 & 11.863 & 10.30 & 04.81 \\
\hline il & 106 & .4207 & .4206 & .4206 & .5040 & .5040 & 0.0000 & 11.916 & 10.30 & 94.73 \\
\hline 4 & 107 & .4204 & .4205 & .4205 & .5010 & .5010 & 0.0000 & 11.025 & 10.37 & 94.65 \\
\hline 43 & 198 & .4204 & .4204 & .4203 & .5020 & .5020 & 0.0000 & 11.042 & 10.37 & 90.00 \\
\hline sa & 100 & .4206 & .4207 & .4207 & .5000 & .5040 & 0.0000 & ii. 911 & 10.36 & 94.60 \\
\hline 45 & 200 & .4205 & .0205 & .4206 & .5000 & .5000 & 0.0000 & 11.010 & 10.30 & 04.60 \\
\hline 46 & 201 & .4206 & .4206 & .4205 & .5010 & .5010 & 0.0000 & ii.001 & 10.30 & 94.73 \\
\hline 47 & 202 & .4207 & .4207 & .4200 & .5020 & .5020 & 0.0000 & 11.061 & 10.37 & 04,05 \\
\hline 40 & 32 & .4204 & .4204 & .0204 & .4090 & .5000 & .0690 & 11.500 & 10.41 & 94.97 \\
\hline 4 & 53 & .4205 & .4205 & .4205 & .4070 & .4000 & .0690 & 11.412 & 10.36 & 94,51 \\
\hline 50 & 90 & 0.0205 & .4200 & $\begin{array}{l}-4200 \\
.420\end{array}$ & 04000 & .4970 & $: 0690$ & 11.057 & 10.42 & 95.11 \\
\hline 51 & 55 & .0204 & .4204 & .4204 & $\because 4900$ & .5000 & .0600 & 11.536 & 10.43 & 95.20 \\
\hline 52 & 56 & .4205 & .4204 & .4204 & .4070 & .4900 & .0000 & 11.472 & 10.42 & 95.00 \\
\hline 3 & 57 & .4205 & .4205 & .4204 & .4970 & .4060 & .0090 & 11.053 & 10.42 & 95.06 \\
\hline 54 & 58 & .4200 & .4204 & .4205 & .4040 & .4950 & .0600 & ii. 004 & 10.42 & 95.05 \\
\hline & & & & & .4990 & .4980 & .0690 & 11.493 & 10,01 & 94,90 \\
\hline 50 & 60 & .4205 & .4205 & .4205 & .4960 & .4990 & .0690 & 11.451 & 10.41 & 95.03 \\
\hline 57 & 1 & .4204 & .4204 & .4204 & .4990 & .4970 & .0090 & 11.004 & 10,39 & 0.59 \\
\hline so & 62 & .4205 & .4205 & .4205 & .4050 & .4960 & .0690 & 11.440 & 10.43 & 99.80 \\
\hline 39 & 63 & .4200 & .0204 & .4204 & .4960 & .4960 & .0690 & 11.402 & 10.42 & 95.00 \\
\hline$\because 0$ & 64 & .4205 & .4205 & 53 & .4960 & .4070 & .0000 & 11.430 & 10.40 & 04.92 \\
\hline 61 & & 4204 & & & 4090 & 4970 & 0 & & & 94,73 \\
\hline
\end{tabular}

AVERABE OIAMETER IS .4205 INCMES WITH A STO DEV OF .00013

AVERABE LENGTH IS .4902 INCHES WITH $\triangle$ STD OEV OF .0026?

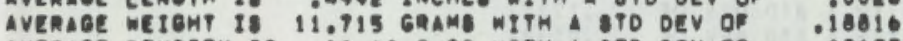

AVERAGE OENEITY IS 10.40 G/CE WITH A STO OEV OF .02197

AVERAGE THEORETICAL DENEITY IO MA.93 PEREENT WITM A BTO DEV OF .19003

TOTAL FUEL LENBTH IS 30.4935 INEMES

TOTAL UOZ WEIOHT IS T14.58T GRAME

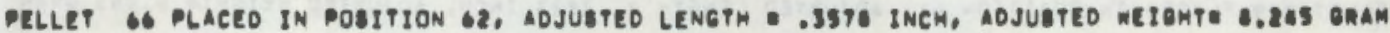


TABLE A.4. Pellet Data for Rod 4 of Instrumented Fuel Assembly (IFA)-527

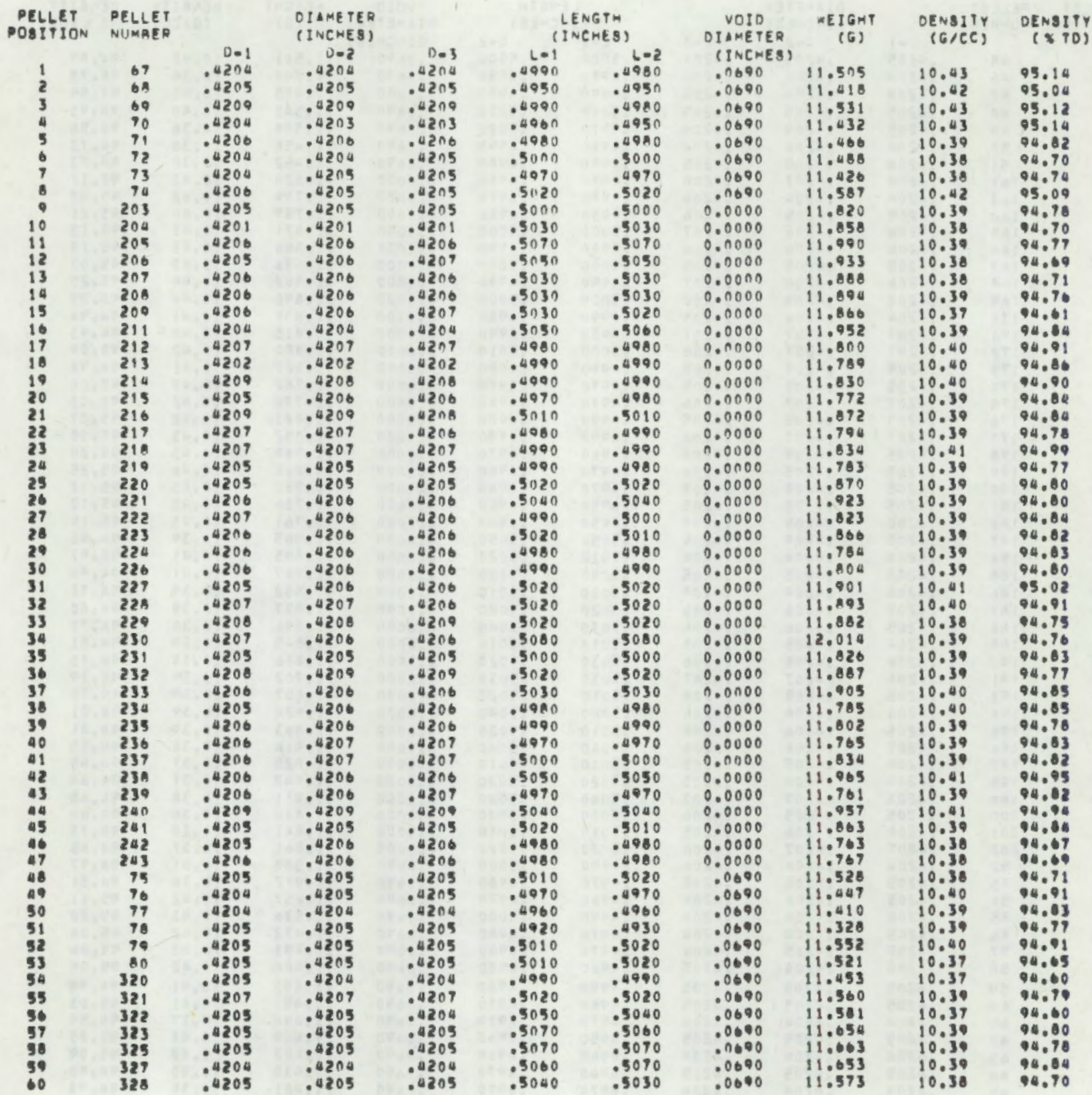

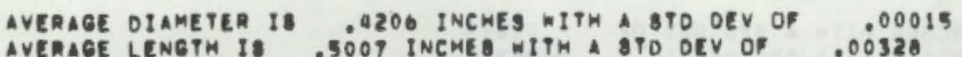

AVERAGE WEIGHT IS 11.735 GAAMB WITH ATD DEV OF . ITBQI

AVERAGE DENSITY IS 10.30 G/CC WITH ATD DEV OF .01331

AVERAGE TMEORETICAL DENBITY IS QU.82 PERCENT WITH A BTD DEV OF .1214O

TOTAL FUEL LENGTH IS 30.0435 INENES

TOTAL UO2 WETEHT IS TOS.0Q1 GRAMG

PELLET 320 PLACED IN POSITION 61, ADJUSTED LENGTM - .2823 INCM, AOJUSTEO MEIGMTE 


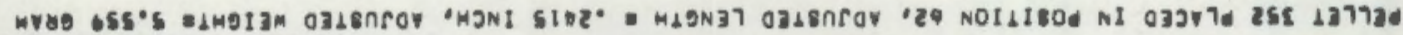

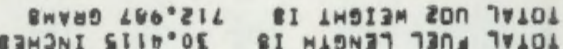

"26"

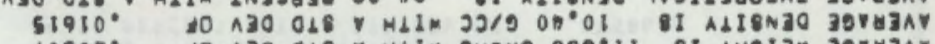

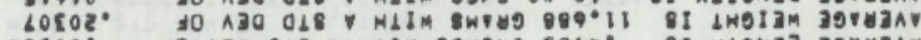

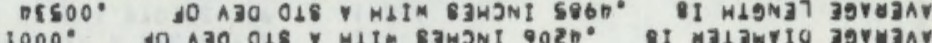

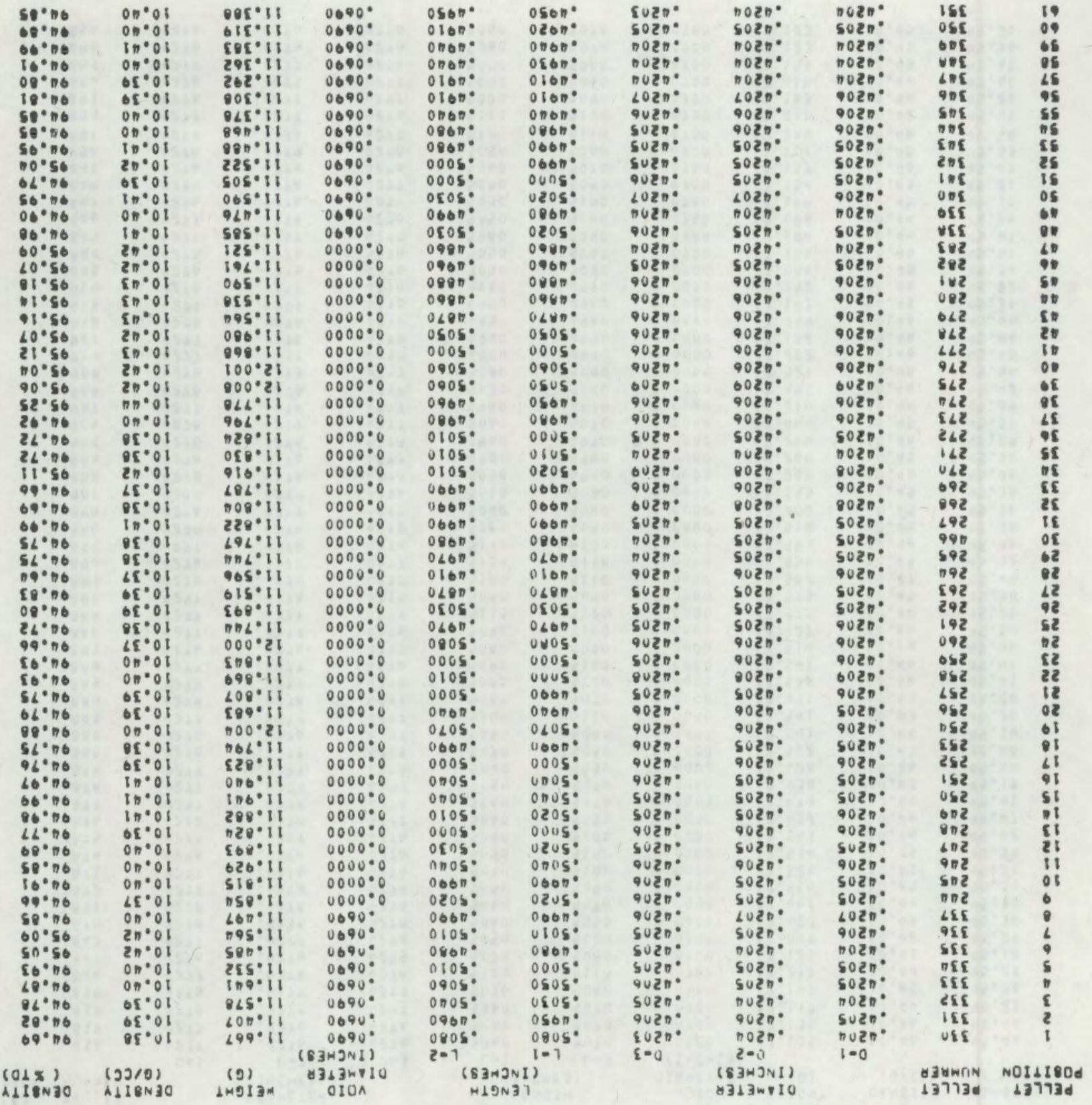

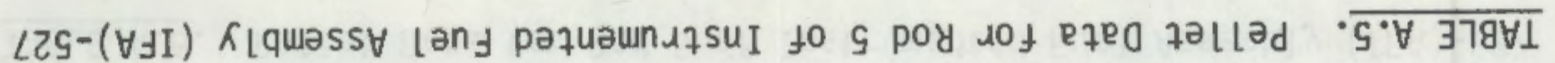


TABLE A.6. Pellet Data for Rod 6 of Instrumented Fuel Assembly (IFA) -527

\begin{tabular}{|c|c|c|c|c|c|c|c|c|c|c|}
\hline \multirow[t]{2}{*}{$\begin{array}{l}\text { PELLET } \\
\text { POSITION }\end{array}$} & \multirow[t]{2}{*}{$\begin{array}{l}\text { PELLET } \\
\text { NUMAER }\end{array}$} & \multicolumn{3}{|c|}{$\begin{array}{l}\text { DI AMETER } \\
\text { (INCHES }\end{array}$} & \multicolumn{2}{|c|}{$\begin{array}{l}\text { LENGTH } \\
\text { (INENES) }\end{array}$} & $\begin{array}{l}\text { VOTO } \\
\text { DIAMETER }\end{array}$ & \multirow[t]{2}{*}{$\begin{array}{c}\text { AE I GN } \\
\text { (G) }\end{array}$} & \multirow[t]{2}{*}{$\begin{array}{l}\text { OENAITY } \\
\text { (G/CC) }\end{array}$} & \multirow[t]{2}{*}{$\begin{array}{r}\text { DENSITY } \\
(x T O)\end{array}$} \\
\hline & & $v=1$ & 0.2 & $0=3$ & $L=1$ & $6=2$ & IINCMES & & & \\
\hline 1 & 836 & .4277 & .4276 & .4276 & .5060 & .5070 & .0700 & 12.135 & 10.46 & 95.44 \\
\hline 2 & 837 & .4277 & .0270 & .4276 & .5060 & .5070 & .0700 & 12.135 & 10.46 & 05.44 \\
\hline 3 & A3A & .4278 & .4278 & . 4277 & .5060 & .5070 & .0700 & 12.117 & 10.44 & 95.23 \\
\hline 4 & 830 & .4276 & .4277 & . 4271 & .5010 & .5080 & .0700 & 12.147 & 10.45 & 95.33 \\
\hline 5 & 840 & .4279 & .4278 & .4278 & .5100 & .51110 & .0700 & 12.217 & 10.40 & 95.27 \\
\hline 6 & a 1 & .4276 & .0276 & .0295 & .5070 & .5080 & .0700 & 12.123 & 10.43 & 05.10 \\
\hline 7 & 84? & .4277 & .4277 & .4276 & .5050 & .5000 & .0700 & 12.069 & 10.42 & 05.09 \\
\hline 5 & 870 & .4278 & .4278 & .4276 & .5040 & .5050 & 0.0000 & 12.420 & 10.45 & 95.36 \\
\hline 9 & 871 & .4290 & .4278 & .4270 & $.5 n \theta 0$ & .5070 & 0.0000 & 12.461 & 10.04 & 95.30 \\
\hline 10 & 672 & .4277 & .4278 & .0278 & .3010 & .5090 & 0.0000 & 12.510 & 10.05 & 95.36 \\
\hline it & 873 & .4277 & .0276 & .4296 & .5000 & .5100 & 0.0000 & 12.526 & 10.45 & 95.31 \\
\hline 12 & 894 & .0276 & .4270 & .4276 & $.5 \cap 90$ & .5100 & 0.0000 & $12.53 \mathrm{a}$ & 10.45 & 95.38 \\
\hline 13 & 875 & .4277 & .4277 & .4276 & .5090 & .5100 & 0.0000 & 12.543 & 10.40 & 05.42 \\
\hline 14 & 876 & .4278 & .4278 & .4297 & $.50<0$ & .5050 & 0.0000 & 12.432 & 10.40 & 95.47 \\
\hline is & 877 & .0277 & .4278 & .4278 & .5060 & .5070 & 0,0000 & 12.473 & 10.46 & 95.41 \\
\hline 16 & 67A & .4277 & .4277 & .4277 & .5060 & .5070 & 0.0000 & 12.438 & 10.43 & 05.17 \\
\hline i7 & 890 & .4277 & .0297 & .4278 & $.50<0$ & .5050 & 0.0000 & 12,426 & 10.46 & 05.44 \\
\hline 10 & 880 & .4276 & .0277 & .4277 & .5070 & $.50 B 0$ & 0.0000 & 12.502 & 10.47 & 95.40 \\
\hline 19 & A8? & .4276 & .4276 & .0297 & .5000 & .5000 & $0.0 \cap 00$ & 12.501 & 10.45 & 05.30 \\
\hline 20 & 883 & .4277 & .4277 & .0277 & .5100 & .5110 & 0.0000 & 12.541 & 10.43 & 95.20 \\
\hline 21 & BAa & .4278 & .4278 & .4297 & .5700 & .5090 & 0.0000 & 12.451 & 10.44 & 95.24 \\
\hline 22 & DA5 & 7.4. & .4277 & .4276 & $.5 n 00$ & .5100 & 0.0000 & 12.546 & 10.46 & 95.41 \\
\hline 23 & $8 A_{6}$ & .4277 & .4277 & .4276 & .5000 & .5100 & 0.0000 & 12.541 & 10.06 & 95.41 \\
\hline 24 & 887 & .4276 & .4276 & .4297 & .5000 & .5000 & 0.0000 & 12.514 & 10.46 & 95.00 \\
\hline 25 & BAA & .0277 & .4277 & .4276 & .5000 & .5100 & 0.0000 & 12.527 & 10.04 & 95.30 \\
\hline 26 & $B 89$ & .4297 & .0277 & .4277 & .5110 & .5120 & 0.0000 & 12.577 & 10.44 & 95.29 \\
\hline 27 & BOC & .4297 & .4278 & .4278 & .5080 & .5090 & $0.0 n 00$ & 12.513 & 10.05 & 95.34 \\
\hline 20 & 893 & .4278 & .4278 & .4277 & .5100 & .51110 & 0.0000 & 12.582 & 10.47 & 95.49 \\
\hline 29 & 804 & .0276 & .4277 & .4277 & .5100 & .5110 & 0.0000 & 12.550 & 10.45 & 95.32 \\
\hline 30 & 805 & .4277 & .4270 & .4270 & .5110 & .5120 & 0.0000 & 12.503 & 10.46 & 95.44 \\
\hline 31 & 096 & .4270 & .4278 & .4270 & $.50 \mathrm{con}$ & .5090 & 0.0000 & 12.515 & 10.45 & 95.34 \\
\hline 32 & 009 & .4276 & .4277 & .0279 & .5000 & .5040 & 0.0000 & 12.400 & 10.45 & 95.36 \\
\hline 33 & 901 & .0278 & .0277 & .4290 & .5010 & .5020 & 0.0000 & 12.343 & 10.45 & 95.38 \\
\hline 30 & 002 & .4278 & .4278 & .4270 & .4980 & .4090 & 0.0000 & 12.285 & 10.40 & 95.40 \\
\hline 35 & 900 & .0270 & .4270 & .4277 & .0980 & .4990 & 0.0000 & 12.260 & 10.45 & 95.34 \\
\hline 36 & 905 & .4270 & .4278 & .4270 & .4960 & .4070 & 0.0000 & 12.214 & 10.44 & 95.20 \\
\hline 37 & 906 & .4270 & .4278 & .4297 & .5060 & .5070 & 0.0000 & 12.460 & 10.45 & 05.31 \\
\hline 30 & 907 & .4277 & .0278 & .0277 & .4960 & .4970 & 0.0000 & 12.210 & 10.44 & 95.29 \\
\hline 39 & 900 & .0270 & .4278 & .0277 & .5030 & .5000 & 0.0000 & 12.401 & 10.46 & 95.42 \\
\hline$\Delta 0$ & 900 & .429 & .4277 & .4277 & .5080 & .5090 & 0.0000 & 12.521 & 10.46 & 95.44 \\
\hline 41 & 110 & .0277 & .0277 & .4277 & . $\triangle 9 B_{0}$ & .4990 & 0.0000 & 12.282 & 10.46 & 95.48 \\
\hline ai & 011 & .4277 & .4270 & .0290 & .4040 & .4050 & 0.0000 & 12.102 & 10.40 & 95.44 \\
\hline 43 & 012 & .4270 & .0278 & .4211 & .40950 & .4000 & 0.0000 & 12.200 & 10.40 & 95.40 \\
\hline 40 & 913 & .4277 & .4277 & .4278 & .4050 & .4960 & 0.0000 & 12.107 & 10.45 & 95.38 \\
\hline 45 & Q1a & .4270 & .0277 & .4278 & .4900 & .4090 & 0,0000 & 12.252 & 10.44 & 95.22 \\
\hline 16 & 84 & .0276 & .4276 & .0276 & .5050 & .5050 & .0700 & 12.080 & 10.45 & 95.36 \\
\hline 4 & Bua & .0276 & .4270 & .0276 & .5050 & .5060 & .0700 & 12.106 & 10.06 & 95.41 \\
\hline 48 & sas & .4277 & .4297 & .4297 & .5000 & .5000 & .0700 & 12.184 & 10.06 & 95.41 \\
\hline & 806 & .4277 & .4277 & .0278 & $.5 n 50$ & .5000 & .0700 & 12.098 & 10.44 & 95.20 \\
\hline 30 & Bat & .0276 & .4276 & .4277 & .5000 & .5100 & .0700 & 12.109 & 10.45 & 95.37 \\
\hline 51 & $84 \mathrm{An}$ & .4276 & .4276 & .4277 & .5080 & .5090 & .0700 & 12.154 & 10.03 & 05.21 \\
\hline 52 & 840 & .4270 & .4290 & .0270 & .5060 & .5070 & .0700 & 12.137 & 10.46 & 95.47 \\
\hline 93 & osn & .4279 & .4279 & .4290 & .5050 & .5000 & .0700 & 12.111 & 10.45 & 95,33 \\
\hline gi & 891 & .0270 & .4278 & .0279 & .5100 & .5110 & .0700 & 12.240 & 10.40 & 95.45 \\
\hline 95 & 052 & & .4277 & .0276 & .5110 & .5120 & .0700 & 12.210 & 10.42 & 95.07 \\
\hline 50 & 053 & .4210 & .4277 & .4297 & .5010 & .5090 & .0700 & 12.163 & 10.40 & 95.26 \\
\hline 97 & 834 & 0270 & 0277 & :427า & .5050 & .5060 & .0700 & 12.118 & 10.06 & is, 8 \\
\hline 30 & 155 & .4270 & .0277 & .4296 & - 5 ก & .5080 & .0700 & 12.152 & 10.45 & 95.35 \\
\hline 30 & es6 & .0276 & .4276 & .4276 & .5000 & .5070 & .9700 & 12.123 & 10.45 & 95.36 \\
\hline 10 & 856 & .4270 & .4276 & .0276 & .5060 & .5090 & .0700 & 12.123 & 10.45 & 95.36 \\
\hline
\end{tabular}

AVENAGE OIAMETER IS .4279 INCMES WITH A STO OEV OF .00008

AVERAGE LENGTH IS .5060 INCHES WITH A OPD DEV OF .00430

AVERAGE WEIGMT IO 12.327 GRAMS WITH APD DEV OF .17310

aVERAGE PMEORETICAL OENBITY IS O5.35 DERCENT WITH A BTO DEV OF .00506

TOTAL PUEL LENGTH IS 30.3990 INCHES

POTAL VO2 WEIGHT IS 730.591 GRAMB

ONLY $\triangle O$ PELLETS UEED IN ROD 
TABLE A.7. Immersion Densities of Archive Instrumented Fuel Assembly (IFA)-527 Fuel Pellets

\begin{tabular}{|c|c|c|c|}
\hline \multirow[b]{2}{*}{$\begin{array}{l}\text { Pellet Batch } \\
\text { and Number }\end{array}$} & \multirow{2}{*}{$\begin{array}{c}\text { Geometric } \\
\text { Density, } \\
\text { \%TD } \\
\end{array}$} & \multicolumn{2}{|c|}{ Immersion Density, \% TD } \\
\hline & & First Test (a) & Second Test ${ }^{(b)}$ \\
\hline $2-210$ & -- & 95.36 & 95.43 \\
\hline $2-300$ & -- & 95.81 & 95.80 \\
\hline $3-470$ & 94.72 & 95.53 & 95.46 \\
\hline $3-633$ & -- & 95.53 & 95.48 \\
\hline $4-677$ & 94.84 & 95.44 & 95.51 \\
\hline $4-688$ & 94.59 & 95.47 & 95.55 \\
\hline $4-822$ & 95.07 & 95.36 & 95.35 \\
\hline $4-835$ & 95.01 & 95.65 & 95.68 \\
\hline $4-978$ & 95.30 & 96.29 & 96.29 \\
\hline $4-984$ & 95.39 & 96.18 & 96.25 \\
\hline
\end{tabular}

(a) July 5, 1978.

(b) July 6, 1978 . 

APPENDIX B

CLADDING CHARACTERIZATION 


\section{APPENDIX B}

\section{CLADDING CHARACTERIZATION}

Tubing for instrumented fuel assembly (IFA)-527 came from the same batch obtained for IFA-431 and -432; specifications and certification may be found in BNWL-1988. The following Zircaloy-2 tubes were used for cladding:

$\begin{array}{cr}\begin{array}{c}\text { Rod } \\ \text { Number }\end{array} & \text { Tube } \\ 1 & 3 A \\ 2 & 19 A \\ 3 & 23 A \\ 4 & 6 B \\ 5 & 21 B \\ 6 & 12 C\end{array}$

Internal profilometry, prior to fuel loading, was performed by Kjeller. A continuous recording air gauge was used. A single linear trace at $0^{\circ}$ was made for each rod (see Figures B.1 through B.6). The equipment was calibrated with calibration rings and has a sensitivity of $\pm 0.002 \mathrm{~mm}$. Table B.1 contains discrete cladding outer and inner diameter measurements that were taken manually. 


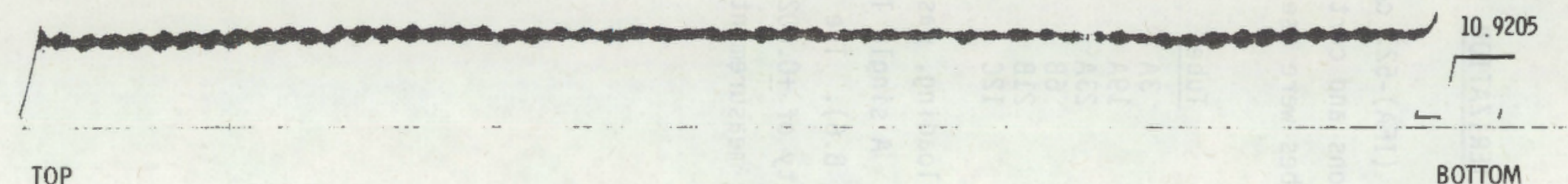

ID MEASUREMENT WITH CONTINUOUS RECORDING AIR GAUGE

SENSITIVITY: $\quad 2 \mu \mathrm{m} / S C A L E$ DIVISION

AXIAL SCALE: $\quad 2.8 \mathrm{~mm} / S C A L E$ DIVISION

CALIBRATION LINES: 10.8385 and $10.9205 \mathrm{~mm}$

TUBE NUMBER: $\quad 3 A$

FIGURE B.1. Cladding Inside Diameter Profilometry Data for Rod 1 of Instrumented Fuel Assembly (IFA) -527 


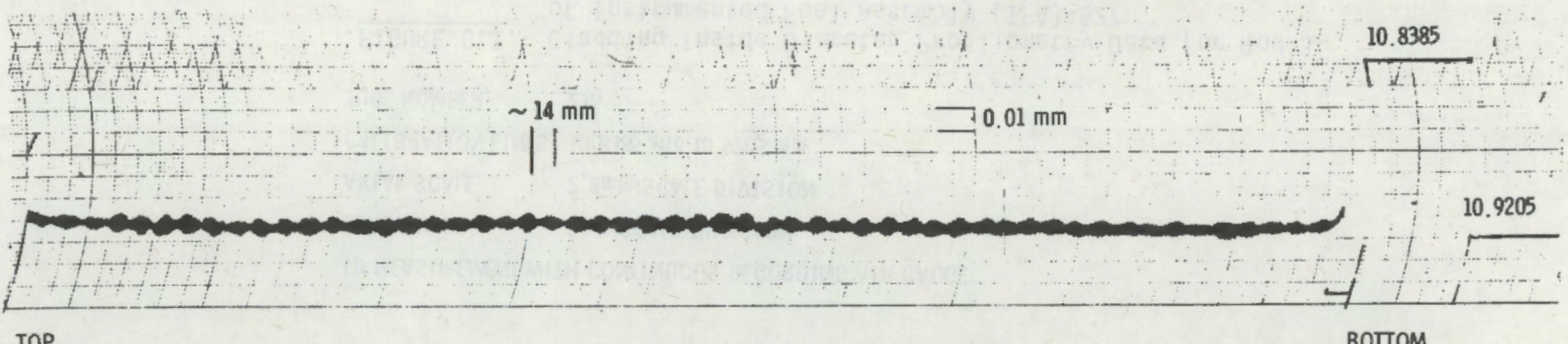

ID MEASUREMENT WITH CONTINUOUS RECORDING AIR GAUGE

SENSITIVITY: $\quad 2 \mu \mathrm{m} / S$ CALE DIVISION

AXIAL SCALE: $\quad 2.8 \mathrm{~mm} / \mathrm{SCALE}$ DIVISION

CALIBRATION LINES: 10.8385 and $10.9205 \mathrm{~mm}$

TUBE NUMBER:

$19 \mathrm{~A}$

FIGURE B.2. Cladding Inside Diameter Profilometry Data for Rod 2 of Instrumented Fuel Assembly (IFA) -527 


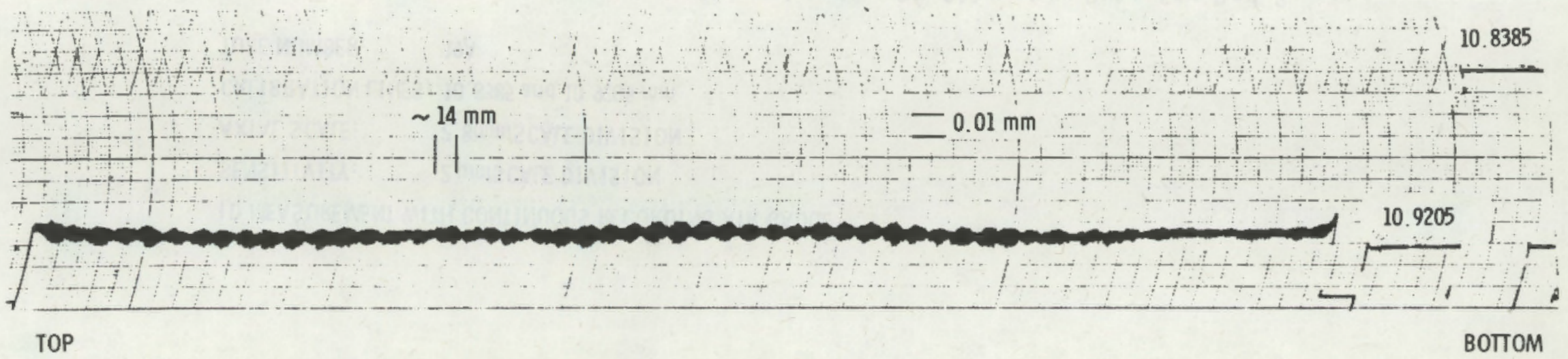

ID MEASUREMENT WITH CONTINUOUS RECORDING AIR GAUGE

SENSITIVITY: $\quad 2 \mu \mathrm{m} / S C A L E$ DIVISION

AXIAL SCALE: $\quad 2.8 \mathrm{~mm} / S$ CALE DIVISION

CALIBRATION LINES: 10.8385 and $10.9205 \mathrm{~mm}$

TUBE NUMBER:

$23 \mathrm{~A}$

FIGURE B.3. Cladding Inside Diameter Profilometry Data for Rod 3 of Instrumented Fuel Assembly (IFA) -527 


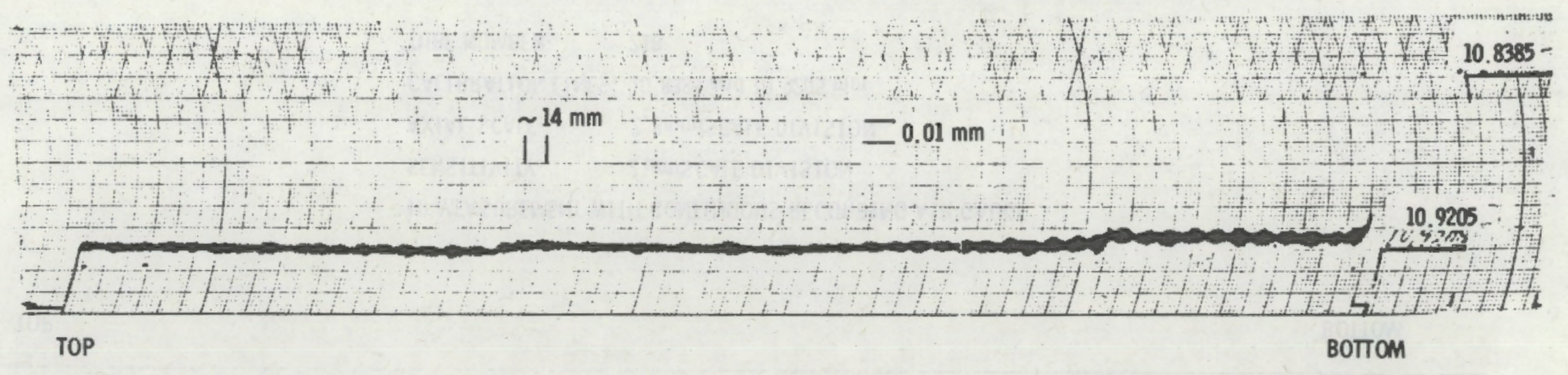

ID MEASUREMENT WITH CONTINUOUS RECORDING AIR GAUGE

SENSITIVITY: $2 \mu \mathrm{m} / S C A L E$ DIVISION

AXIAL SCAL:

$2.8 \mathrm{~mm} / \mathrm{SCALE}$ DIVISION

CALIBRATION LINES: 10.8385 and $10.9205 \mathrm{~mm}$

TUBE NUMBER:

$6 \mathrm{~B}$

FIGURE B.4. Cladding Inside Diameter Profilometry Data for Rod 4 of Instrumented Fuel Assembly (IFA) -527 


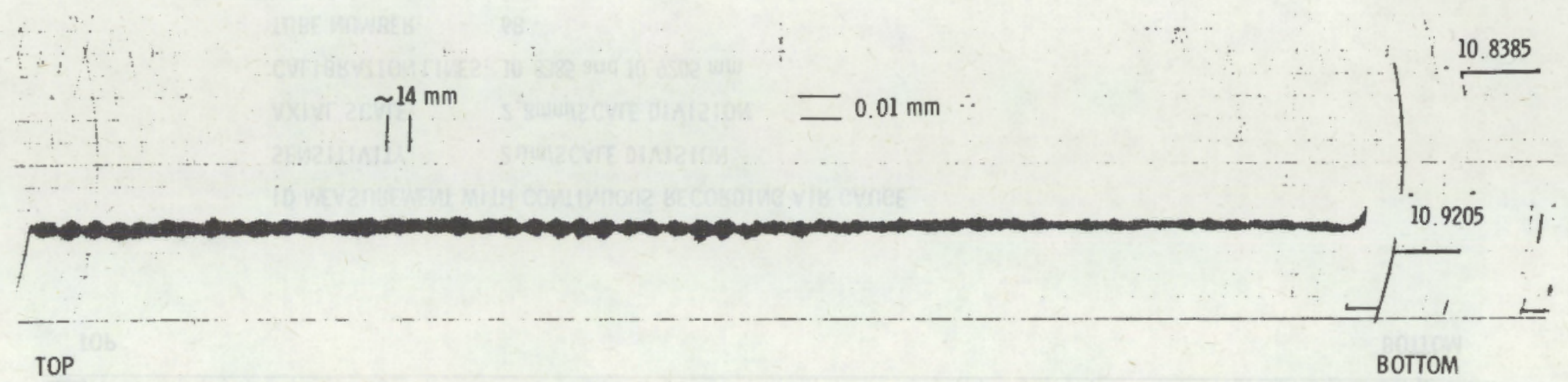

ID MEASUREMENT WITH CONTINUOUS RECORDING AIR GAUGE

SENSITIVITY: $\quad 2 \mu \mathrm{m} / S C A L E$ DIVISION

AXIAL SCALE: $\quad 2.8 \mathrm{~mm} / \mathrm{SCALE}$ DIVISION

CALIBRATION LINES: 10.8385 and $10.9205 \mathrm{~mm}$

TUBE NUMBER: $\quad 21 B$

FIGURE B.5. Cladding Inside Diameter Profilometry Data for Rod 5 of Instrumented Fuel Assembly (IFA) -527 


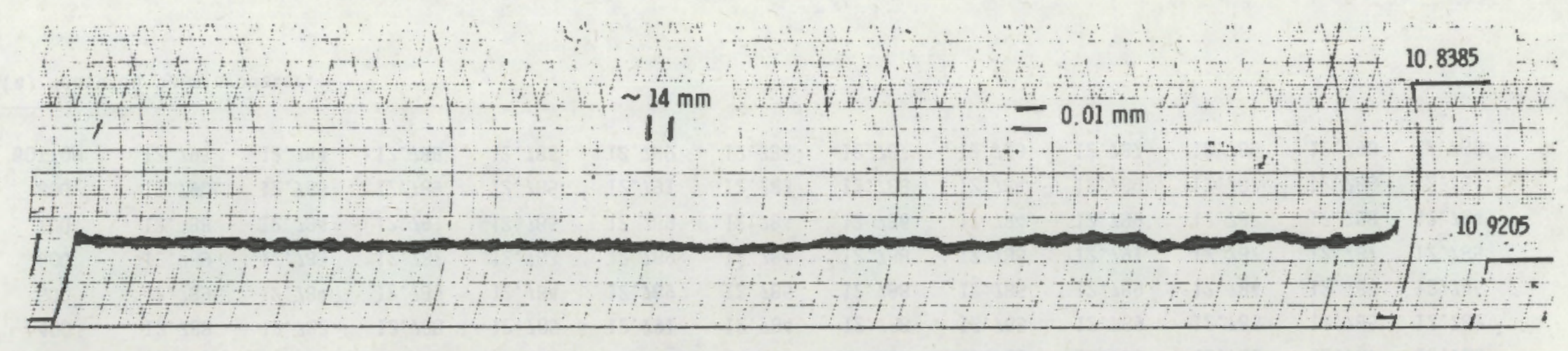

ID MEASUREMENT WITH CONTINUOUS RECORDING AIR GAUGE

SENSITIVITY: $\quad 2 \mu \mathrm{m} / S C A L E$ DIVISION

AXIAL SCALE: $\quad 2.8 \mathrm{~mm} / \mathrm{SCALE}$ DIVISION

CALIBRATION LINES: 10.8385 and $10.9205 \mathrm{~mm}$

TUBE NUMBER: $\quad 12 \mathrm{C}$

FIGURE B.6. Cladding Inside Diameter Profilometry Data for Rod 6 of Instrumented Fuel Assembly (IFA) -527 
TABLE B.1. Cladding Outer Diameter Measurements

Distance
fram Top fram Top
of Rod,

$\begin{array}{ccc}\operatorname{Rod} 1 & \text { Cladding Outer Diameter, (a) } \mathrm{mm} \\ \operatorname{Rod} 3 & \operatorname{Rod} 4\end{array}$

TOP

$\begin{array}{ll}\frac{\max }{12.789} & \frac{\min }{12.785} \\ 12.788 & 12.783\end{array}$

$\frac{\max }{12.791} \frac{\min }{12.787}$

$\max \operatorname{Rod}$

4

$\begin{array}{lll}100 & 12.788 & 12.783\end{array}$

$12.789 \quad 12.784$

$12.788 \quad \overline{12.784}$

$\frac{\max }{12.789} \frac{\text { min }}{12.784}$

$\frac{\text { Rod } 5}{\frac{\max }{12.790} \frac{\min }{12.787}}$

$\frac{\text { Rod } 6}{\frac{\max }{12.784}} \frac{\min }{12.779}$

$\begin{array}{lll}200 & 12.789 & 12.785\end{array}$

12.788

12.784

$12.790 \quad 12.785$

$12.788 \quad 12.785$

$12.789-12.787$

$12.787 \quad 12.785$

$\begin{array}{lll}300 & 12.788 & 12.782\end{array}$

12.789

12.786

$12.789 \quad 12.785$

$12.790 \quad 12.785$

12.790

12.788

$12.788 \quad 12.783$

$\begin{array}{lll}400 & 12.788 & 12.782\end{array}$

$12.788 \quad 12.785$

2.789

12.783

$12.788 \quad 12.785$

12.789

12.786

$12.787 \quad 12.783$

$\begin{array}{lll}500 & 12.789 & 12.784\end{array}$

$12.789 \quad 12.784$

12.784

$12.788 \quad 12.785$

12.789

12.785

$12.785 \quad 12.782$

$\begin{array}{lll}600 & 12.789 & 12.783\end{array}$

12.787

12.783

12.789

12.785

$12.788 \quad 12.785$

12.789

12.784

$12.788 \quad 12.785$

$\begin{array}{lll}700 & 12.788 & 12.784\end{array}$

800

12.790

12.785

12.791

12.785

12.789

12.784
12.784

12.788

12.785

12.791

12.787

$12.787 \quad 12.785$

BOTTOM

12.793

12.784

12.788

12.785

12.791

12.783

12.786

12.784

$12.789 \quad 12.787$

$\begin{array}{ll}12.788 & 12.784\end{array}$

$12.789 \quad 12.785$

12.787

12.783

12.787

12.787

$12.788 \quad 12.784$

(a) Measured by micrometer. 


\section{APPENDIX C}

FUEL FABRICATION 


\section{APPENDIX C}

\section{FUEL FABRICATION}

\section{ADOITIONAL PELLETS FOR HALDEN ASSEMBLIES $(a)$}

\section{Preproduction Sinterability Test Plan}

\section{Purpose of Test}

The purpose of this test is to qualify a cold wall refractory metal furnace to successfully sinter a $4-\mathrm{kg}$ batch of pellets made with depleted powder. Approximately 24 pellets of Halden material will be included to establish parameters for the production of Halden pellets.

\section{Modifications to Molybdenum Boats}

The molybdenum boats used to load material into the furnace need to have randomly spaced holes of approximately 1/8-in. diameter drilled in the bottom. This should increase the circulation of the $\mathrm{H}_{2}$ over the pellets.

3. Special Instructions for Handling Halden Material

- granulate "as-received" $\mathrm{UO}_{2}$ to pass through a 100 -mesh screen

- run tap density

- slùg $300 \mathrm{~g}$ of powder in three $100 \mathrm{~g}$ increments, using the 2-in. die and approximately 5 -ton pressure; record slug size and density

- granulate the slugs to 20 mesh

- blend $0.4 \%$ sterotex in the combined $300-\mathrm{g}$ lot

- press pellets (approximately $12 \mathrm{~g}$ each) with existing pellet die (normal 0.541-in. diameter pellets with flat ends) using a pressure range from 3 to 5 tons; target density range should be $5.2+0.1 \mathrm{~g} / \mathrm{cm}^{3}$; record pressure, dimensions, and weight and calculate the green pellet density; bubble test for integrity and identify each pellet.

(a) Prepared by J. E. Spasoff; reviewed by N. C. Davis. 
- drill three of the green pellets with a No. 43 tungsten carbide drill 0.089 in.

4. Sintering Parameters

- heating rate approximately $100^{\circ} \mathrm{C} / \mathrm{h}$

- soak $8 \mathrm{~h}$ at $1700^{\circ} \mathrm{C} \pm 20^{\circ} \mathrm{C}$

- furnace cool approximately $400^{\circ} \mathrm{C} / \mathrm{h}$

- furnace operating data supplied by circular chart.

5. Final Test Evaluation

- record the as-sintered weight of pellets

- record minimum diameter of each pellet

- grind pellets to cleanup diameter

- measure, weigh, and calculate density

- break a pellet to inspect microstructure visually

- record results and recormendations for production

- prepare production process parameter sheet for approval.

6. Preparation of Depleted $\mathrm{UO}_{2}$ Powder

- $4 \mathrm{~kg}$ of depleted $\mathrm{UO}_{2}$ powder will be handled in the same manner as the Halden powder.

Note: If this sinterability test proves successful for both the performance of the furnace and the Halden material, production of the $10 \%$ pellets could be started. 
Powder Identification and Preparation:

Cak Ridge Powder Lot 30-2785

Same as released for [FA-513 pellets

Slug Data: Quantity $\sim 300$ grams

$\frac{2.01 \frac{\text { Diameter }}{2.010}}{2.010}$

$\frac{\frac{\text { Length }}{0.443}}{\frac{0.465}{0.460}}$

$\frac{\frac{\frac{\text { Weight }}{101.60}}{99.75}}{100.7}$

Density 24.4

$\frac{\sim 4.15}{v_{4.22}}$

Sintered Run Number BREW \#31

Green Pellet

Green Diameter 0.5407 Dish V.V.
Sintered Peilet

Sintered V.V.

Calculation Factor

Sintered Weight

190 net

Sinter Ground $x=$ Cored

Pellet Length Weight Volume Density Diame- DiameNumber "inches" grams $\mathrm{cm}^{3} \mathrm{a} / \mathrm{cm}^{3}$

\begin{tabular}{|c|c|c|c|c|c|c|c|c|}
\hline $10-1$ & 0.673 & 12.809 & 5.06 & 0.423 & 0.4202 & 0.525 & 12.373 & 10.3705 \\
\hline-2 & 0.872 & 16.528 & 5.09 & 0.422 & 0.4186 & 0.680 & 15.913 & 10.3769 \\
\hline-3 & 0.562 & 10.837 & 5.12 & 0.4255 & 0.4237 & 0.440 & 10.542 & 10.3699 \\
\hline-4 & 0.498 & 9.670 & 5.16 & 0.4255 & 0.4237 & 0.392 & 9.394 & 10.3723 \\
\hline-5 & 0.498 & 9.764 & 5.21 & 0.427 & 0.4237 & 0.393 & 9.420 & 10.3746 \\
\hline-6 & 0.499 & 9.745 & 5.19 & 0.427 & 0.4237 & 0.392 & 9.408 & 10.3878 \\
\hline$x-7$ & 0.490 & 9.642 & 5.23 & 0.428 & 0.4237 & 0.387 & 8.999 & \\
\hline$x-8$ & 0.490 & 9.671 & 5.24 & 0.428 & 0.4237 & 0.388 & 9.034 & \\
\hline-9 & 0.492 & 9.677 & 5.23 & 0.428 & 0.4237 & 0.388 & 9.300 & 10.3744 \\
\hline-10 & 0.493 & 9.724 & 5.24 & 0.428 & 0.4237 & 0.390 & 9.341 & 10.3667 \\
\hline-11 & 0.481 & 9.758 & 5.39 & 0.4315 & 0.4298 & 0.384 & 9.496 & 10.4013 \\
\hline-12 & 0.479 & 9.724 & 5.39 & 0.4315 & 0.4298 & 0.382 & 9.453 & 10.4084 \\
\hline$x-13$ & 0.468 & 9.827 & 5.58 & 0.4365 & 0.4298 & 0.377 & 9.037 & \\
\hline$x-14$ & 0.468 & 9.712 & 5.51 & 0.436 & 0.4298 & 0.373 & 8.978 & \\
\hline-15 & 0.467 & 9.750 & 5.55 & 0.435 & 0.4298 & 0.374 & 9.308 & 10.4680 \\
\hline-16 & 0.466 & 9.700 & 5.53 & 0.4345 & 0.4298 & 0.375 & 9.308 & 10.4401 \\
\hline-17 & 0.464 & 9.640 & 5.52 & 0.434 & 0.4298 & 0.372 & 9.242 & 10.4497 \\
\hline$x-18$ & 0.456 & 9.713 & 5.66 & 0.4385 & 0.4352 & 0.367 & 9.088 & \\
\hline
\end{tabular}

C. 3 


\section{EVALUATION OF SINTERABILITY-PREPRODUCTION TEST 31}

Preproduction test $31\left(10 \%\right.$ enriched $\mathrm{UO}_{2}$ ) confirmed the previous satisfactory results on the same powder lot, processed as IFA-513, Batch 1. The $4-\mathrm{kg}$ batch of depleted pellets sintered in this run was completely satisfactory, qualifying the furnace for production. Density and dimensional results provide assurance that parameters can be established to fabricate the additional Halden pellets. The following observations and comments are based on the test results and the proposed parameters for processing:

- A visual inspection of the pellets indicated good physical integrity. The cross section appearance of a fractured pellet showed uniform microstructure.

- The new molybdenum boats, with the perforations for gas distribution shall be used, with $100 \% \mathrm{H}_{2}$ flowing through water until the temperature is greater than $900^{\circ} \mathrm{C}$. From 900 to $1700^{\circ} \mathrm{C}$, gas may be $50 \% \mathrm{H}_{2}$ and $50 \% \mathrm{Ar}$, with the $\mathrm{H}_{2}$ continuous through the water.

- The only powder pretreatment necessary is to reduce it to pass a 100 -mesh screen prior to slugging.

- The press tooling previously used is satisfactory. Pellets pressed to $5.15 \pm 0.05 \mathrm{~g} / \mathrm{cm}^{3}$ will yield the required $0.4205-\mathrm{in}$. diameter with minimum grinding. Pellets (136 quantity) that require a finished diameter of $0.4275 \mathrm{in}$. should be pressed to a green density of $5.45 \mathrm{~g} / \mathrm{cm}^{3}$. This should be reconfirmed with a sample in the first production batch of the smaller pellets.

- The pressed length should be held to $0.636 \pm 0.010 \mathrm{in}$. to maintain the specified sintered length of $0.500 \mathrm{in}$. High green density pellets should be checked since they will reduce less.

- The drill used for themocouple hole 43 produced a final inside diameter of 0.069 to $0.070 \mathrm{in.}$, which is within the specifications. 
- Extremely uniform distribution of the sterotex will be necessary to maintain the $95 \% \pm 0.5 \%$ density.

- The process parameter sheet and density control charts are being prepared for approval and release for production. 


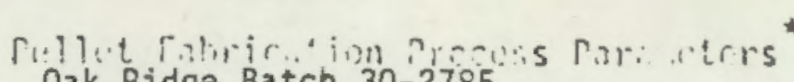
Oak Ridge Batch 30-2785 inle . 5-1-78

Rev. $1-6-22-78$ $\therefore$; t Halden W026209

isliet joliticatiuns:
Fintilin: nt 10\% "rise 2 jijicution nquntity

\section{Dunsity}

$\pm \underline{0 .} 7 ! ; \%$

(Additional

Hatden

IFA-513

Pertets) -

\section{5}

$95.0 \%$

136

$95.0 \%$
Refersince

Diameter Length

\begin{tabular}{l} 
Length \\
$\pm 0.010^{\prime \prime}$ \\
\hline
\end{tabular}

$\underline{0.4205}-0.500$

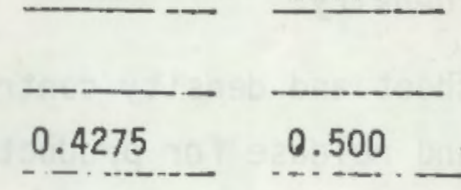

Halden IFA-513 Release.

2

Fowder Preparation:

Maximuın Batch Size: 560 grams see CSS-306-1.3

Powder Blending Time: all -100M homogenous

Slug Density_ $4.3 \pm 0.1 \quad$ Slug Size $2100 \mathrm{~g} \quad$ Control Chart_Plot $270 \%$

Giranulate_ -20 Mesh: Lubricant $0.3 \pm 0.1$ Weight $\%$

Special Instructions: Process in 3 pellet batch - Batch 2, 3 and 4

(Batch 1 was original IFA 513 pellets) 2324 pellets per batch

with Batch 4 including the 136 pellet to be ground $0.4275^{1}$ diameter

$\mathrm{Pe}^{*}$ at Pressing and Sintering

Green Density_ $5.15 \pm 0.05^{\star 1} \quad \mathrm{gm} / \mathrm{cm}^{3} \quad$ Length 20.635 Control Chart $210 \%^{\star 2}$

Press Tooling Use flat face punch and die that yields $0.547^{\prime \prime}$ gram pellet

$100^{\circ} / \mathrm{h}$ to $1000^{\circ} \mathrm{C}$

Sintering Heating Rate $200^{\circ} / \mathrm{h}$ to $1700^{\circ} \mathrm{C}$ Maximum Temperature $1700 \quad{ }^{\circ} \mathrm{C}:$. Time $800 \%$ to $900^{\circ} \mathrm{C} \& \mathrm{Hours}$ Cooling Rate $400 \quad \mathrm{H}_{2}$ Flow 50-50\% $\mathrm{H}_{2}-\mathrm{AR}$ to 1709 urge Argon

Special Instructions: $\mathrm{H}_{2} \mathrm{Flow}$ - through water bubbler $100 \% \mathrm{H}_{2}$ to $>900^{\circ} \mathrm{C}$ $50 \% \mathrm{H}_{2}-50 \%$ AR from 2900 to $1700^{\circ} \mathrm{C} 8 \mathrm{hr}$.

Grind pellets in accordance with above dianeter specification, clean in Ultrasonic Alcohol Bath and dry $100^{\circ} \mathrm{C} \pm 10^{\circ} \mathrm{C}$ for one hour. Inspection in accordance with 8atch Inspection sample plan.

Counnents: ${ }^{\star 1} 5.15 \mathrm{~g} / \mathrm{cm}^{3}$ for all the 0.4205 dia pellets, increase green density to 5.45 for the larger 0.4275 peliets

*2 Number all pellets plot 25 to 10 pellets at start of pressing or any re-start च10\% during pressing

Prepared by: JE Spasoff \& NC Davis Date:_6-22-78 Approved by: Date:

*Process parameters as listed are based on final sinterability or pre-production Test Results. (Attached) 
Pellet Fabrication Follower Data Sheet

Oak Ridge

Batch \#2

Project. Halden w/o 26209 Lot Number 30-2785

Powder Preparation: (Control chart attached)

Slug Density $4.3 \pm 0.1$

Slug Size $\quad \sim 100$ grams

Granulate_ $4000 \quad-20+100$ mesh

Lubricant

$0.3 \%$

w/o sterotex

NA

-100 mesh

NA Re-slug

Blend 10 Min.
Date $\quad 5 / 2 / 78$

Enrichment_9.9\% Release 2

Comments Had $107 \mathrm{~g}$. left from sinterability test, which had $0.4 \%$ sterotex added.

Ball milled 4012 grams for 5 min. Then added the 107 grams with $0.4 \%$ sterotex and blended 5 min. more. Total wt. $\mathrm{UO}_{2}$ powder $=4118$ grams.

Pellet Pressing: Batch No. 2 Identification Each pellet numbered Green Density $\sim 5.15$ Green Length_.636 Quantity_ 3904

(See control chart attached)

Pellet Sintering: $\quad$ Furnace Run No. Brew \#32 Date $5 / 3 / 78$

Time

8 hours

Temperature

$1700^{\circ} \mathrm{C}$

Pyrometer

Average Pellet Diameter $\quad 0.425$

Batch Weight 3859

Operator_NCD/JEL/JES

Pellet Grinding: Specified Diameter Grind 319 pellets to $0.4205+.0005$ Batch Weight 3802 grams

Operator_JEL

Pellet Cleaning \& Drying: Cleaned with ethyl alcohol in ultrasonic cleaner. Bried for 2 hrs. at $80-85^{\circ} \mathrm{C}$ Operator__.JES Batch Inspection 100\% Diameter .4205+.0005 Length . 500+0.01 Dish__ Dens. $100 \%$ Visual_ $100 \% \quad$ Chips \& Cracks

Analytical DB-122_Composite___ Isotopic $x \quad$ Chemical $x \quad$ Oxygen/Uranium $x$ Uranium 
Pellet Fabrication Follower Data Sheet

Oak Ridge $\quad$ Date $5 / 3 / 78$
Batch $\# 3$

Project Halden w/o 26209 Lot Number 30-2785 Enrichment $9.9 \%$ Release 2

Powder Preparation: (Control chart attached)

Siug Density $4.3 \pm 0.1$ Slug size 100 grams

Granulate 4200 $-20+100$ mesh NA -100 mesh NA Re-slug

Lubricant $0.3 \%$ w/o sterotex 12.6 grams $4200+12 \cdot 6=4212 \cdot 6$ grams $\mathrm{UO}_{2}$

Blend 10 Min. Operator JES

Comments Blended in ball mill for 10 minutes. Total $\mathrm{vO}_{2}$ weight 4212.6

\begin{tabular}{lll} 
Pellet Pressing: & Batch No._3 3 & Identification Each pellet numbered \\
Green Density $\sim 5.15$ & Green Length_.636 Nuantity 4205 \\
\hline
\end{tabular}

(See control chart attached)

Pellet Sintering: Furnace Run No. Brew \#33 Date_5/8/78

Time_ 8 hours Temperature $1700^{\circ} \mathrm{C} \quad$ Pyrometer -

Average Pellet Diameter_ $0.425 \quad$ Batch Weight_ 3932 Operator JEL/NCD/JES

Pellet Grinding: Specified Diameter Grind 320 pellets to $0.4205 \pm .0005$ Batch Weight 3820 grams

Operator JEL

Pellet Cleaning \& Drying: Cleaned with ethyl alcohol in ultrasonic cleaner. Dried for 2 hrs. at $80-85^{\circ}$ C. 3724 grams net Operator JES

Batch Inspection $\frac{100 \%}{100 \%}$ Diameter $\frac{.4205 \pm .0005}{100 \%}$ Lisual_ $100 \%$ Chips \& Cracks

Ana lytical $\underline{\mathrm{DB}-122}$ Composite $X$ Isotopic Chemical $\$ \quad 0 x y g e n /$ Uranium $S$ Uranium Comments Pellet \#418 
Pellet Fabrication Follower Data Sheet

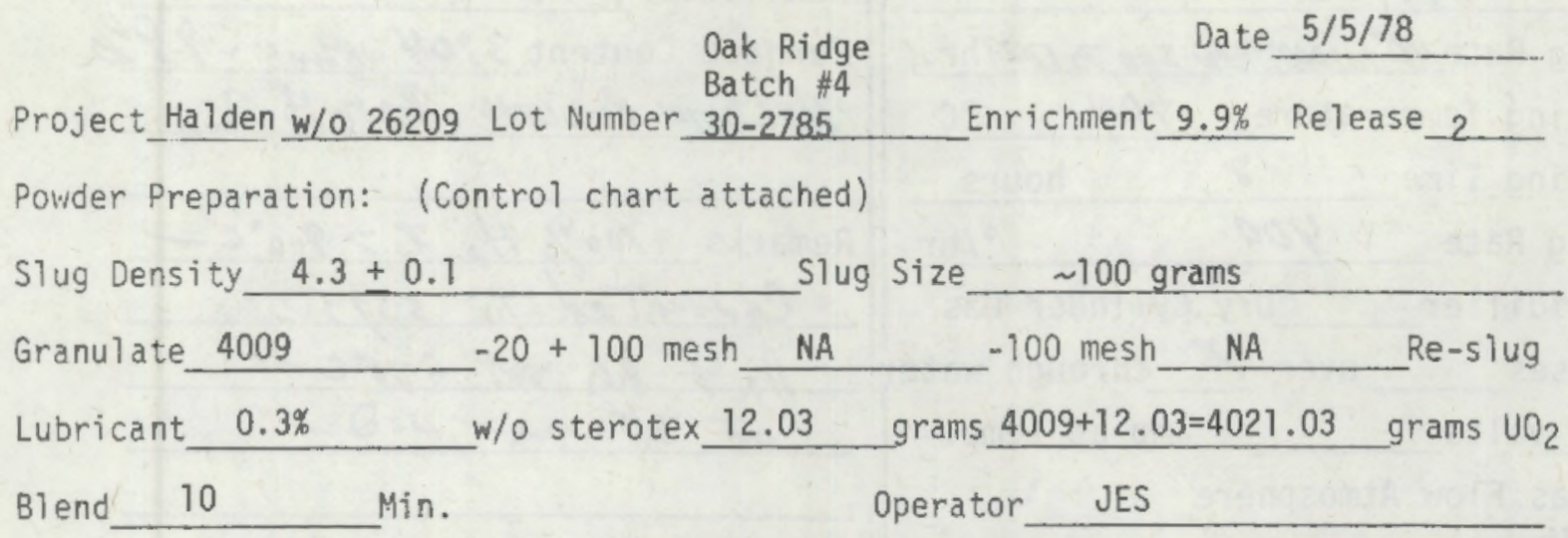

Comments. Blended in bal1 mill for 10 minutes. Added $\sim 380$ grams powder left over

from batch \#3 pressing operation. Blended an additional 3 minutes.

Pellet Pressing: Batch No. 4_._Identification Each pellet numbered

Green Density $5.15 \& 5.45$ Green Length $\sim .636 \quad$ Quantity_ 4399

(See control chart attached)

Pellet Sintering: $\quad$ Furnace Run No. Brew \#34_0ate_ 5/11/78

Time 8 hrs. Temperature $1700^{\circ} \mathrm{C} \quad$ Pyrometer _ _ _

Average Pellet Diameter 0.425 and 0.434 Batch Weight 4369

Operator JEL/NCD/JES

Pellet Grinding: Specified Diameter Grind 195 pellets to $.4205+.0005$ and

Batch Weight 4293 grams 150 pellets to $.4295+.0005$

Operator_.JES

Pellet Cleaning \& Drying: Cleaned with ethyl alcohol in ultrasonic cleaner. Dried for 10 minutes at $80-85^{\circ} \mathrm{C}$ Operator JES

Batch Inspection 100\% Diameter. $.4295 \pm .0005$ Length $.500+.010$ Dish__ Dens.

$100 \%$ Visual_ 100\%_Chips \& Cracks

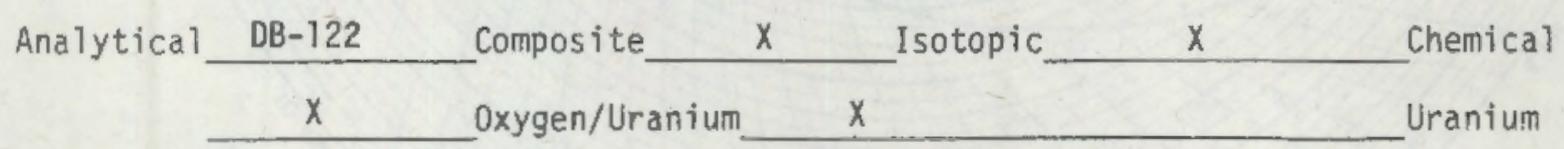

Comments Pellet \#977. Pellet \#791 thru 799 were inadvertently numbered 781 to 789

A line was scribed under number to indicate the 790 series. 
BREW FURNACE NO. 3 SINTERING DATA

Date $\quad 5 / 3 / 78$

Heating Rate $100^{\circ}$ Yol0000 $10001000 / \mathrm{hr}$.

Sintering Temperature $\frac{1700{ }^{\circ} \mathrm{C}}{8}$ hours
Sintering Time $\quad$ Co

Cooling Rate

$\mathrm{H}_{2}$ Humidi fier

$\% / \mathrm{hr}$

$\mathrm{H}_{2}$ passes

volts

400

Dry Cylinder Gas over $x$ through water

Gas Flow Atmosphere

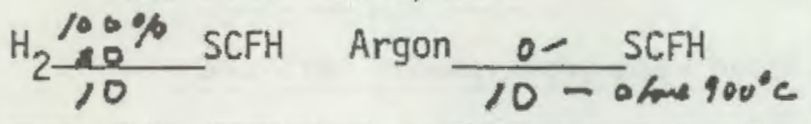

Run Number 32

Furnace Content 3904 gens $-9.9 \%$

HDLDEN PELLATS BateAt 2

Remarks $100 \% \mathrm{H}, \mathrm{z}>900^{\circ} \mathrm{C}$

Corrented to su/50

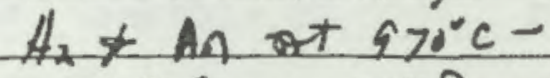

at $3: 50 \mathrm{pm}-\mathrm{NeQ}$ -

NCOanis + $32 \cos t \theta$

Operator

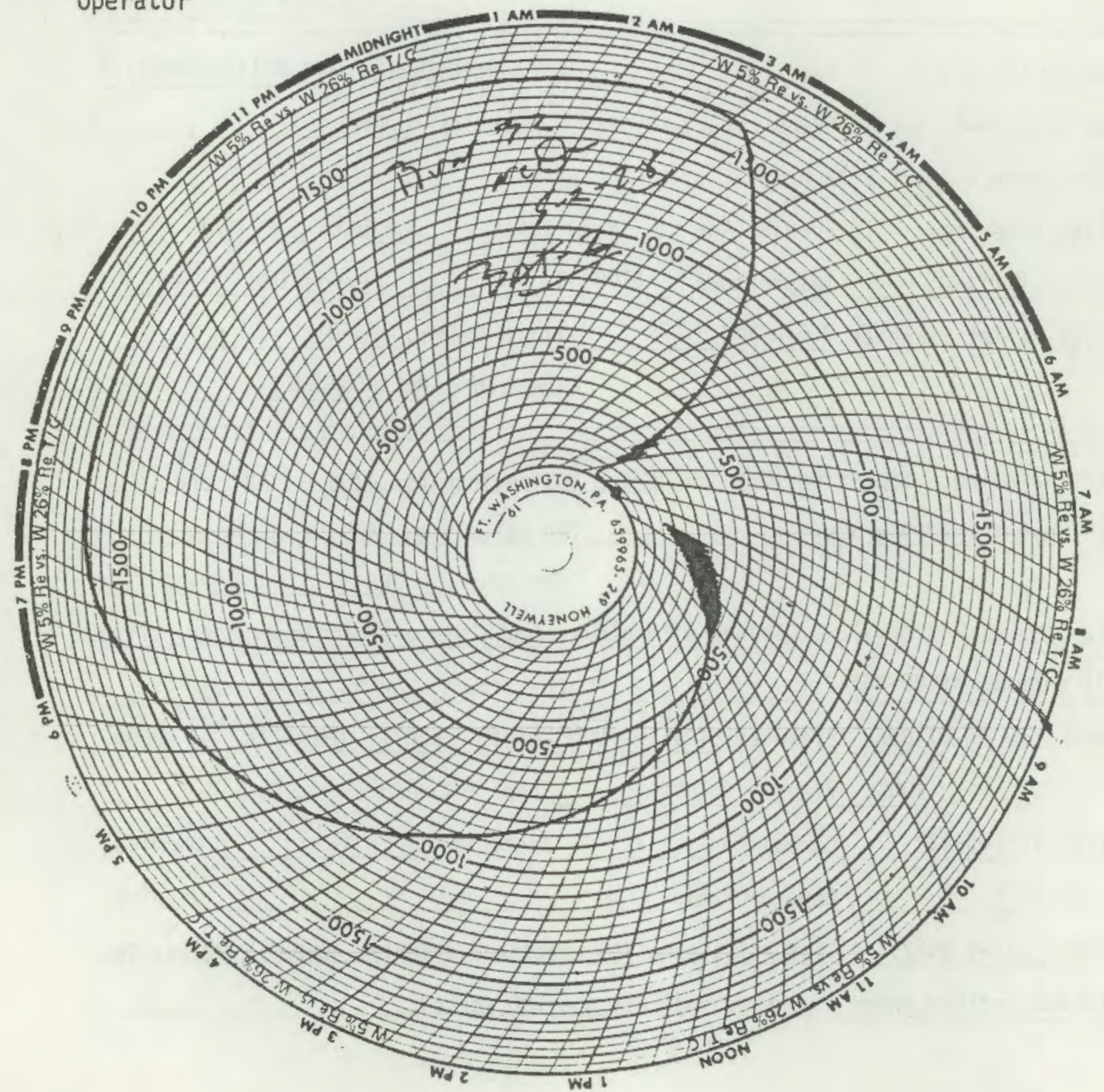

C. 10 
BREW FURNACE NO. 3 SINTERING DATA

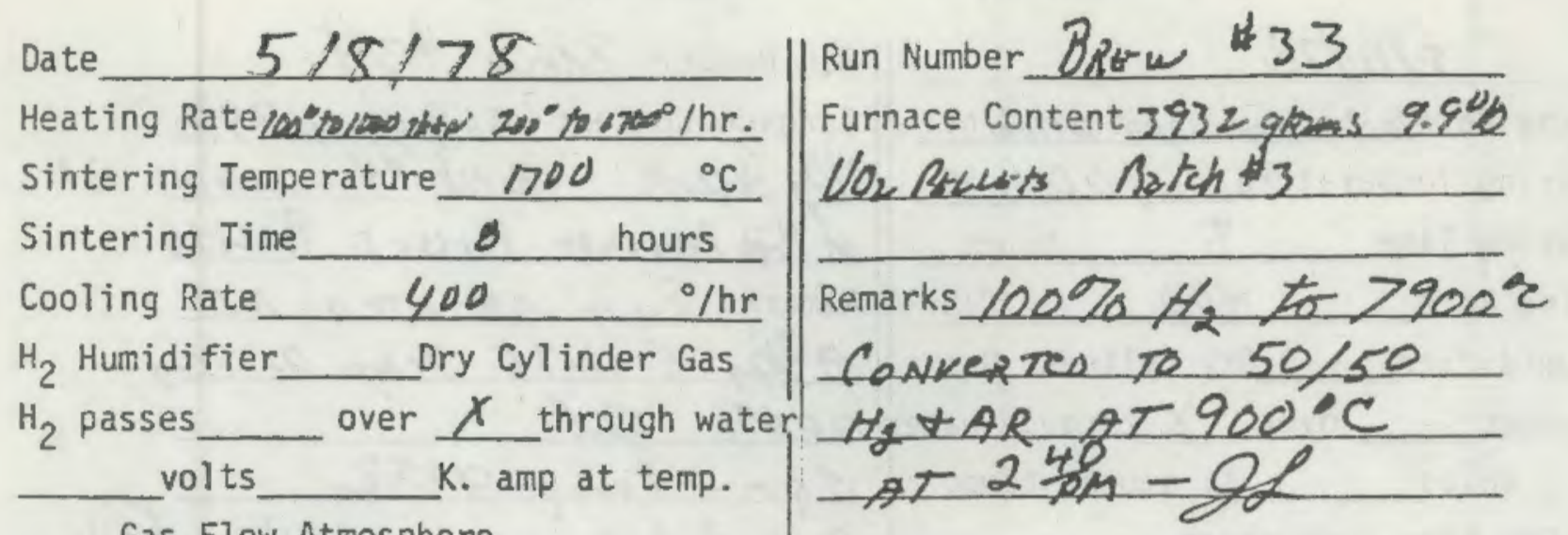

100 Flow Atmosphere
$\mathrm{H}_{2} \frac{10}{10} \mathrm{SCFH}$ Argon ro SCFH

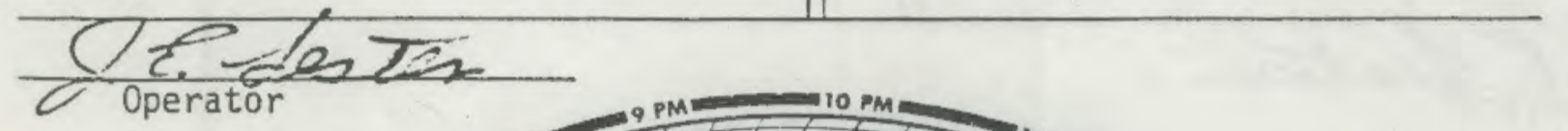


BREW FURNACE NO. 3 SINTERING DATA

Date_ $5 / 1 / 78$

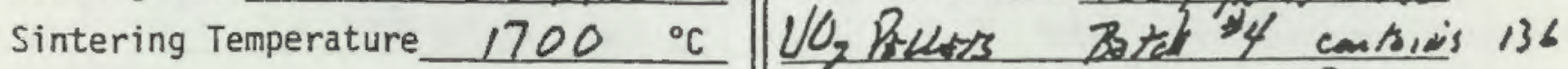

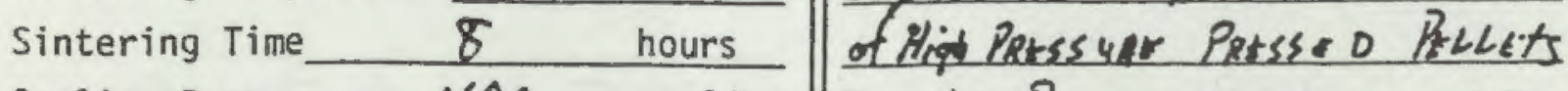
Cooling Rate $400 \quad \% \mathrm{hr}$ Remarks Ru A ABeTted $12 T$

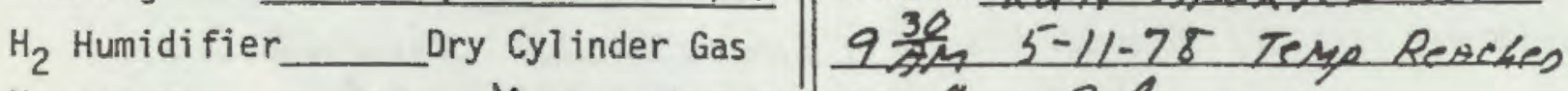
$\mathrm{H}_{2}$ passes volts over

Gas Flow Atmosphere $\mathrm{H}_{2} \frac{100}{10} \mathrm{SCFH}$ Argon $\frac{\mathrm{O}}{10 \mathrm{ADOV}} \mathrm{SCFH} 90^{\circ} \mathrm{C}$

Operator

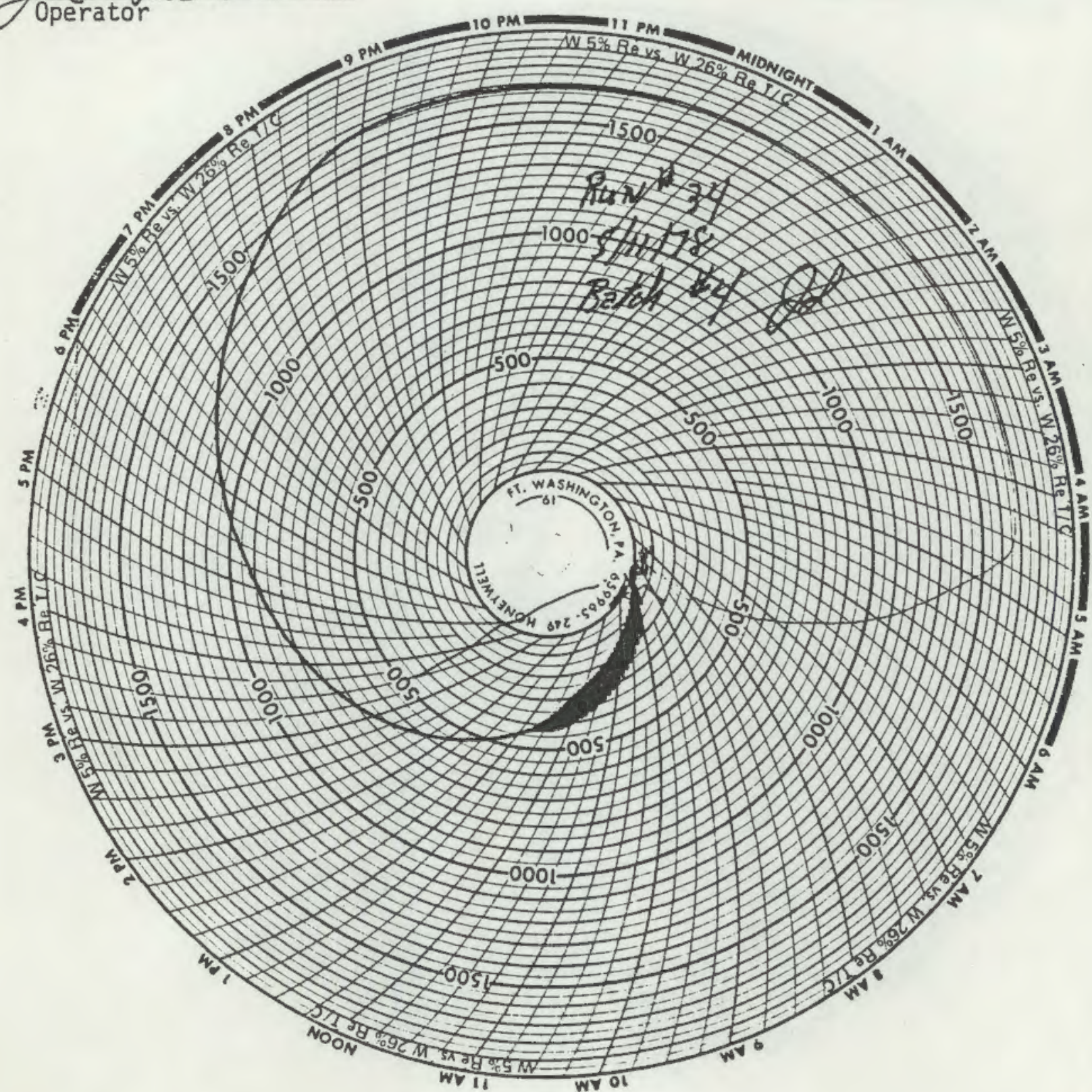

C. 12 


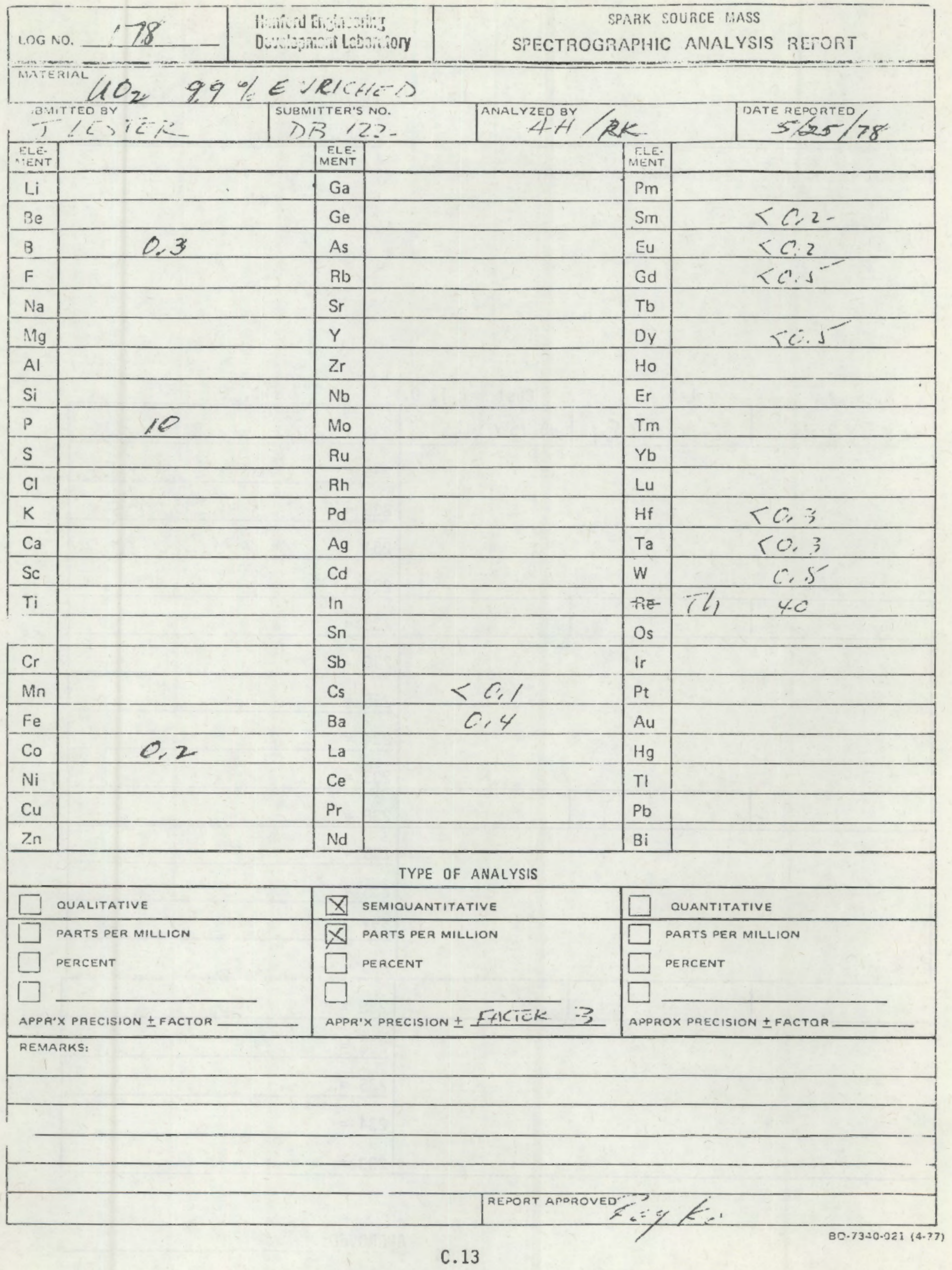




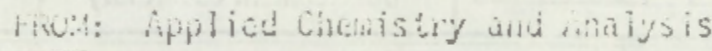

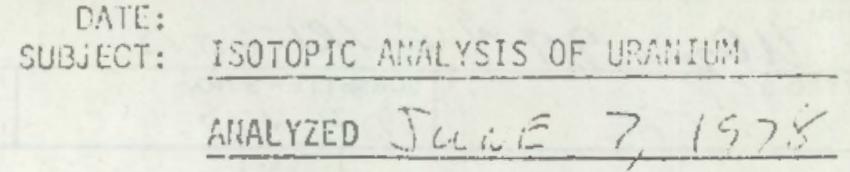

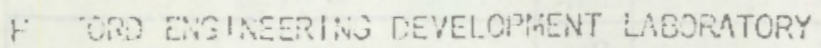

TO: I. IEST В $R$

cos $F, i E$

M. S. \#_ Lab \# Customer I. D.

\begin{tabular}{|c|c|c|c|c|}
\hline 1175376 & $C \dot{0} 042 \dot{5}$ & 1) $13 / 22$ & $238=$ & $90.00 \pm 0.05$ \\
\hline & & & $236=$ & cicos $50^{*}=3 \cdot 0.2$ \\
\hline & & & $235=$ & $9.84 \pm 0,05$ \\
\hline & & & $234=$ & $0.075=0.002$ \\
\hline & & & $233=$ & \\
\hline & & & $233=$ & \\
\hline & & & $235=$ & \\
\hline & & & $235=$ & \\
\hline & & & $234=$ & \\
\hline & & & $233=$ & \\
\hline & & & $238=$ & \\
\hline & & & $236=$ & \\
\hline & & & $235=$ & \\
\hline & & & $234=$ & \\
\hline & & & $233=$ & \\
\hline & & & $238=$ & \\
\hline & & & $236=$ & \\
\hline & & & $2.35=$ & \\
\hline & & & $234=$ & \\
\hline & & & $233=$ & \\
\hline
\end{tabular}




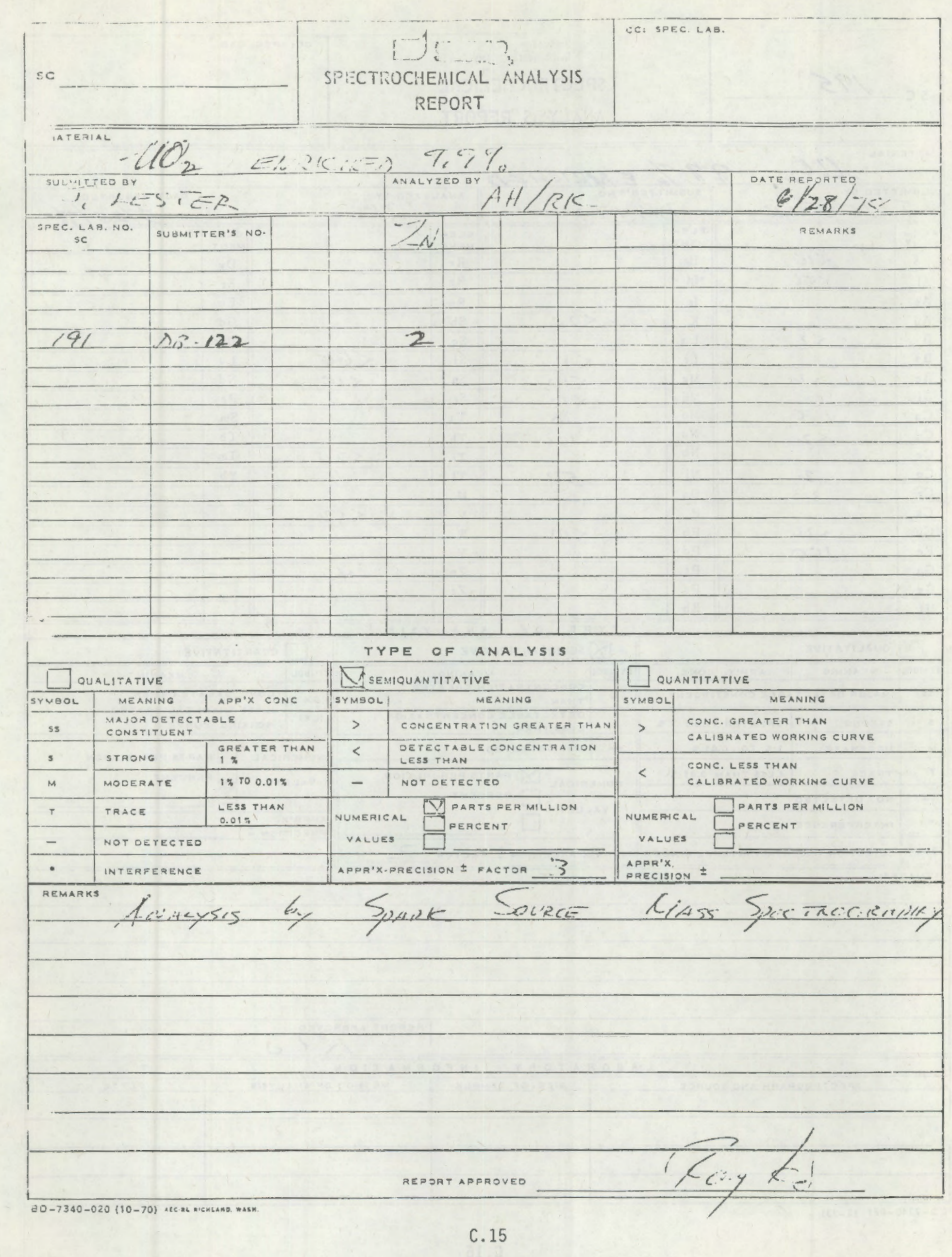




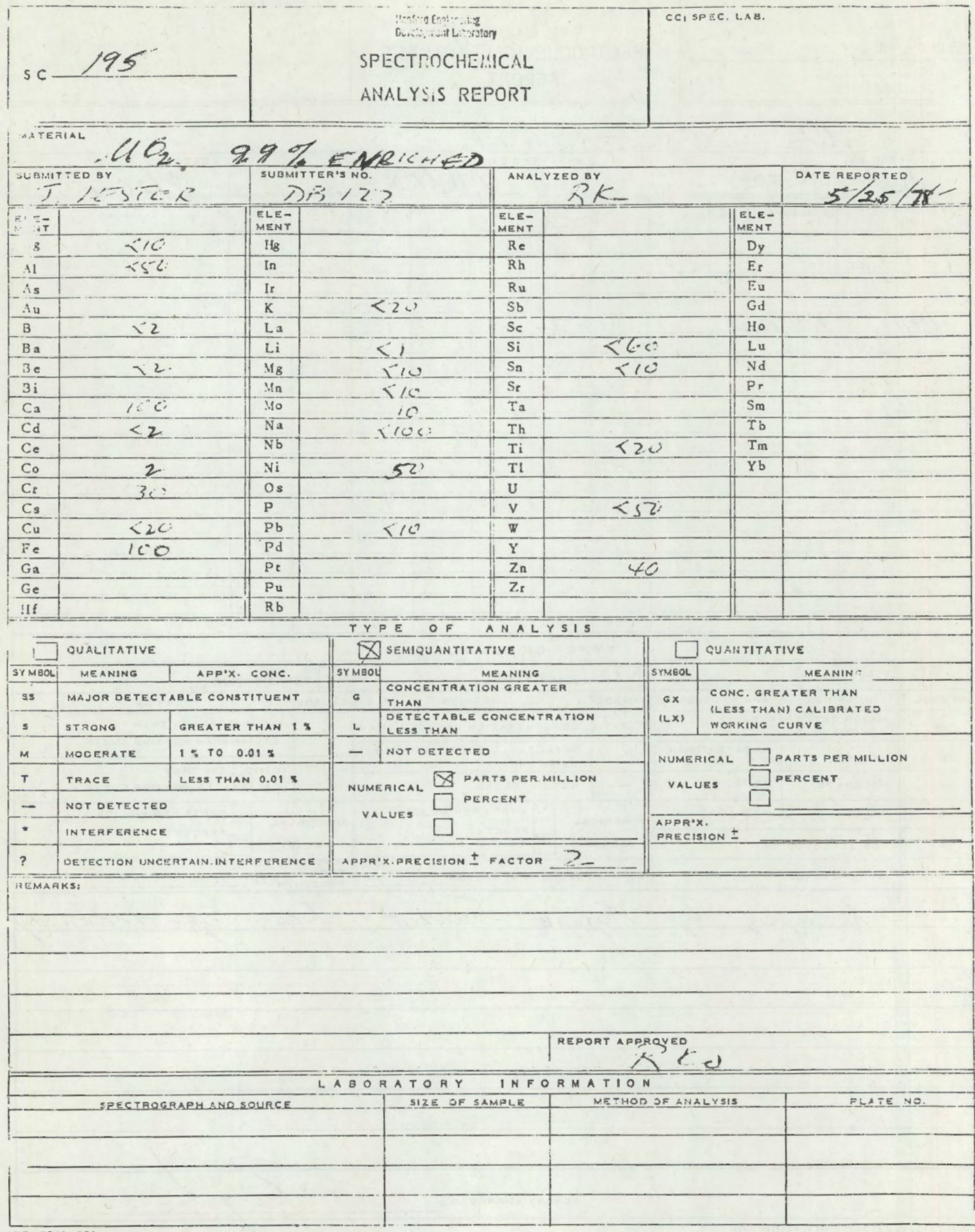




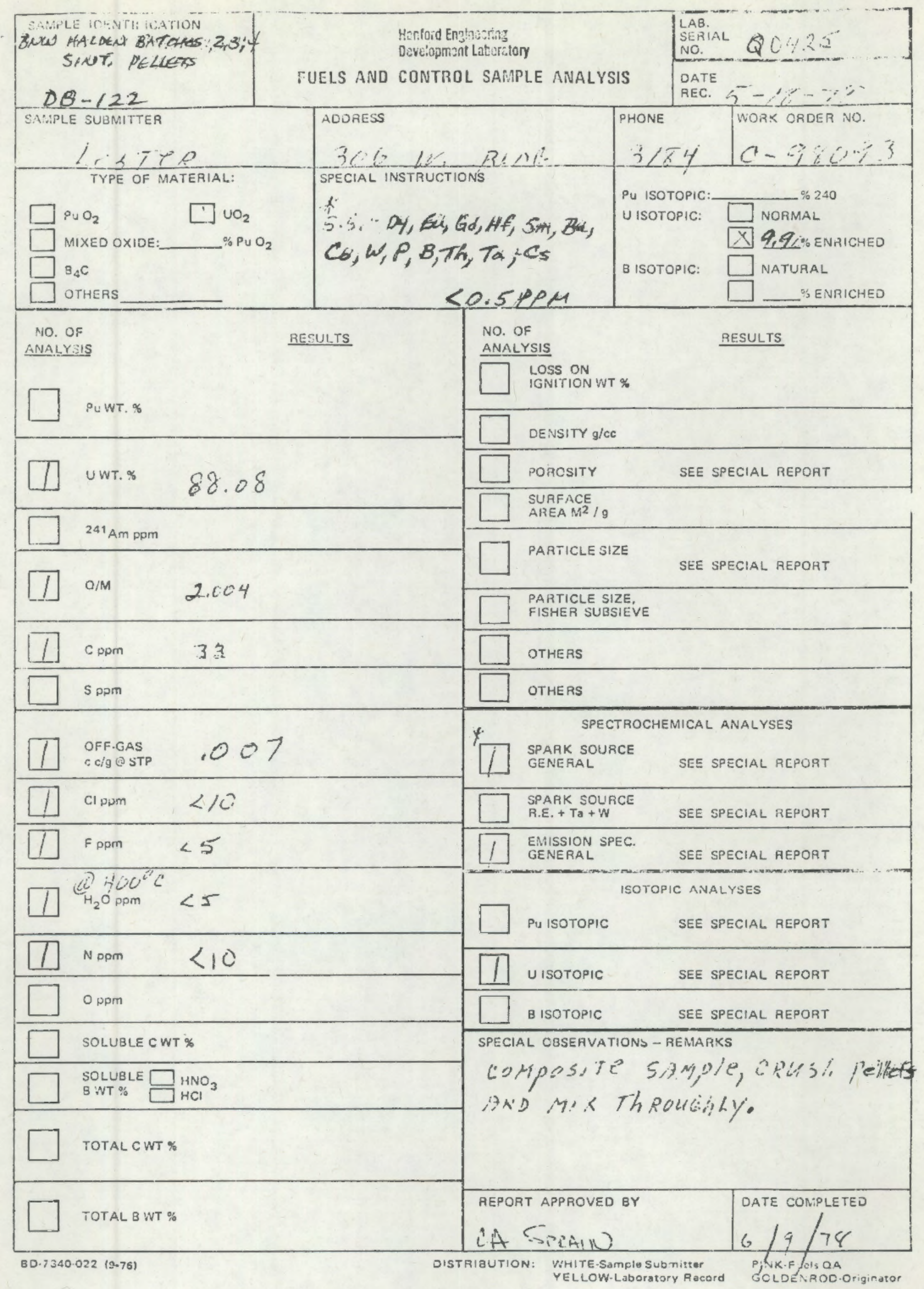

C. 17 



\section{APPENDIX D}

FUEL THERMAL CONDUCTIVITY DATA 
TABLE D.1. Instrumented Fuel Assembly (IFA)-527 (Pellet 822) Measured Diffusivity and Calculated Thermal Conductivity

\begin{tabular}{|c|c|c|}
\hline $\mathrm{T}_{1}{ }^{\circ} \mathrm{C}$ & $a, m^{2} / s$ & $\lambda, \omega / m-K$ \\
\hline 179 & $2.242-6$ & 6.425 \\
\hline 398 & $1.546-6$ & 4.855 \\
\hline 494 & $1.400-6$ & 4.416 \\
\hline 581 & $1.266-6$ & 4.037 \\
\hline 698 & $1.158-6$ & 3.732 \\
\hline 800 & $1.043-6$ & 3.383 \\
\hline 900 & $9.440-7$ & 3.076 \\
\hline 1007 & $8.839-7$ & 2.893 \\
\hline 1099 & $8.437-7$ & 2.769 \\
\hline 1301 & $7.021-7$ & 2.324 \\
\hline 1379 & $6.821-7$ & 2.269 \\
\hline 1379 & $6.979-7$ & 2.325 \\
\hline 1294 & $7.309-7$ & 2.418 \\
\hline 1202 & $7.623-7$ & 2.511 \\
\hline 1098 & $8.242-7$ & 2.705 \\
\hline 1010 & $8.743-7$ & 2.861 \\
\hline 891 & $9.596-7$ & 3.128 \\
\hline 795 & $1.043-6$ & 3.382 \\
\hline 679 & $1.177-6$ & 3.787 \\
\hline 542 & $1.361-6$ & 4.322 \\
\hline 434 & $1.518-6$ & 4.745 \\
\hline 266 & $1.923-6$ & 5.747 \\
\hline 358 & $1.647-6$ & 5.065 \\
\hline 483 & $1.429-6$ & 4.499 \\
\hline 598 & $1.252-6$ & 3.997 \\
\hline 698 & $1.130-6$ & 3.639 \\
\hline 817 & $1.009-6$ & 3.274 \\
\hline 910 & $9.427-7$ & 3.074 \\
\hline 1001 & $8.737-7$ & 2.859 \\
\hline 1102 & $8.267-7$ & 2.714 \\
\hline 1190 & $7.552-7$ & 2.487 \\
\hline 1301 & $7.261-7$ & 2.404 \\
\hline 1384 & $6.964-7$ & 2.321 \\
\hline 1382 & $6.614-7$ & 2.203 \\
\hline 1306 & $6.944-7$ & 2.294 \\
\hline 1190 & $7.565-7$ & 2.491 \\
\hline 1092 & $8.268-7$ & 2.713 \\
\hline 968 & $8.960-7$ & 2.928 \\
\hline 873 & $9.648-7$ & 3.140 \\
\hline 770 & $1.064-6$ & 3.443 \\
\hline 674 & $1.147-6$ & 3.690 \\
\hline 540 & $1.370-6$ & 4.348 \\
\hline 441 & $1.504-6$ & 4.706 \\
\hline 354 & $1.674-6$ & 5.146 \\
\hline 211 & $1.940-6$ & 5.660 \\
\hline
\end{tabular}

\begin{tabular}{|c|c|c|}
\hline I. ${ }^{\circ} \mathrm{C}$ & $\alpha, m^{2} / s$ & $\lambda, w / m-K$ \\
\hline 186 & $2.121-6$ & 6.102 \\
\hline 284 & $1.779-6$ & 5.355 \\
\hline 397 & $1.529-6$ & 4.745 \\
\hline 491 & $1.345-6$ & 4.243 \\
\hline 601 & $1.217-6$ & 3.886 \\
\hline 719 & $1.143-6$ & 3.688 \\
\hline 826 & $1.063-6$ & 3.452 \\
\hline 908 & $9.539-7$ & 3.109 \\
\hline 1005 & $8.915-7$ & 2.917 \\
\hline 1098 & $8.679-7$ & 2.848 \\
\hline 1198 & $7.550-7$ & 2.486 \\
\hline 1283 & $7.207-7$ & 2.383 \\
\hline 1391 & $6.712-7$ & 2.238 \\
\hline 1390 & $6.579-7$ & 2.193 \\
\hline 1281 & $7.182-7$ & 2.374 \\
\hline 1198 & $7.661-7$ & 2.523 \\
\hline 1104 & $8.269-7$ & 2.714 \\
\hline 1007 & $9.044-7$ & 2.959 \\
\hline 909 & $9.836-7$ & 3.206 \\
\hline 814 & $1.056-6$ & 3.425 \\
\hline 490 & $1.378-6$ & 4.344 \\
\hline 403 & $1.520-6$ & 4.723 \\
\hline 211 & $2.022-6$ & 5.899 \\
\hline 765 & $1.053-6$ & 3.407 \\
\hline 665 & $1.199-6$ & 3.853 \\
\hline 522 & $1.320-6$ & 4.181 \\
\hline 436 & $1.454-6$ & 4.545 \\
\hline 312 & $1.736-6$ & 5.273 \\
\hline 422 & $1.471-6$ & 4.585 \\
\hline 468 & $1.377-6$ & 4.325 \\
\hline 531 & $1.338-6$ & 4.240 \\
\hline 594 & $1.267-6$ & 4.041 \\
\hline 641 & $1.197-6$ & 3.835 \\
\hline 708 & $1.115-6$ & 3.593 \\
\hline 852 & $1.017-6$ & 3.304 \\
\hline 861 & $1.009-6$ & 3.280 \\
\hline 813 & $9.967-7$ & 3.231 \\
\hline 756 & $1.064-6$ & 5.438 \\
\hline 698 & $1.120-6$ & 3.607 \\
\hline 643 & $1.169-6$ & 3.750 \\
\hline 582 & $1.258-6$ & 4.009 \\
\hline 534 & $1.327-6$ & 4.206 \\
\hline 472 & $1.385-6$ & 4.335 \\
\hline 390 & $1.571-6$ & 4.867 \\
\hline 264 & $1.825-6$ & 5.452 \\
\hline 277 & $1.810-6$ & 5.434 \\
\hline 377 & $1.569-6$ & 4.848 \\
\hline 479 & $1.584-6$ & 4.356 \\
\hline 880 & $9.814-7$ & 3.195 \\
\hline 964 & $9.245-7$ & 3.021 \\
\hline 1061 & $8.539-7$ & 2.799 \\
\hline 1161 & $7.819-7$ & 2.572 \\
\hline 1253 & $7.304-7$ & 2.411 \\
\hline 1355 & $6.927-7$ & 2.302 \\
\hline 1355 & $7.061-7$ & 2.347 \\
\hline 1258 & $7.335-7$ & 2.422 \\
\hline 1169 & $7.821-7$ & 2.573 \\
\hline 1074 & $8.461-7$ & 2.775 \\
\hline 981 & $9.043-7$ & 2.959 \\
\hline
\end{tabular}

D.1 
TABLE 0.2. Instrumented Fuel Assembly (IFA)-513 (Pellet 324) Measured Diffusivity and Calculated Thermal Conductivity

Specimen 1

\begin{tabular}{|c|c|c|}
\hline $\mathrm{T},{ }^{\circ} \mathrm{C}$ & $a, m^{2} / s$ & $\lambda, W / \mathbb{M}-\mathrm{K}$ \\
\hline 179 & $2.062-6$ & 5.907 \\
\hline 281 & $1.752-6$ & 5.265 \\
\hline 384 & $1.560-6$ & 4.825 \\
\hline 466 & $1.378-6$ & 4.328 \\
\hline 659 & $1.161-6$ & 3.727 \\
\hline 750 & $1.070-6$ & 3.458 \\
\hline 840 & $9.848-7$ & 3.200 \\
\hline 927 & $9.244-7$ & 3.016 \\
\hline 1027 & $8.860-7$ & 2.901 \\
\hline 1124 & $8.046-7$ & 2.642 \\
\hline 1217 & $7.682-7$ & 2.531 \\
\hline 1305 & $7.186-7$ & 2.379 \\
\hline 1415 & $6.614-7$ & 2.211 \\
\hline 1413 & $6.689-7$ & 2.235 \\
\hline 1344 & $6.954-7$ & 2.309 \\
\hline 1268 & $7.347-7$ & 2.427 \\
\hline 1169 & $7.694-7$ & 2.531 \\
\hline 1071 & $8.416-7$ & 2.759 \\
\hline 970 & $9.007-7$ & 2.943 \\
\hline 884 & $9.530-7$ & 3.103 \\
\hline 798 & $1.041-6$ & 3.373 \\
\hline 700 & $1.091-6$ & 3.513 \\
\hline 595 & $1.225-6$ & 3.909 \\
\hline 508 & 1. $315-6$ & 4.186 \\
\hline 430 & $1.451-6$ & 4.555 \\
\hline 334 & $1.646-6$ & 5.049 \\
\hline 230 & $1.936-6$ & 5.709 \\
\hline 188 & $2.101-6$ & 6.052 \\
\hline 182 & $2.044-6$ & 5.867 \\
\hline
\end{tabular}

Specimen 2

\begin{tabular}{|c|c|c|}
\hline $\mathrm{T},{ }^{\circ} \mathrm{C}$ & $\alpha, \mathrm{m}^{2} / \mathrm{s}$ & $\lambda, W / \mathrm{m}-\mathrm{K}$ \\
\hline 187 & $2.057-6$ & 5.920 \\
\hline 188 & $2.094-6$ & 6.029 \\
\hline 279 & $1.766-6$ & 5.305 \\
\hline 356 & $1.574-6$ & 4.839 \\
\hline 611 & $1.234-6$ & 3.945 \\
\hline 680 & $1.118-6$ & 3.593 \\
\hline 914 & $9.313-7$ & 3.036 \\
\hline 990 & $8.940-7$ & 2.923 \\
\hline 1067 & $8.583-7$ & 2.814 \\
\hline 1140 & $8.053-7$ & 2.646 \\
\hline 1228 & $7.483-7$ & 2.467 \\
\hline 1310 & $7.177-7$ & 2.376 \\
\hline 1384 & $8.763-7$ & 2.253 \\
\hline 1284 & $6.783-7$ & 2.260 \\
\hline 1335 & $6.975-7$ & 2.314 \\
\hline 1266 & $7.373-7$ & 2.435 \\
\hline 1193 & $7.730-7$ & 2.545 \\
\hline 1117 & $8.160-7$ & 2.679 \\
\hline 1043 & $8.655-7$ & 2.835 \\
\hline 960 & $9.096-7$ & 2.971 \\
\hline 878 & $9.638-7$ & 3.137 \\
\hline 790 & $1.023-6$ & 3.315 \\
\hline 714 & $1.117-6$ & 3.602 \\
\hline 648 & $1.151-6$ & 3.692 \\
\hline 576 & $1.243-6$ & 3.958 \\
\hline 504 & $1.325-6$ & 4.184 \\
\hline 391 & $1.509-6$ & 4.675 \\
\hline 308 & $1.685-6$ & 5.110 \\
\hline 218 & $1.972-6$ & 5.772 \\
\hline 218 & $1.972-6$ & 5.770 \\
\hline
\end{tabular}




\section{DISTRIBUTION}

No. of

Copies

\section{OFFSI TE}

A. A. Churm

DOE Patent Division 9300 S. Cass Avenue

Argonne, IL 60439

400 U.S. Nuclear Regulatory Commission Division of Technical Information and Document Control

7920 Norfolk Avenue

Bethesda, MD 20014

2 DOE Technical Inf ormation Center

4 Chief, Fuel Behavior Research Branch

Division of Reactor Safety Research

U.S. Nuclear Regulatory Commission Washington, DC 20555

G. P. Marino

Fuel Behavior Research Branch Division of Reactor Safety Research

U.S. Nuclear Regulatory Commission Washington, DC 20555
No. of

Copies

\section{ONSITE}

50 Pacific Northwest Laboratory

W. J. Bailey

J. 0. Barner

C. E. Beyer

E. R. Bradley (3)

M. E. Cunningham (12)

J. L. Daniel (3)

N. C. Davis (3)

S. K. Edler

M. D. Freshley

E. R. Gilbert

R. L. Goodman

R. J. Guenther

C. R. Hann

D. D. Lanning (3)

R. K. Marshail

C. L. Mohr

C. Nealley

F. E. Panisko

W. N. Rausch

R. E. Schreiber

R. E. Williford (3)

C. L. Wilson

Publishing Coordination (2)

Technical Information YO (5) 



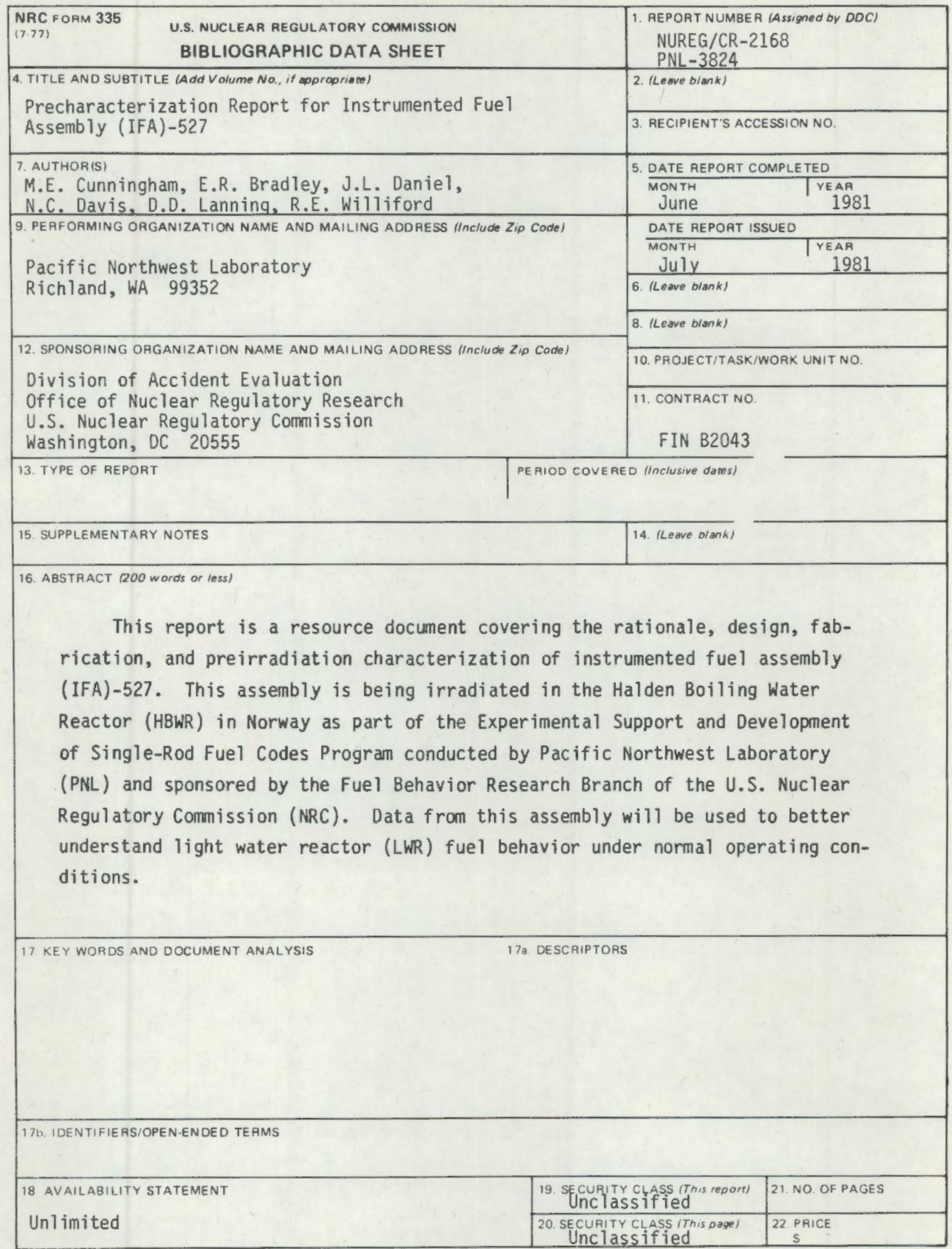


